BIJDRAGEN TOT DE KENNIS DER FAUNA VAN CURAÇAO.
Resultaten eener Reis van Dr. C. J. VAN DER HORST in 1920.

\title{
POLYCHAETEN VON CURAÇAO
}

VON

\author{
H. AUGENER \\ Hamburg.
}

(Mit 9 Textfiguren).

.Herr Dr. C. J. vAN DER HoRst im Amsterdam hatte die Freundlichkeit, mir die von ihm im Jahre 1920 bei Curaçao gesammelten Polychaeten zur Bearbeitung zu übergeben. Ich kann hiermit das Ergebnis dieser Untersuchung vorlegen. Von dem umfangreichen Material hat Dr. R. HoRST in Leiden in einer Mitteilung (Bijdragen tot de Dierkunde. Afl. XXII. 5. Dez. 1922) bereits 9 errante Polychaetenformen aufgeführt, von denen 2 als Arten 'nicht näher begrenzt sind. Ich habe die von Dr. HoRsT beschriebenen Arten gleichfalls untersucht und sie unter der von mir für richtig gehaltenen Benennung der Vollständigkeit halber in meine Arbeit mit aufgenommen. Ferner sind einige von dem ebengenannten Herrn mir zugestellte Polychaeten aus anderen Teilen des Westindien-Meeres von mir mit verwertet worden.

In meiner grossen Westindien-Arbeit (an anderer Stelle - Ueber westindische und einige andere Polychaeten-Typen 1925 - vorläufig als W. M. 1919 angeführt) sind in einem Nachtrage eine Anzahl von Polychaeten von Curaçao verzeichnet, die von Prof. E. Hentschel (Zool. Mus. Hamburg) dort gesammelt wurden. Da das Manuskript der erwähnten Arbeit zur Zeit nicht mehr in meinen Händen ist, konnte ich die festgestellten Arten in die vorliegende Arbeit nicht mit einordnen. Im Übrigen verweise ich bezüglich westindischer Polychaeten auf meine hoffentlich bald erscheinende grosse Westindien-Arbeit und auf die vorläufige darüber erschienene Mitteilung (Sitzungsber. Ges. naturf. Freunde. 1. Nov. 1922), ferner auf meine weiter vorn citierte Arbeit über westindische Polychaeten-Typen (1925) der zoologischen Museen von Kopenhagen und Wien.

Das von mir untersuchte Material enthält 85 Arten, von denen 48 auf die Errantia, 37 auf die Sedentaria entfallen, und gehört der Litoralfauna, dem Mangrove-Gürtel u. s. w. an. Unter den Familien stehen bei den Errantia an Zahl der Arten die kleinen Syllidae mit 13, die im Westindien-Meer reich entwickelten Eunicidae ebenfalls mit 13 und die Nereidae mit 5 Arten an der Spitze. Bei den Sedentaria halten die Serpulidae mit mindenstens 10, die Sabellidae mit 7, und die Terebellidae mit 6 Arten die Spitze.

Einige bemerkenswerte Formen mögen hier erwähnt sein. Es sind das unter den Errantia Bhawania goodei Webst., Eulepis weberi Horst, Hermenia verruculosa Gr., Euphione (Chaetacanthus) magnificus Gr., Ancistrosyllis rigida Fauv., Pseudosyllides n. g. curaçaoënsis n. sp., Eunice schemacephala Schm., die westindische Palolo-Eunice. Von den Sedentaria wären zu erwähnen Scolecolepis vanderhorsti n. sp. und ganz besonders auch Poecilochaetus serpens Allen und Saccocirrus major Pier., der letztere als Vertreter einer äusserst artenarmen eigenartigen Wurmfamilie, ferner Heteromastides bifidus Aug.. Sabella bahamensis Aug. ist wegen ihrer abdominalen Knospenbildung hervorzuheben, Hypsicomatides loangoënsis Aug. wegen ihrer ungewöhnlich hohen Thoraxsegmentzahl. Unter den Sabellidae und Serpulidae finden sich die für die westindischen Korallenformationen charakteristischen, durch Grösse hervorragenden Vertreter wie Sabellastarte magnifica Shaw und Spirobranchus giganteus Pall. 
Ich halte es für angebracht, hier noch einige Betrachtungen anzuschliessen über 2 mir erst nachträglich im Rahmen ihrer Zeitschrift zugänglich gewordene Arbeiten von TREADwELL über Polychaeten des Westindien-Meeres. Diese 2 Arbeiten sind folgende:

I) Polychaetous Annelids from Florida, Porto Rico, Bermuda and the Bahamas. - Papers from the

Department of Marine Biology of the Carnegie Institution. Washington. V. XI. 1917.

II) Leodicidae of the West Indian Region. - loc. cit. V. XV. 1921.

In den folgenden Zeilen werde ich in erster Linie die in meiner Curaçao-Arbeit und von TREADwELL aufgeführten Arten berücksichtigen, eventuell auch einige andere Formen.

I. 1917.) Lepidonotus inquilinus n. sp. ist kein Lepidonotus, sondern nach Kopfbildung, Segment-, Elytrenzahl u.s. w. ein Scalisetosus. - Harmothö̈ variegata n. sp. ist eine Malmgrenia, möglicherweise identisch mit M. curaçaoënsis. -- Phyllodoce tortugae n. sp. ist eine unklare Form mit gewissen Anklängen an Ph. erythrophylla Schm. - Lumbriconereis cingulata n. sp. kann, falls sie eine neue Art ist, ihren Artnamen nicht behalten, da dieser von EHLERS bereits früher $(1897,1900,1901)$ für eine Lumbriconereis von Südwest-Amerika verwendet worden ist. - Sabella alba n. sp. und Parasabella sulfurea n. sp. gehören nach der strichförmigen Gestalt des Buccalborstenbündels in die Verwandtschaft von Hypsicomus. S. alba mag ein Hypsicomus und dann identisch mit $H$. torquatus Gr. sein, wofern sie ein ventral ganzrandiges Collare hat, was der Fall zu sein scheint. $P$. sulfurea hat der Beschreibung und Abbildung nach ein ventro-median eingeschnittenes Collare und.würde danach mit Hypsicomatopsis circumspiciens Ehl. zusammenfallen. - Metalaonome brunnea n. sp. endlich, eine kleine Sabellide, soll am Thorax keine ventralen Federborsten ausser den Haken besitzen. Da das Collare nach der Abbildung 4-lappig ist, mag es eine junge Sabellastarte sein und zu S. magrifica Shaw gehören. Wie ich in einer gegenwärtig noch nicht erschienenen Arbeit über australische Polychaeten ausgeführt habe, ist die Gattung Metalaonome C. Bush, die von dieser Autorin für Bispira mariae Lob. errichtet wurde, irrtümlicherweise aufgestelt worden. $B$. mariae hat nämlich am Thorax ausser den ventralen Haken ventrale Federborsten und ist eine Distylia im Sinne von C. BusH.

II. 1921). Diese Arbeit, mit ausführlichen Beschreibungen versehen, die durch die beigegebenen Aquarell-Abbildungen der lebenden Würmer in sehr erwünschter Weise unterstützt werden, führt u.a. aus der Gattung Eunice (bei TREADWELl Leodice) allein 19 Arten auf. Ich beschränke mich darauf, folgende Arten aus dieser Arbeit $z u$ erwähnen. - Leodice unifrons Verr. Sie ist identisch mit Eun. vittata d. Chiaje und fällt als Synonym mit dieser zusammen. - Leodice stigmatura Verr. ist, falls man sie überhaupt von L. unifrons sive vittata trennen will, eine Unterform derselben mit längerer bis fast ans Hinterende reichender Kiemenregion. - Leodice denticulata Webst. muss als jüngeres Synonym nebst den von TREADWELl aufgeführten Synonymen mit Eun. filamentosa Gr. vereinigt werden. - Leodice spongicola n. sp. Sie passt ausgezeichnet zu Eun. filamentosa Gr. und ist ein kleineres Exemplar der letzteren. - Leodice longisetis Webst. Sie ist das, wofür ich sie hielt, nämlich nebst ihren Synonymen bei Treadwell (u. a. Eun. violaceo-maculata Ehl.) als Synonym mit Eun. macrobranchia zu vereinigen. Leodice mutilata Webst. Sie ist identisch mit meiner Eun. mutilata von Curaçao und hat eine bis weit ans Körperende heranreichende Kiemenregion. Angaben über die Zahl der hinteren kiemenlosen Segmente werden aber nicht gemacht. - Leodice rubrivittata n. sp. Sie stimmt so gut mit Eun. vittata d. Chiaje überein, dass ich sie für diese halten muss. Die hintere Grenze der Kiemenregion wird nicht angegeben, scheint aber weit vor dem Körperende zu liegen. - Leodice guanica n. sp. Eine kleinere Art mit meist einfädigen Kiemen, könnte wohl zu Eun. culebra Treadw. gehören. - Leodice filamentosa Gr. Eine mittelgrosse Form mit Kiemen vom 30ten Segment an, ist allem Anschein nach wirklich Eun. filamentosa Gr. Irrtümlich ist die Angabe von Eun. hamata Schm. als Synonym, da diese eine Marphysa ist. -Leodice fucata Ehl. Die Palolo-Eunice muss den Namen Eun. schemacephala erhalten. - Leodice cariboa Gr. TREAdwell führt Eun. siciliensis (TrEadwell 1901) als Synonym an, was nicht statthaft ist, da GrubE's Eun. cariboa vielleicht mehr als eine Art enthielt und ihr Originalmaterial nicht mehr erhalten ist; TREADWELl's cariboa muss Eun. siciliensis heissen. - Leodice culebra Treadw. Diese, mittelgross, durch die schwache Entwicklung und das unregelmässige Auftreten der Kiemen gekennzeichnet, ist nach meiner jetzigen Kenntnis wohl identisch mit Eun. gagzoi Aug. Da im Berliner Zoologischen Museum etwas Material der Eun. gagzoi unter dem Namen der Eun. cariboa steht, so wäre es angebracht, wenn man das überhaupt wollte, Eun. culebra mit Eun. gagzoi unter dem Namen 
cariboa Gr. auftreten zu lassen. Bezeichnender Weise sagt TREADWELl, dass Eun. culebra in Spalten des Korallengesteins lebe in enger Vergesellschaftung mit Nicidion kinbergi Webst., dem sie in Form und Erscheinung sehr ähnlich ist. - Von 3 weiteren Eunicen, Leodice tenuis, notata und bucciensis n. sp. sp. mag $L$. bucciensis, mit Kiemen vom 20ten resp. 21 ten Segment an, eine Eun. filamentosa sein.

Von den Lysidice-Arten ist $L$. sulcata von TREADwell, der $L$. brachycera Schm.? als Synonym anführt, gewiss mit L. ninetta Aud. \& Edw. identisch. - Nicidion kinbergi Webst. wird von TREADWELL auch für Westindien angegeben, doch erwähnt er von $N$. brevis Ehl. garnichts. - Lumbriconereis cingulata Treadw. (siehe auch weiter vorn) ist eine Art mit einfachen Haken. Da L. cingulata Ehl. (1897) ausser einfachen Haken am Mittelkörper u.s.w. komplexe Haken am Vorderkörper hat, muss der Name "cingulata" von TREadwell geändert werden. - L. floridana Ehl. ist die von mir so benannte Art. Lumbriconereis robusta Ehl. wird nicht aufgeführt. - Arabella maculosa Verr. Sie ist vermutlich identisch mit Aracoda iricolor Mont. Die Oberkieferstücke zweiter Ordnung sind von gleicher Grösse und der Oberkieferapparat insgesamt passt zu Ar. iricolor. - Aglaurides diphyllidia Schm. Sie ist identisch mit meiner Oenone fulgida Sav. TREadwell, der sie u. a. auch von Curaçao anführt, schliesst unter den Synonymen ausdrücklich die Oenone diphyllida von EHLERs (1887) von Florida Reef und Haiti aus, was mir nicht verständlich erscheint. EHLERS hatte sichèrlich die Art von SCHMARDA vor sich, die wiederum den Artnamen "fulgida" zu führen hat. - Von den 4 angeführten Stauronereis-Arten ist TREADWELL's Stauronereis rubra Gr. offenbar identisch mit St. angolana Aug; das Original der St. rubra ist nicht mehr vorhanden und daher dieser Name fallen zu lassen. - Ferner gehört vielleicht Stauronereis melanops Ver. zu St. angolana. - Stauronereis vittata Gr., die TREADwell für Bermuda und Tortugas angibt und als eine Art ohne dorsale Gabelborsten beschreibt, stammte in ihrem nicht mehr erhaltenen Original-Material von der Pazifik-Küste Central-Amerikas und ist als Art am besten ganz fallen $z u$ lassen.

Fam. Amphinomidae.

Eurythoë complanata Pall.

Spaansch Water, 14. IV. 20, aus Porites furcata.

Caracas-Bai: 3. V. 20, unter Steinen am Ufer; 11. V. 20, an einer kleinen steinigen Stelle; 25. V. 20.

Diese Amphinomide ist in der Sammlung mit mehr als 50 Exemplaren und in den verschiedensten Grössen vertreten.

Ich habe alle diese Würmer im Anschluss an meine entsprechenden Feststellungen an Tieren dieser Art von Ceylon (1926) auf etwa vorhandene, im Freileben erworbene Verstümmelungen und nach solchen eingetretene Regenerationen untersucht. Es ergab sich hierbei, dass etwa 19 Exemplare sich hinten in verschieden weit vorgeschrittener Regeneration befanden resp. in ganz wenigen Fällen am Vorderende verstümmelt waren. In einzelnen Fällen machte die Verstümmelungsstelle durchaus den Eindruck einer im Freileben erfolgten Vernarbung, ohne dass die Regeneration bereits eingesetzt hätte.

\section{Hermodice carunculata Pall.}

Spaansch Water: 3. IV. 20 ; 7. IV. 20; 29. IV. 20 ; 15. V. 20 ; 7. IV. 20, 17. IV. 20 und 19. IV. 20, unter Steinen \& aus Porites furcata; 5. V. 20, aus Porites furcata.

Spaansche Haven, 16. IV. 20, gedretscht.

Caracas-Bai: unter Steinen; 23. IV. 20, von Korallen; 8. IV. 20; 1. V. 20.

Wie die vorhergehende Art findet sich auch diese grosse Art in den verschiedensten Grössen, und in mehr als 70 Exemplaren vor.

Was Regeneration im Gefolge von im Freileben erlittenen Verstümmelungen angeht, so habe ich solche bei etwa 17 Individuen und zwar nur am Hinterende feststellen können. Bei einigen Tieren hierunter war die Regeneration schwierig als solche zu erkennen. Ich gląube aber nicht fehlzugehen, wenn ich in diesen Fällen eine nahezu vollendete Regeneration annehme.

Fam. Chrysopetalidae.

Bhawânia goodei Webst.

Spaansch Water, 5. V. 20, aus Korallen.

Caracas-Bai, 25. V. 20. 
Von den 2 vorhandenen Individuen dieser kleinen Wurmform war das eine ein in zwei Teile zerbrochenes, vermutlich vollständiges Tier von ca. 12,5 mm Länge. Ein zweites noch kleineres, ca. $5 \mathrm{~mm}$ langes Exemplar habe ich zwischen vielen anderen Würmern herausgefunden.

Wie bei einem früher von mir gesehenen westindischen Tier dieser Art sind die Dorsalpaleen erheblich dunkler gefärbt als bei Bh. myrialepis Schm. Betrachtet man die Paleen in continuo am Wurm, so sehen sie kupfer-goldig aus und zeigen nur schwachen Glanz.

Ich finde diese Würmchen übereinstimmend mit WEBSTER's Beschreibung. Die Anhänge der komplexen Ventralborsten sind wie bei anderen Bhawanien auf der einen Profilkante fein gewimpert, was von WEBSTER nicht abgebildet wird und wohl von ihm übersehen wurde.

Fam. Sigalionidae.

Sthenelais boa Johnst.

? Stenelais boa Horst 1922.

Spaansche Haven, 16. IV. 20.

Diese Sigalionide wird von HORST nur mit wenigen Zeilen angeführt. Aus eigener Anschauung des einzigen vorhandenen Exemplars kann ich noch folgendes über das Tier ausführen.

Das hinten wohl so gut wie vollständige Tier ist ca. $27 \mathrm{~mm}$ lang, vom Kopffühler ist nur das Basalglied erhalten. - Ein Elytron aus der Gegend des 12ten Parapods hat ca. 27 einfache Randfransen. Von diesen Randfransen sind etwa 10 an dem vom Elytron-Hilus abgewendeten Ende der Fransenreihe kurz keulenförmig, während die übrigen ca. 17 von längerer, gewöhnlicher, schwach gegen das Ende verjüngter Fadenform sind. Auf der Elytronfläche sind die kleinen, kurz konischen, zerstreuten Oberflächenpapillchen deutlicher nur auf den Randpartien des Elytrons, am deutlichsten und am dichtesten gestellt sind sie in einer breiten Zone parallel dem Hilusrande. Einwärts von und entlang dem gefransten Rande stehen noch einige Reihen von z. T. etwas längeren, fadenförmig-spitzen, z. T. kurzen, schwach keuligen Flächenpapillen.

An einem Elytron aus der Körpermitte sind gleichfalls ca. 27 Randfransen zu erkennen, von denen die dem Elytron-Hilus zunächst stehenden ca. 17 die verjüngte Fadenform haben, während die übrigen, vom Hilus entfernten, kurz keulig sind. McINTOSH hat von Elytren grosser boa-Exemplare. (1900) wohl 20 Randfransen abgebildet, was zu dem Befunde an dem Curaçao-Wurm gut passen würde, wenn man die ca. 10 kurz keuligen Fransen an den Elytren derselben nicht als Fransen im eigentlichen Sinne mitzählt. Die kleinen Oberflächenpapillchen sind am mittleren Elytron vorhanden wie bei dem Elytron vom Vorderkörper. Aber am Hilusrande treten diese Papillchen in viel geringerer Zahl auf als auf dem Elytron vom Vorderkörper, und zwar nicht in der Anordnung eines Längsstreifens sondern in einer länglichen Gruppe angeordnet. Diese Papillengruppe liegt zwischen dem Hilus und der Elytronnarbe, d. h. am innersten Winkel des Hilus. Endlich finden sich wie auf den vorderen Elytren parallel dem gefransten Elytronrande mehrere Reihen fadenförmiger Oberflächenpapillen auch auf den mittleren Elytren.

Die Untersuchung der Borsten wurde an einem Parapod aus der Gegend des 15ten Segments vorgenommen und ergab folgenden Befund bezüglich der Ventralborsten. a) Ventral-supra-acicular. Zu oberst ganz wenige (z. B. 2) einfache, geblätterte. Lanzenborsten. Ventralwärts davon 2 bis 5 ziemlich zarte komplexe Borsten mit im Profil einseitig gesägtem Schaftende und mit langem, zartem, etwa 5-gliedrigem Anhang. Noch weiter ventralwärts folgen ca. 5 kräftige, komplexe Sichelborsten mit so gut wie glattem Schaftende und mit kräftiger, einfacher, ausnahmsweise 2-gliedriger Endsichel. b) Sub-acicular. $\mathrm{Zu}$ oberst wenige, zartere komplexe Borsten mit glattem Schaftende und mit zartem, mehrgliedrigem Anhang (z. B. 3-gliedrig). Hierauf folgen ventralwärts ca. 6 mittelkräftige Borsten mit glattem Schaftende und mit kurzer, einfacher Endsichel. $\mathrm{Zu}$ unterst am Ventralast endlich finden sich ca. 10 zarte Borsten mit auf der einen Profilkante schwach gesägtem Schaftende und mit zarten 2oder 3- (4?) gliedrigen Anhängen; an wenigen alleruntersten Borsten mag der Anhang einfach sein. Anhänge der komplexen Borsten am Ende 2-zähnig.

Von den Styloden an den Rudern ist hier und da etwas zu sehen. 
Der Wurm ist gelbbraun gefärbt, von der braunen Fleckenzeichnung der Elytren bei europäischen, z. B. britischen Exemplaren ist nichts zu sehen.

Ich glaube mit HoRst dieses Tier zu Sth. boa stellen zu können, die ja u. a. auch an der Küste von Westafrika vorkommt.

Spaansche Haven, 6. V. 20.

$$
\text { Sthenolepis gracilior Aug. }
$$

Diese Art ist durch ein einziges, hinten nicht ganz vollständiges Tier von ca. $25 \mathrm{~mm}$ Länge vertreten, mit ca. 82 Segmenten. Die Charaktere sind der Art entsprechend. Von den geblätterten einfachen Lanzenborsten oben am ventralen Parapodast sah ich 5 an einem Parapod aus der vorderen Körperhälfte.

Fam. Eulepidae.

Eulepis weberi Horst 1922.

Eulepis weberi Horst.

Spaansche Haven, 6. V. 20.

Spaansch Water, 4. V. 20.

Von den 2 dieser Wurmform angehörenden Exemplaren stammt das grosse, ca. $50 \mathrm{~mm}$ lange, von HORST beschriebene Originalexemplar von Spaansche Haven.

Auf Grund eigener Untersuchung dieses Wurmes möchte ich noch folgendes über denselben bemerken zur Ergänzung von HoRsT's Beschreibung.

Mit Rücksicht auf die notwendige Schonung des Tieres habe ich an dem stark eingezogenen Kopfe desselben immerhin feststellen können, dass 3 kurze Kopffühler vorhanden sind in harmothoider Anordnung wie bei anderen Eulepis. - Das Analsegment trägt wie z. B. bei Eul. fimbriata Treadw. und splendida Treadw. einen erheblich langen, fadenfeinen Analcirrus, der sich, nach vorn gelegt, etwa über die 15 letzten Segmente erstreckt. Links neben ihm steht ein kurzer, fleischiger, cylindrischer Fortsatz - er ist rechts nicht aufzufinden - dessen Bedeutung mir nicht ganz klar ist. Dieser Fortsatz mag ein in Entwicklung begriffener, dorsaler Parapodast sein, es bedarf der Untersuchung von anderen grossen Individuen der Art, um hierüber Genaueres zu ermitteln. Soweit ich erkennen kann, steht das letzte Elytron rechts am vorletzten, links am drittletzten Parapod; diese beiden Elytren sind ganz klein und ohne Randfortsätze.

Ich fand später unter meinem Untersuchungsmaterial von Spaansch Water noch ein 2tes Exemplar dieser Art. Das Tier ist viel kleiner als das Original, vollständig ca. $14 \mathrm{~mm}$ lang, mit 35 oder 36 Segmenten. Die Zahl der Elytrenpaare beträgt ca. 18, an der hinteren Körperstrecke stehen die Elytren an einer Anzahl aufeinander folgender Segmente. Der lange unpaare Analcirrus ist auch hier vorhanden und reicht nach vorn gelegt über die ca. 13 letzten Segmente hinweg. - Aus dem Vergleiche dieser 2 verschieden grossen Individuen ergibt sich, dass bei dieser bemerkenswerten Wurmform die Zahl der Segmente und der Elytrenpaare erheblich zunimmt mit der Grösse der Tiere.

\section{Fam. Polynoidae.}

Hermenia verruculosa Gr.

Lepidonotus verruculosus Horst 1922.

Spaansch Water, aus Porites furcata. Caracas-Bai.

Ich habe von dieser Polynoide 2 Exemplare gesehen, die wegen ihrer von Lepidonotus abweichenden Charaktere in der Gattung Hermenia verbleiben müssen.

Euphione (Chaetacanthus) magnificus Gr.

Iphione magnifica Grube 1875.

Lepidonotus branchiatus Treadwell 1900.

Lepidonotus (Physalidonotus) magnificus Augener 1922.

Lepidonotus branchiatus Horst 1922.

Chaetacanthus magnificus Seidler 1922.

Spaansch Water, aus Porites furcata.

Caracas-Bai, 19. IV. 20. 
Ich habe diese bei Curaçao offenbar nicht seltene, auffallende grosse Polynoide in mindestens 30 Exemplaren von verschiedener Grösse vor mir gehabt und führe sie unter dem vorstehenden von mir für richtig gehaltenen Namen an, nachdem ich nach Untersuchung des Grubeschen Originals (1922) noch vor SEIDLER feststellen konnte, dass das Tier mit der Gattung Iphione nichts zu tun hat.

Ich habe über diese Würmer noch folgendes $z u$ bemerken. Sie sind mehr oder minder mit Fremdstoffen, Schlamm und dgl. bedeckt, und zwar oft sehr stark. Das hart chitinisierte Mittelfeld der Elytren der grossen Individuen kann von fremden Organismen als Substrat benutzt sein zur Anheftung, so bei einem Wurm von Spirorbis-Röhren, bei einem anderen von krustenförmigen kleinen Bryozoën-Kolonien.

Kleine Exemplare der Art von ca. 15-18--20 mm Länge haben wie die mittleren und grossen einspitzige Ventralborsten. Aber bei den kleinen Individuen ist nicht das für die grossen Exemplare so charakteristische chitinöse einheitliche Mittelfeld der Elytren entwickelt. So finde ich an Stelle des Mittelfeldes bei 2 kleinen Tieren nur wenige, näher aneinander gerückte, sich nicht berührende, dunkle Elytronpapillen. Bei einem 3ten kleinen Exemplar sind erst ganz wenige harte Komponenten des Mittelfeldes entwickelt. Es ergibt sich hieraus, dass das chitinöse Mittelfeld erst bei Tieren mittlerer Grösse sein charakteristisches Aussehen erlangt. - Die branchialen Fortsätze der Parapodien sind auch bei $15 \mathrm{~mm}$ langen Exemplaren vorhanden, doch nur bei sehr genauer Untersuchung zu erkennen. - Bei allen Individuen befindet sich unterhalb der Wurzel des Mittelfühlers ein kegelförmiger Facialtuberkel.

Ich stimme mit HoRsT durchaus darin überein, dass die $P$. branchiata Treadw. von Porto Rico mit der hier von mir beschriebenen Art identisch ist. TREADWELl hatte Tiere von 20 bis $25 \mathrm{~mm}$ Länge vor sich. Da er von dem harten Mosaikfeld der Elytren garnichts erwähnt, war dieses bei seinen Tieren wohl noch nicht charakteristisch entwickelt.

Ich verweise bezüglich dieser Polynoide auch auf meine vorläufige Mitteilung (1922) und meine grosse Westindienarbeit (192?).

Bemerkungen über Lepidonotus suluënsis Horst 1917. (Hierzu Textfig. 1).

Dieser auffallende Lepidonotus gehört nicht dem westindischen Meeresgebiet an; da er aber in gewissen Beziehungen der Gattung Euphione gleicht, mögen einige nach meiner eigenen Anschauung

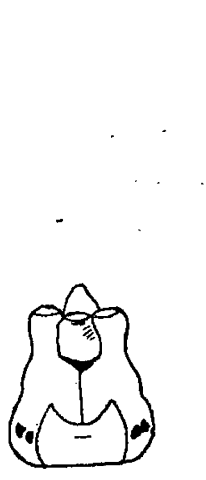

A

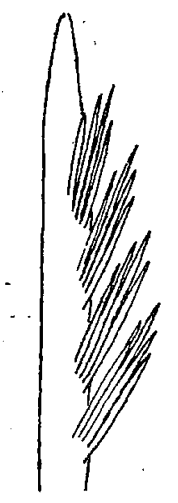

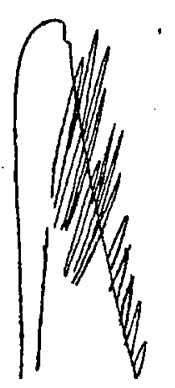

C

Fig. 1. Lepidonotus suluënsis Horst. A. Kopf mi dem zweizipfligen Nuchalfortsatz und dem Facialtuberkel. Von den Fühlern nur die Basalglieder gezeichnet. $23 \times$. B. Endstrecke einer der obersten Ventralborsten eines mittleren Parapods, mit einfacher Endspitze. Profil. $390 \times$. C. Unterste Ventralborste desselben Parapods. Endstrecke. Profil. $390 \times$

Zahn undeutlich, ebenso an wenigen obersten supra-acicularen Borsten. An letzteren - sie haben eine schmälere, schlankere nackte Endstrecke als die Hauptmasse der Ventralborsten - scheint der sekundäre Zahn ganz zu fehlen. Die Dorsalborsten — es finden sich 16 oder 17 an mittleren Rudern sind alle Borsten von kräftigerer Form, durchaus nicht haarartig fein wie bei Euphione; von der ausserdem bei vielen Lepidonotus-Arten auftretenden zarteren Dorsalborstenform ist bei L. suluënsis nichts vorhanden. Am 2ten Ruder von suluënsis sind die Ventralborsten durchaus nicht so auffallend zarter als die Ventralborsten der Mittelruder, wie das bei Euphione squamosa der Fall ist. 
Am Kopf stimmt die Lage der Augen überein mit Euphione, die Augen jeder Seite liegen dicht zusammengedrängt an den seitlichen Hinterecken des Kopfes. Dagegen zeigt das Buccalsegment mediodorsal bei suluënsis eine ganz andere Bildung wie bei der Euphione. Bei Euphione ist das Buccalsegment in der Mediane in einem einzigen, kurz eiförmigen Fortsatz (Nuchalpapille) nach vorn vorgezogen. Bei suluënsis ist eine grosse, zweispitzige Nuchalpapille vorhanden, deren 2 kegelförmige Spitzen durch eine starke mediane konkave Ausrandung getrennt sind. Unterhalb der Basis des unpaaren Kopffühlers ist ein deutlicher, kegelförmiger Facialtuberkel entwickelt.

Zusammenfassend lässt sich über $L$. suluënsis folgendes aussagen. Diese Polynoide bildet eine vermittelnde Form zwischen Lepidonotus und Euphione. Die Lage der Kopfaugen, die Chitinhaare der Ventralborsten' und die Elytren passen zu Euphione. Abweichend von Euphione ist die Form der Dorsalborsten, die Zweizähnigkeit der Ventralborsten und die Form der Nuchalpapille, endlich auch das Fehlen branchialer Ruderfortsätze, wenigstens doch bei dem einzigen kleinen suluënsis-Exemplar. Die von mir gegebenen Figuren mögen zur genaueren Kenntnis des L. suluënsis noch beitragen.

Harmothoë crucis Gr. (Oerst.).

Harmothoë spec. Horst 1922.

Harmothoë crucis Augener 1925.

Caracas-Bai, 13. V. 20, aus Korallen.

Spaansch Water, 20. v. 20.

Diese von HoRsT nicht näher begrenzte kleine Harmothoë sah ich in ganz wenigen Exemplaren, die sämtliche Elytren verloren hatten. Ein vollständiges Individuum enthält 37 Parapodsegmente. Ges'chlechtsprodukte wurden festgestellt. - Von sonstigen Charakteren sei erwähnt, dass das Buccalsegment dorso-median vorn in eine deutliche, dreieckige Nuchalpapille vorgezogen ist. Am Kopfe befinden sich die vorderen Augen an den Seitenecken des Kopfes oder wenn man will, ein wenig vor der halben Kopflänge. Die am Ende 2-zähnigen Ventralborsten wie die mit wohl entwickelter, scharf zugespitzter, glatter Endstrecke versehenen Dorsalborsten passen gut zu dieser Art.

Bezüglich der Synonymie verweise ich auf meine Arbeit über westindische Polychaetentypen (1925).

Malmgrenia curaçaoënsis Horst. (Textfig. 2).

Paralepidonotus boholensis var. curaçaoënsis Horst 1922.

Spaansch Water, 10. IV. 20.

? Caracas-Bai, 25. V. 20.

Diese von HORST als Varietät der indo-malayischen Harmothö̈ boholensis Gr. aufgefasste Polynoide lag mir aus meinem. Material nur in einem schlecht erhaltenen, einzigen, unvollständigen Individuum vom 10. IV. 20. vor. Ich kann aber auf Grund der Vergleichung der Originalexemplare von HoRst folgendes über diese Würmer angeben. Ein paar elytrenlose, verstümmelte Malmgrenien von Caracas Bai, 25. V. 20. mögen auch hierher gehören.

Von den 3 von mir gesehenen Exemplaren ist nur ein einziges in vollständiger Länge erhalten und hat mit 39 Parapodsegmenten eine Länge von ca. $18 \mathrm{~mm}$. Am ausgestülpten Pharynx stehen $2 \times 9$ weiche Mündungspapillen.

Die Färbung ist bräunlich-fleischfarben, ventral düsterer als dorsal und irisierend. Grade über den Ansatz der Ruderbasen hinweg verläuft ventral jederseits ein aus segmentalen Flecken zusammengesetzter, schwarzer Längsstreif. Dorsal findet sich an einzelnen Segmenten des hinteren Körperdrittels ein schwarzer Fleck auf der Ruderbasis. Endlich tragen einige hintere Segmente an ihrem Hinterrande dorsal einen queren, schwarzen Fleck von verschiedener Breite und Länge, von linsenförmigem oder lanzettlichem Umriss. Ventro-median kann eine schwarze Längslinie vorhanden sein.

Am Kopf sind die Paarfühler, gleichviel ob der Pharynx ausgestülpt ist oder nicht, stets unterständig im Sinne von Harmothoë; von frontalen, harmothoiden Kopfspitzen konnte ich bei keinem Exemplar etwas entdecken. Die vorderen Augen liegen etwas vor der Mitte des Kopfseitenrandes seitlich am Kopfe. Das Buccalsegment ist medio-dorsal in eine kleine, dreieckige Nuchalpapille vorgezogen, die mehr oder weniger deutlich bei allen Exemplaren zu erkennen ist. - Die Palpen sind an 
ihrer Endhälfte schwarz, an ihrer Spitze weiss. Die Fühler grösstenteils schwarz, die Dorsalcirren mit schwärzlichen Ringen geziert.

Die leicht sich ablösenden Elytren sind hübsch gezeichnet, wie sich aus der Figur ersehen lässt, und in ihrer Zeichnung äusserlich denen der $H$. boholensis etwas ähnlich. Auf ihrer Oberfläche und am Rande sind sie vollkommen glatt; von Oberflächenpapillen findet sich wie bei anderen Malmgrenien an den mittleren Elytren lediglich entlang dem Hilusrande ein breiter Streifen sehr kleiner, kegelförmiger Papillen, die nur bei stärkerer Vergrösserung deutlich zu machen sind.

An den Parapodien, so den normalen mittleren, ist von einer ventralen Lamelle im Sinne der H. boholensis absolut nichts zu erkennen, d. h. eine. solche fehlt. Im übrigen sind die Parapodien harmothoid gebaut; an der Spitze des kegelförmig zugespitzten Ventralastes steht eine schwarze, fingerförmige Terminalpapille. Der Ventralcirrus reicht etwa halb so weit seitwärts wie die Ventralborsten. Einmal sah ich einen gegabelten Ventralcirrus, gewiss eine Zufallserscheinung.

Die Dorsalborsten finden sich annähernd $\mathrm{zu} 16$ an einem mittleren Parapod und sind viel geringer an Zahl und kürzer als bei $H$. boholensis. Sie sind merklich stärker als die Ventralborsten, mit sehr schwacher Skulptur versehen, und im Profil kaum etwas gebogen, die kürzeren etwas mehr gebogen und am Ende spitziger. Die kurze Endspitze ist stumpfspitzig und durch eine Einkerbung schwach 2-zähnig. - Die Ventralborsten, zu etwa 20 an den mittleren Rudern vorhanden, haben an ihrer erweiterten Strecke an deren konvexer Kante im Profil zahlreiche feine, deutliche Sägezähnchen, mindestens 30 Zähnchen an den mittleren

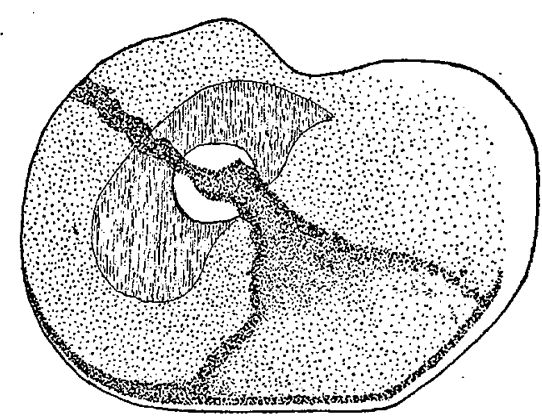

A

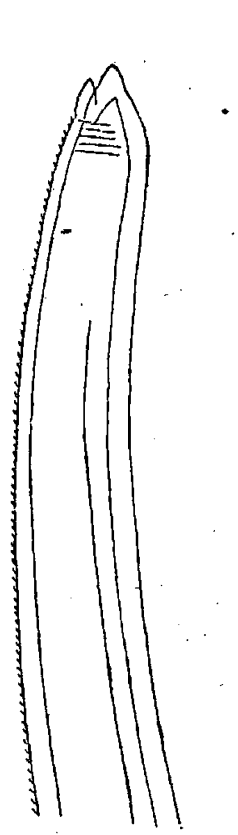

B

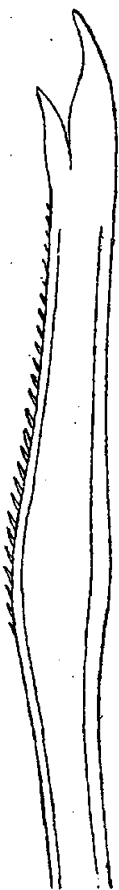

C

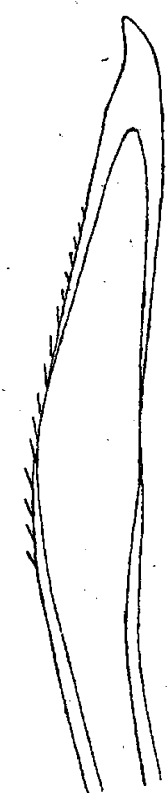

D

Fig. 2. Malmgrenia curaçaoënsis Horst. A. Mittleres Elytron. Von oben. $24 \times$. B. Mittlere lange Dorsalborste, von einern mittleren Parapod. Profil. $320 \times$. C. Mittlere stark zweizähnige Ventralborste. Desgl. Profil. $390 \times$. D. Unterste, einspitzige Ventralborste. Desgl. Profil. $600 \times$.

Borsten. Die meisten Ventralborsten sind am Ende stark 2-spitzig, der sekundäre Zahn ist kräftig und etwa halb so lang wie der Endzahn. - Die Dorsalcirren und sonstigen Körperanhänge sind vollkommen glatt.

Die hier beschriebene Polynoide ist eine Malmgrenia und ganz verschieden von $H$. boholensis, sie muss daher einen selbstständigen Namen führen und wird von mir als $M$. curaçaoënsis Horst bezeichnet. Was $H$. boholensis anbetrifft, so ist diese Art sicher eine harmothoide Polynoide; wovon ich mich selbst durch Untersuchung von Exemplaren dieser Art überzeugt habe. In dieser Hinsicht muss ich FAUVEL (1919) beistimmen in Abweichung von HoRsT, der sie in nähere Beziehung zu Lepidonotus bringt. Für die Unterbringung der Harmothoë-artigen Polynoiden ohne frontale Kopfspitzen, wie es die 2 hier besprochenen Arten sind, ist die Gattung Malmgrenia zu empfehlen, sei es als selbstständige Gattung oder als Untergattung von Harmothoë.

Im Zusammenhang mit $M$. curaçaoënsis mag hier noch einer Malmgrenia-artigen. Polynoide gedacht sein, die ich aus Westindien in einer vorläufigen Mitteilung (Sitzungsber. Ges. naturf. Freunde. 1922. 1. Nov. p. 40) unter dem Namen Harmothoë roberti beschrieben habe. Das. Tier hat die Charaktere einer Malmgrenia, aber deutliche Kopfspitzen wie bei typischen Harmothoë. Die Borsten sind 
wie bei $M$. curaçaoënsis beschaffen, die Elytren aber viel blasser als bei letzterer gezeichnet. Eine unpaare Nuchalpapille konnte ich nicht feststellẹn, das könnte aber an einem speziellen Spannungszustande der Nuchalpartie an dem übrigens gut konservierten, kleinen Wurm liegen. $\mathrm{Da}$ nur das einzige Exemplar vorlag, bleibt es unsicher, ob alle Individuen dieser Form frontale Kopfspitzen haben. FAUvel fasst (1923) nebst einer Anzahl anderer harmothoider Polynoiden auch die Malmgrenia andreapolis McInt. (1900) als Varietät von $H$. lunulata d. Chiaje - letztere ist eine Malmgrenia - auf. Als Unterschied von der Hauptart wird an erster Stelle das Vorhandensein frontaler Kopfspitzen bei $M$. andreapolis aufgeführt. Man könnte, dieser Betrachtungsweise folgend, dann auch die $H$. roberti als Varietät von $M$. curaçaoënsis auffassen. Es müsste eine ganze Anzahl Individuen der $H$. roberti untersucht werden in Hinsicht darauf, ob bei dieser Form immer d. h. normalerweise frontale Kopfspitzen entwickelt sind. So lange das nicht erwiesen ist, wird man daran denken müssen, dass bei der einzigen $H$. roberti die frontalen Kopfspitzen besonderen Umständen wie der Konservierungsmethode $\mathfrak{u}$. a. ihre Entstehung zu verdanken haben. Sind bei $M$. andreapolis wirklich als Regel frontale Kopfspitzen im Sinne typischer Harmothö̈ entwickelt? Aus McINTOSH's Beschreibung und Figuren ist das nicht sicher $\mathrm{zu}$ beurteilen.

\section{Fam. Phyllodocidae.}

Phyllodoce (Anaitides) erythrophylla Schm.

Spaansch Water, 7. IV. 20, aus Porites furcata. Caracas-Bai, 19. IV. 20.

Von Spaansch Water ist ein kleineres Exemplar von ca. $40 \mathrm{~mm}$ Länge vorhanden, am dem von den Kopfanhängen und Buccalcirren nichts rechtes mehr erhalten ist. Die wenigen erhaltenen Dorsalcirren passen in ihrer Form zu dieser Art. Der Rücken ist rostbraun, an den Seiten heller, die Dorsalcirren sind dunkelbraun.

Von Caracas-Bai liegt ein noch kleineres Tier mit regenerierendem Hinterende vor, mit etwas gedrungeneren Dorsalcirren und entsprechender Körperfärbung wie bei dem ersten Wurm. Es scheinen 4 Paar Buccalcirren vorhanden zu sein. Der Rüssel ist bei beiden Tieren eingezogen. Ich stelle beide Tiere zu Ph. erythrophylla, die nach meinen Ausführungen (1925) die Ph. oculata Ehl. (1887) als Synonym aufzunehmen hat.

Fam. NEREIDAE.

Nereis riisei Gr. (Oerst.).

Nereis glandulata - Hoagland. 1919.

Spaansch Water: 17. IV. 20; 25. V. 20; 13. IV. 20, aus Porites furcata; aus Porites furcata \& Siderastraea; aus Spongien an Mangrove-Wurzeln, 8. IV. 20.

Spaansche Baai, 11. V. 20.

Caracas-Bai: 1. V..20; 3. V. 20, unter Steinen am Ufer; in Spongien.

Nach den zahlreichen, in verschiedener Grösse von dieser Nereis vorhandenen Exemplaren es liegen z. B. vom 8. IV. 20, aus Spongien von Mangrove-Wurzeln allein ungefähr 40 Individuen vor - muss diese Art einer der häufigsten Polychaeten bei Curaçao sẹn. Eines der grössten Individuen ist vollständig ca. $103 \mathrm{~mm}$ lang. Im Allgemeinen sind diese Würmer agam, einzelne Tiere haben vergrösserte Augen und Ansätze zur Epitokie.

Besondere Erwähnung verdient ein Tier von Spaansch Water 13. IV. 20., das mit 3 agamen Tieren vom gleichen Fundort zusammenlag, also nicht pelagisch erbeutet wurde. Es ist ein vollständiges, epitokes Männchen von ca. 27 mm Länge, mit ausgestülptem Rüssel. Von den Paragnathen-Gruppen des Rüssels sei nur erwähnt, dass in VII und VIII 5 Paragnathen vorhanden sind, eine Zahl, die ich bei einem beliebig herausgegriffenen, agamen Exemplar ebenfalls fand.

Das vorliegende $\sigma^{7}$ bestätigt die früher von mir an riisei- $\sigma^{\top}$ beobachtete Tatsache, dass die vordere, atokale Körperregion in ihrer Segmentzahl individuell variiert. Dieser Wurm hat die geringste bisher von mir festgestellte Segmentzahl in der vorderen Körperregion und ist zugleich das kleinste bisher mir zu Gesicht gekommene Männchen. - Das erste epitokale Parapod ist das 16te Parapod, es ist das 1ste mit Lappenanhängen ausgestattete Parapod. Am 1sten bis 7ten Parapod des Wurmes ist 
der Dorsal- und Ventralcirrus in seiner Form modifiziert. - Der After hat ein ganz anderes Aussehen wie bei agamen Individuen und ist ganz ähnlich wie bei epitoken $\sigma^{7}$ z. B. der $N$. cultrifera Gr. gestaltet. Der After ist nämlich ein rundlich-pilzartiges oder scheibenförmiges Gebilde, dessen Mündung von mehreren Reihen von kurzen, cylindrischen, am Ende etwas verjüngten Papillen umgeben ist, die äussersten Papillen sind die längsten.

Synonym mit $N$. riisei ist ohne Z Zweifel die $N$. glandulata von Porto Rico (Ruth Hoagland. Bullet. Amer. Mus. Nat. Hist. V. 41. 1919. p. 575, Tab. XXX, Fig. 1-6).

Ich verweise bezüglich dieser Nereis auf meine grosse Westindien-Arbeit und meine Untersuchung westindischer Typen.

$$
\text { Nereis (Ceratonereis) mirabilis Kinb. }
$$

Spaansche Haven, 10. IV. 20.

Caracas-Bai: 3. IV. 20, unter Steinen am Ufer; im Sande.

Diese Nereis wird vertreten durch sehr wenige agame Exemplare, von denen 2 vollständige ca. 21 resp. $31 \mathrm{~mm}$ lang sind.

Ich habe mich über diese Nereis eingehend in meiner grossen Westindien-Arbeit geäussert. In der genannten Arbeit habe ich eine gut erhaltene, dorsale Sichelborste vom Hinterkörper und mit 2-zähniger Sichel abgebildet. An einem der Curaçao-Exemplare gelang es mir ebenfalls eine solche gut erhaltene Borste aufzufinden; sie hat am Ende der Sichel gleichfalls einen wohl entwickelten sekundären Zahn und eine gut entwickelte, am Ende der Sichelschneide ziemlich lange Wimperung.

\section{Nereis (Perinereis) bairdi Webst.}

$[=$ Nereis (Perinereis) melanocephala Mc Int.]

Caracas-Bai, 3. V. 20, unter Steinen am Ufer.

Ein einziges, kleines agames Tier vertritt diese Art. Von den Paragnathen-Gruppen am ausgestülpten Rüssel erwähne ich nur folgende: I) 8; V) 1; VI) 2 quer; VII und VIII) ca. 35, querer Gürtel. An den Fähnchen der hinteren Ruder entspringt der Dorsalcirrus deutlich ein Stück vor der Fähnchenspitze.

Dieses Tier ist sicher eine Nereis melanocephala McInt., wie ich sie früher von Westindien und Westafrika sah. Ich bin jetzt aber zu der Ueberzeugung gekommen, wiewohl ich keine Exemplare der $N$. bairdi von Bermuda gesehen habe, dass WeBSTER's ein Jahr früher (1884. Bullet. Un. St. Nation. Mus. No. 25. p. 312, Tab. VIII, Fig. 22-28) beschriebene Art identisch mit der N. melanocephala McInt. (1885) ist.

\section{Nereis (Perinereis) variegata Gr.}

Spaansch Water, 25. V. 20.

Spaansche Baai: in der Brandung; 11. V. 20.

Caracas-Bai, 25. V. 20

Boca grandi, 12. V. 20

Die mir in Anzahl von dieser Nereis vorliegenden Exemplare sind klein, total bis ca. $30 \mathrm{~mm}$ mindestens lang. Sie sind agam mit Ausnahme eines epitoken Männchens, ganz vereinzelt zeigt auch ein Exemplar mal vergrösserte Augen und beginnende epitokale Umformung an den Parapodien.

Die Rückenfärbung dieser Würmer ist recht ähnlich wie bei den früher von mir von Annobon (1918) gesehenen Exemplaren, bräunlich, mit oder ohne helle Segmentgrenzen. Die Tiere sind kenntlich an ihrer langen Stirnpartie und daran, dass an den dorsalen Ruderfähnchen der Dorsalcirrus nur anfangs subterminal, bald aber d. h. am Hinterkörper terminal am Fähnchen entspringt. Charakteristisch ist ausserdem die Anordnung der Paragnathen von Gruppe II, III und IV. Als Beispiel für die Paragnathen führe ich ein mittelgrosses Exemplar an: I) Kleine Gruppe von 4 oder 5 Par.; II, III, IV je aus mehreren hinter einander liegenden Kammzahnreihen bestehend; V) 1, etwas lamellenartig hoch; VI) 1, quer leistenförmig; VII + VIII) Quergürtel aus 2 (bis ?3) Querreihen, etwa 15 Par. sicher, es mögen eventuell aber einige beim Aufschneiden des eingezogenen Rüssels verloren gegangen sein.

Über das epitoke $\sigma$ lässt sich folgendes aussagen. Es enthält Sperma und ist vollständig ca. 
24,5 mm lang, mit ca. 82 Rudersegmenten. Die Rückenfärbung ist wie bei den atoken Individuen, ohne besondere dunkle Zeichnung; in der vorderen (atokalen) Region steht dorsal an der Ruderbasis ein dunkelbrauner Querstrich, der aber im Gesamtbilde des Wurmes garnicht auffällt. Das 1ste Ruder mit Lappenbildung auch am Ventralast ist das 15te Ruder, das daher wohl als das. 1ste epitokale Ruder anzusprechen ist. Einige Ruder vorher zeigt sich an der Wurzel des Dorsalcirrus ein ganz kleines Läppchen. Die Dorsalcirren der 7 ersten atokalen Ruder sind in ihrer Form modifiziert, indem die untere Hälfte oder die unteren $3 / 5$ verbreitert und gegen den fadenförmigen Endabschnitt etwas abgesetzt sind, wie EHLERS das (1901) von einem südwest-amerikanischen 13,5 mm langen, epitoken Tier beschrieben hat. Die Ventralcirren dieser 7 Ruder sind in ihrer Form ähnlich modifiziert wie die Dorsalcirren, was bei beiden Cirrenformen an den letzten der in Frage stehenden Ruder schwächer ausgeprägt ist. Den Perinereis-Arten entsprechend haben die Dorsalcirren der epitokalen Ruder an ihrer unteren Kante keine Wärzchen. Die dorsalen Ruderfähnchen als Ganzes sehen von der Seite betrachtet gekrümmter aus als die der agamen Tiere, indem ihre obere Kante etwas konvex, ihre untere Kante etwas konkav gebogen ist. - Das Aftersegment des $\sigma^{7}$ trägt 2 gewöhnliche Analcirren; der After ist am Rande krenuliert, ohne längere Papillen, höchstens ganz kurz papillös.

Die voll epitokalen Ruder passen zu der Abbildung solcher auf Tab. XIV, Fig. 20 und 21 bei EHLERS (1901). Der vorliegende Wurm ist zwar schon sehr weit epitokal umgeformt, hat aber den Gipfel der Epitokie noch nicht ganz genau erreicht. An einem epitokalen Ruder von der Körpermitte sehe ich unter dem Mikroskop noch ganz wenige atokale Borsten; die epitokalen Messerborsten scheinen noch nicht ganz voll ausgewachsen zu sein.

EHLERS hatte (1901) von Südwest-Amerika 2 epitoke Tiere der $N$. variegata beschrieben, von 13,5 mm Länge mit 13, und von $16 \mathrm{~mm}$ Länge mit 16 Segmenten in der atokalen Vorderregion. Diese Angaben sind nicht genau genug, immerhin würde das Curaçao- $\sigma^{7}$ in den Rahmen dieser 2 Zahlen fallen mit der Zahl seiner atokalen Segmente. Ueber das Geschlecht seiner 2 Tiere äussert sich EHLERS nur vermutungsweise dahin, dass das kleinere ein Männchen sein könnte.

Nereis (Platynereis) dumerili Aud. und Edw.

Spaansch Water, 25. V. 20.

Caracas-Bai, 25. V. 20.

Es fanden sich zwischen $N$. riisei 9 agame Exemplare der $N$.dumerili. Ein Exemplar, ca. $42 \mathrm{~mm}$ lang und erheblich grösser als die übrigen, ist ein Weibchen mit grossen Eiern, mit vergrösserten Augen und mit beginnender epitokaler Umwandlung der Ruder.

Ueber diese weltweit verbreitete Nereis habe ich mich ausführlicher in meiner grossen Westindien-Arbeit geäussert.

Fam. HESIONIDAE.

Hesione proctochona Schm.

Hesione proctochona Horst 1922.

Spaansch Water: 7. IV. 20, aus Porites furcata; 18. V. 20.

Spaansche Haven, aus Porites furcata.

Die vorliegende Art ist mit gegen 20 Exemplaren bis zu einer Totallänge von ca. $35 \mathrm{~mm}$ vertreten. Die dieser Hesione eigentümliche dorsale Querstreifung hebt sich meist wenig von der Körpergrundfärbung $\mathrm{ab}$ und ist öfter kaum zu erkennen. - Die die Acicula-Endspitze der Ruder umfassende Terminalpapille ist mehr oder weniger deutlich erkennbar, ebenso die zweite, kürzere Papille am Ruderende.

Bei etlichen Individuen ist der Pharynx vollkommen ausgestülpt. An ihm ist dorsal in der DorsoMediane eine kurze weiche, ei-, bis stumpf kegelförmige Papille erkennbar. Sie liegt je nach dem Streckungsgrade des Pharynx ziemlich nahe am Vorderrande des Kopfes bis zu ca. $1 / 4$ der Pharynxlänge von ersterem entfernt.

Die gleichfalls westindische $H$. praetexta Ehl. (1887) ist nach meiner eigenen Vergleichung mit H. proctochona eine von letzterer in der Körperzeichnung und Form der Borsten verschiedene Art. Sie stimmt vollkommen überein mit $H$. pantherina Risso und muss als Synonym mit dieser vereinigt werden. 
Spaansch Water, 25. V. 20.

An den wenigen vorliegenden Individuen sind die Fühler, Dorsalcirren etc. meist abgefallen. Die Tiere sind düster graubräunlich oder reiner dunkelgrau oder braungelb. Das ungefähr grösste Tier hat bei einer Länge von ca. $12 \mathrm{~mm}$ etwa 47 Segmente excl. Buccalcirrensegmente und hat an den mittleren Rudern etwa 35 Ventralborsten. Dieser.Wurm, von reiner dunkelgrauer Färbung, ist ein Männchen mit Sperma. Dorsal an den Rudern tritt eine (zuweilen 2) einfache, gegabelte Haarborsten auf im Sinne der $P$. pallida Clap., deren kürzere Zinke etwa $1 / 4$ bis allerhöchstens $.1 / 3$ so lang ist wie die längere Zinke. Es macht viel Mühe, überhaupt in situ erhaltene Dorsalborsten aufzufinden und sie ausserdem dann in Profillage $z \mathfrak{u}$ bekommen. Die Ventralborsten sind an ihrer Spitze an sich einspitzig, dort aber mit einer Endscheide versehen.

Diese Hesionide ist nahe verwandt mit $P$. pallida Clap., wird aber grösser und segmentreicher und ist anders gefärbt. Ich finde die kürzere Gabelzinke der Dorsalborsten kürzer als sie z. B. PRUvor \& RAcovitza für $P$. pallida (1895) abgebildet haben. Ich betrachte bis auf weiteres die vorliegenden Würmer als zu $P$. obscura Verr. gehörend.

Ancistrosyllis rigida Faùv.

Ancistrosyllis rigida Fauvel 1919.

Kynephorus inermis Ehlers 1920.

Caracas-Bai, 1. V. 20.

Das einzige Exemplar dieser Wurmform ist ein mehrere Male eingeroltes, daher schwierig zu untersuchendes Tier von ungefähr $33 \mathrm{~mm}$ Länge und mit annähernd 108 Segmenten. Die Färbung ist gelbbraun, am Vorderende dicht medial an den Parapodien entlang mit etwas schwärzlicher Zeichnung. $\mathrm{Ob}$ das Hinterende durchaus intakt ist, ist nicht ganz sicher zu entscheiden, eigentlich verletzt scheint es nicht zu sein. Der ziemlich starre Körper ist sehr schlank und gestreckt, ganz wie bei K. inermis Ehl.

Am Vorderende ist der kurze glatte Rüssel ausgestülpt, von cylindrischer, an den Seiten kaum etwas eiförmiger Form. Auf dem Kopf sind unter dem Mikroskop jederseits 1 oder 2 Augen zu erkennen. Deutlich ist der kurze Mittelfühler hinten auf dem Kopf, während von den Paarfühlern nichts zu finden ist; letztere sind sicherlich ursprünglich vorhanden gewesen und abgefallen. An den Palpen scheint eine kurze Papille vorhanden zu sein, wie sie FAuvel von seinen Südsee-Exemplaren beschrieben hat. Hinter dem Kopl folgt eine buccale Partie mit 2 Paar Buccalcirren, ohne Borsten. Die nun folgenden, sehr kurzen, zweiästigen Parapodien sind ganz wie bei Anc. rigida und $K$. inermis beschaffen. Dorsal an ihnen findet sich die starke Acicula-artige, am Ende kaum ein wenig gebogene Hakenborste. Am Ventralast stehen längere, einfache Haarborsten und zwischen ihnen kürzere Gabelborsten.

Dieser Wurm ist unzweifelhaft identisch mit der Anc. rigida Fauv., andererseits kann ich ihn aber auch nicht von dem $K$. inermis Ehl. trennen und ziehe den letzteren als Synonym zu Anc. rigida. EHLERS hat für seine Art die neue Familie Kynephoridae errichtet, die nunmehr wieder mit der Familie Hesionidae zu vereinigen ist. EHLERS hat allerdings eine von der meinigen abweichende Auffassung bezüglich der Bewertung der Anhangsorgane am Vorderende der Würmer. Er schreibt diesem 7 Fühler und 2 Unterfühler zu, spricht dem 1sten Segment jegliche Anhänge ab, teilt dagegen dem 2ten Segment 1 Paar Cirren zu. Ich glaube nicht fehlzugehen, wenn ich die 7 Fühler im Sinne von EhLERS so deute, dass in ihnen die 3 Kopffühler und die 2 Paar Buccalcirren der Anc. rigida einbegriffen sind. Die von der Ancistrosyllis scheinbar abweichende Beschaffenheit der im Sinne von EHLERS auf den Kopf folgenden 2 ersten Segmente ist aller Wahrscheinlichkeit nach nur durch besondere Kontraktionsverhältnisse der Kynephorus-Tiere so gewesen, in Wirklichkeit aber wie bei Ancistrosyllis, d. h. auf die Buccalcirren-tragende Partie wird auch bei Kynephorus ein Segment mit regelrechten Parapodien, mit Dorsal- und Ventralcirrus folgen.

Ich halte es nicht für undenkbar, dass die hier besprochenen Arten vielleicht identisch sind mit der Anc. albini Lnghns. (1881) von den Canaren. Die wesentlichen Charaktere stimmen ganz überein. Das andere Aussehen des Vorderendes der canarischen Art ist möglicherweise nur darauf zurückführbar, 
dass LANGERHANS' einziges, hinten verstümmeltes Exemplar lebend untersucht wurde, wobei die kontrahierende Wirkung des Alkohols auf den Wurmkörper nicht in Erscheinung tritt. Im frischen Zustande kann sehr wohl z. B. der mediane Einschnitt vorn zwischen den Palpen schwächer sein als an Alkoholtieren.

Die Verbreitung der Anc. rigida ist circummundan im Warmwassergebiet. Sie wurde gefunden in der Südsee, im Roten Meer und im Indo-Malayischen Bezirk und konnte von mir selbst für DeutschNeu-Guinea aus der Sammlung DAHL (1927) festgestellt werden.

Fam. Syllidae.

Syllis (Typosyliis) variegata Gr.

Boca labadera, 12. V. 20.

Caracas-Bai: 10. V. 20, aus Spongien; 6. V. 20.

Diese schon früher von mir für Westindien festgestellte Syllide lag mir in 3 agamen, kleinen Individuen vor. Die dorsale Brillenzeichnung ist bei dem einen Wurm deutlich, bei dem zweiten hinten mit einem kurzen Stück in Regeneration befindlichen blass, doch noch erkennbar.

Syllis (Typosyllis) corallicoloides Aug.

Spaansch Water, 12. IV. 20

Caracas-Bai, 25. V. 20.

Die zahlreichen von mir zu dieser Art gestellten Sylliden sind überwiegend agame, kleine z. T. grössere Tiere von blass rostgelblicher oder zart fleischfarbener Färbung, mit zarten, langen Dorsalcirren.

Der Pharynxzahn liegt bei einer Anzahl untersuchter Individuen dieser Würmer ganz vorn im Eingange des chitinösen Pharynxrohres. Bei diesen Sylliden, so bei Exemplaren von Caracas-Bai, ist der Pharynx und Muskelmagen merklich länger als bei S. prolifera Krohn, bei welcher der Pharynxzahn auch weiter nach hinten, etwa auf der Hintergrenze des vorderen Pharynxlängendrittels liegt. Der Muskelmagen hat auch bei diesen kleinen Individuen merklich mehr Querreihen als z. B. CLAPARÈDE für prolifera abgebildet hat, etwa so viele wie LANGERHANS für Madeira-Tiere der letzteren angegeben hat. Vielleicht sind aber diese Würmchen trotzdem zu S. prolifera zu rechnen. Bei einem grösseren Typosyllis-Exemplar aus dem europäischen Meeresgebiet, das ich vor Jahren einmal vergleichen konnte, und das mit dem Namen einer der von Fauvel (1923) z. B. als Synonym mit S. prolifera zusammengezogenen Typosyllis-Arten benannt war, lag der Pharynxzahn bei konserviertem Zustande des Wurmes dort, wo er bei $S$. prolifera liegen soll, d. h. eine. Strecke nach hinten vom Pharynxeingang entfernt.

\section{Syllis (Typosyllis) tortugaënsis Aug.}

Caracas-Bai, 10. V. 20, aus Spongien.

Spaansch Water, 25. V. 20.

Von jedem Fundort liegt ein agames, grösseres Exemplar einer Typosyllis vor, das ich mit etwas Reserve der vorstehenden Art zuordne. Der Wurm von Caracas-Bai ist von gestrecktem Habitus und bei vollständiger Erhaltung ca. $22 \mathrm{~mm}$ lang bei einer Segmentzahl von um 130 herum.

Dieser Wurm stimmt im Ganzen mit dem Typus-Exemplar überein, so in der kräftigen Form der Fühler und Cirren. Die Dorsalcirren sind an der mittleren Körperstrecke schwach spindelförmig und alternieren nur unbedeutend an Länge, z. B. mit ca. 18 und 15 Gliedern. Die Fühlerglieder sind nicht gut zählbar. Die Parapodien sind am Ende vorn etwas lippenartig vorgezogen. Pharynx und Muskelmagen sind lang und reichen etwa bis ins 15te resp. 25te Segment nach hinten. Analcirren mit einigen 20 Gliedern etwa. Pharynxzahn ganz vorn am Vorderrande des Pharynx. - Das Buccalsegment ist dorsal recht gut abgegrenzt und sichtbar. Von ihm erstreckt sich medio-dorsal eine vorn sanft ausgerandete Nuchalfalte von hinten her auf den Kopf hinauf, die den Eindruck einer normal vorhandenen Nuchalbildung macht.

Der zweite Wurm, von derselben Länge wie der erste, ist mit einem kleinen Stück hinten in Regeneration. Auch bei ihm sind Pharynx und Magen lang und der Pharynxzahn liegt ganz am Vor- 
derende des Pharynx. Die Nuchalfalte ist auch hier erkennbar, doch greift sie nicht so deutlich nach vorn auf den Kopf hinauf und ist weniger dünn-lamellenartig. Wie das erste Tier ist auch das zweite einfarbig, im übrigen von gleichem gestrecktem Habitus.

\section{Syllis (Typosyllis) fusco-suturata Aug.}

Spaansch Water: 8. IV. 20, von Mangrove-Wurzeln; 29. IV. 20, aus Spongien. Caracas-Bai, 25. V. 20.

Wenige kleine, agame Individuen vertreten diese Art. Das einzige Tier vom 8. IV. 20. ist ockergelblich, bei ihm sind die sonst von mir bei dieser Art beobachteten, dorsalen, dunklen Querlinien in den Segmentfurchen nicht erkennbar. Bei einem anderen Tier sind sie erkennbar, doch heller als ich sie früher sah. Im übrigen passen Ruder- und Borstenbildung gut zu dieser Art. Am Mittel- und Hinterkörper treten auch die Borsten mit den kurzen, klauenartig stark gebogenen, einspitzigen Sicheln auf. Bei dem Wurm vom 8. IV. 20. haben die Dorsalcirren am Mittelkörper etwa 30 bis einige 30 Glieder.

$$
\text { Syllis (Typosyllis) tigrinoides Aug. }
$$

Spaansch Water, 14 IV. 20, aus Porites furcata.

Das einzige Exंemplar ist ein agames, vollständiges Tier von ca. $11 \mathrm{~mm}$ Länge, mit ca. 122 Segmenten. Färbung orange-bräunlich, am Vorderkörper dorsal pro Segment 2 dunkelbraune Querlinien, die hintere viel schwächer als die vordere. Die dorsale armillaris-artige Zeichnung des Originals ist bei diesem Wurm nicht ausgeprägt, höchstens an einer Stelle vielleicht spurweise.

Der nicht vollkommen gestreckte Pharynx, dessen Zahn ganz an seinem Vorderende liegt, reicht bis an das 14te, der Muskelmagen mit etwa 32 Querreihen bis an das 29te Segment nach hinten. An 2 Nachbarrudern der vorderen Körperhälfte sind die Dorsalcirren gegen 50- (der längere) und gegen 30-gliedrig (der kürzere). Ein erhaltener Analcirrus hat etwa 30 schwierig zu zählende Glieder. Ob einfache Nadelborsten im Sinne von $S$. variegata etc. an den hinteren Parapodien vorkommen, ist zweifelhaft, vereinzelt glaube ich eine solche und zwar kräftige oben am Borstenbündel gesehen zu haben, sie ist schwer feststellbar.

Die sichere Erkennung der 2 Lippen an den Parapodien im Verein mit den übrigen Merkmalen ergibt mit Sicherheit, dass es sich um diese Art handelt und nicht um S. variegata, an die ich zuerst auch dachte. Bei stärkerer Mikroskopvergrösserung erkennt man hinten am Kopf eine wie ein Nuchallappen aussehende Bildung; sie bedeckt den Kopf von hinten bis zur Basis des Mittelfühlers und bis an oder etwas auf die hinteren Augen hinauf. "Ueber diese Frage müsste aber reicheres Material noch untersucht werden.

\section{Syllis (Ehlersia) sexoculata Ehl.}

Caracas-Bai, 25. V. 20.

Ein einziges kleines, agames, hinten verstümmeltes Tier passt gut zu dieser Art. Von den Ehlersia-Borsten mit langer Endgräte sind 1 oder 2 pro Ruder vorhanden.

$$
\text { Syllis (? Synsyllis) gracilis Gr. }
$$

Caracas-Bai, 5. v. 20.

Diese weltweit verbreitete, auch von mir bereits für Westindien festgestellte Art, ist durch 2 agame Exemplare vertreten.

\section{Haplosyllis spongicola Gr.}

Caracas-Bai: 29. IV. 20; 5. V. 20, aus Korallen.

Spaansch Water, 25. V. 20.

Diese für Westindien schon bekannte Art ist mir in 3 agamen Exemplaren zu Gesicht gekommen. 


\section{Branchiosyllis oculata Ehl.}

Spaansch Water, 29. IV. 20, aus Spongien.

Ich sah von dieser charakteristischen kleinen Syllide 2 agame Exemplare, von denen das etwas grössere ca. $8 \mathrm{~mm}$ lang ist. Mit Sicherheit hat das eine Tier ein hinteres, weissliches Regenerat, das sich durch seine helle Färbung gegen den übrigen Körper abhebt; bei dem anderen Wurm scheint hinten auch ein noch ganz kurzes Regenerat vorhanden zu sein. An der mittleren Körperstrecke zählte ich bis 6 Sichelborsten pro Ruder. Die dunkelbraunen, scharfen Querlinien der Rückenfläche scheinen wenigstens ist das am Hinterkörper doch deutlicher zu sehen - jeweils dem Vorder- und Hinterrande eines Segments anzugehören, worauf das zweitfolgende Segment (nach Überspringung des nächstfolgenden, nicht in dieser Weise gezeichneten Segments) wieder die 2 dunklen Querlinien trägt. Am Vorderkörper hat man mehr den Eindruck, dass je in einer Segmentfurche eine dunkle Querlinie verläuft.

Westpunt, 15. V. 20.

$$
\text { Opisthosyllis brunnea Lnghns. }
$$

Das einzige Exemplar ist ein braun gefärbtes, agames, hinten nicht ganz vollständiges Tier von ca. 4,5 mm Länge, mit ca. 47 Segmenten. Die gegliederten Körperanhänge sind mehr oder weniger eingerollt, sodass der Wurm äusserlich täuschend an Eusylliden erinnert, bei denen solches sich zeigt.

Die gegliederten Körperanhänge sind deutlich gegliedert, ein Dorsalcirrus vom Vorderkörper wohl einer der längeren Cirren - hat ungefähr 35 Glieder. Am Kopf sind Stirnaugen erkennbar und ein deutlicher Nuchallappen. An Rudern vom vorderen Körperende finden sich ca. 13 Borsten pro Ruder mit einspitzigen Sicheln. - Der Pharynx reicht etwa bis ins 12te, der Muskelmagen mit annähernd 60 Querreihen bis ins 26te Segment. Der Pharynxzahn liegt im vorletzten Segment der Pharynxzone und ist von einem quadratisch-kreisförmigen Hof umgeben, von dem nach rechts und links eine helle Querlinie quer über den Pharynx zieht.

Der vorliegende Wurm passt gut zu der an der westafrikanischen Küste verbreiteten Art: Die Op. nuchalis Verr. von Bermuda (1899 [1900], p. 620) ist eine offenbar nahestehende Art mit einspitzigen Borstensicheln, hat aber eine andere, gelblichweisse Färbung.

\section{Trypanosyllis zebra Gr.}

Spaansch Water: 13. IV. 20, 14. IV. 20 und 5. V. 20 aus Porites furcata; 29. IV. 20; 25. V. 20.

Diese an ihrem abgeplatteten Körper gut erkennbare, grosse Syllide war mit etwa 8 agamen Individuen vertreten von ca. 43 bis $54 \mathrm{~mm}$ Länge und bis ca. $4 \mathrm{~mm}$ Breite. An 2 Tieren war das Hinterende in Regeneration begriffen. Die dorsale segmentale dunkle Färbung der vorderen Körperstrecke ist oft nur sehr schwach durch eine helle Querlinie wieder halbiert. - Eines der grössten Exemplare trägt hinten eine männliche Geschlechtsknospe von ca. 36 Segmenten, die noch im Anfange ihrer Entwicklung steht, doch am Kopfsegment Augen schon erkennen lässt. An einem abgebrochenen Hinterende findet sich ebenfalls eine männliche Knospe, von ca. 18 Segmenten.

\section{Pseudosyllides n. g.}

Diagnose: In gewisser Hinsicht der Gattung Syllides gleichend, so in dem Besitze eines vorn glattrandigen Pharynx und eines kurzen Muskelmagens. Abweichend von Syllides ist der mit Drüsen versehene Übergangsdarm hinter dem Muskelmagen und die Beschaffenheit der Fühler und vordersten Cirren, sie sind wie die übrigen Dorsalcirren und die Analcirren schwächer gegliedert und gegen die Spitze deutlich verschmälert. Borsten komplexe Sichelborsten und eine obere einfache Borste pro Ruder.

Pseudosyllides curaçaoënsis n. sp. (Textfig. 3).

Spaansch Water, zwischen Algen vom Boot.

Das Material dieser kleinen Wurmform ist sehr dürftig und besteht aus einem Vorderende, einem Hinterende und einem ganzen, hinten etwas auseinandergerissenen Exemplar. Das Vorderende ist ca. 
$5 \mathrm{~mm}$ lang. Der ganze Wurm war stark zusammengeknäuelt, daher schlecht zu untersuchen. Er ist annähernd 17 bis $18 \mathrm{~mm}$ lang mit ungefähr 76 Segmenten, und von langgestrecktem, dick fadenförmigem Habitus. Die ca. 16 letzten Segmente sind mit Sperma erfüllt; von einem etwaigen Knospenkopfe konnte ich nichts erkennen. Am Analsegment stehen 2 gegliederte Analcirren von der Länge etwa der 41/2 letzten Segmente. Von einem unpaaren Analschwänzchen ist nichts sicheres auszumachen, doch mag

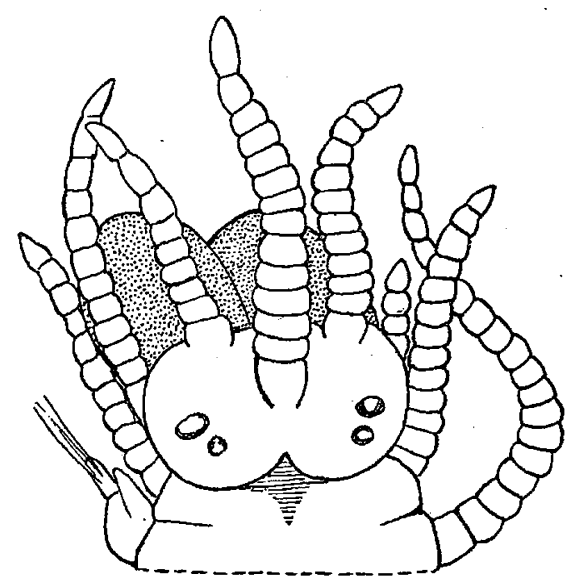

A

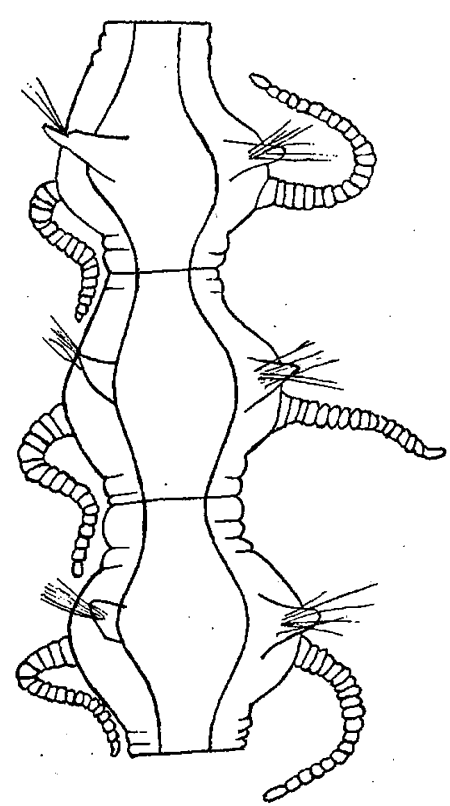

$\mathrm{D}$

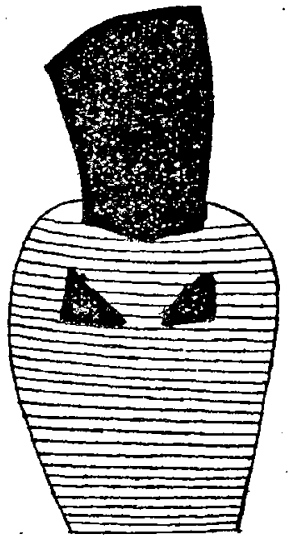

B

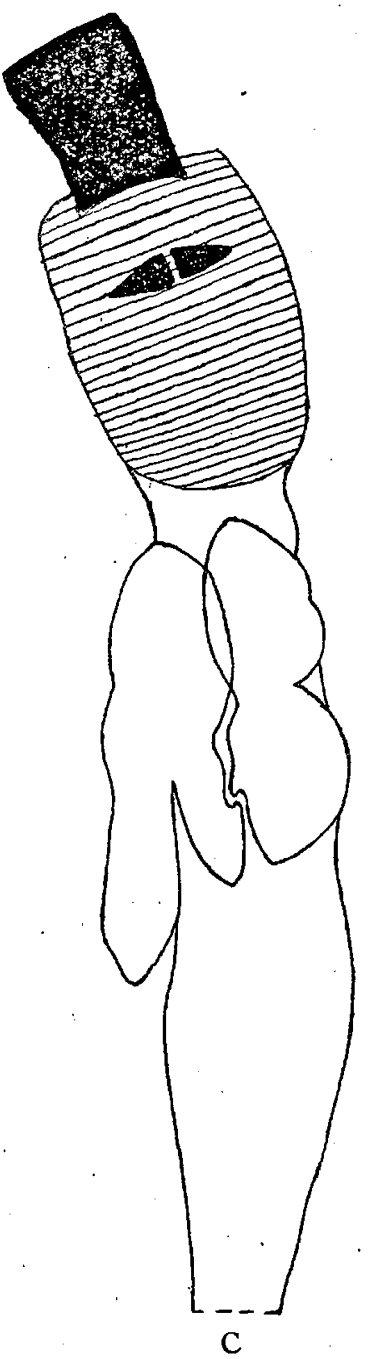

Fig. 3. Pseudosyllides n. g. curaçaoënsis n. sp. A. Vorderende. Von oben. $175 \times$. B. Muskelmagen des ganzen Wurmes mit dem Organ darin. Von oben. ca. $117 \times$. C. Chitinpharynx und Muskelmagen mit dem Organ darin und dem Drüsendarm nebst einem Stück des Mitteldarmes. Von dem zweiten Exemplar. Von oben. ca. $117 \times$. D. 3 Segmente vom Mittelkörper. Von oben. ca. $145 \times$. E Analende mit den Analcirren. Von oben. $220 \times$. F. Sichelborste von einem der vordersten Parapodien. Profil. ca. $900 \times$. G. Sichelborste vom hinteren Körperdrittel. Profil. ca. $900 \times$.

ein solches vorhanden sein. Das lose, aus etwa 31 Segmenten bestehende Hinterende ist ebenfalls mit Sperma erfüllt und gehört wohl bei Verlust einer mittleren Körperstrecke zu dem losen Vorderende.

Diese Syllide hat unverkennbar gewisse Charactere gemeinsam mit Syllides convoluta Webst. \&

Bened. (The Annelida Chaetopoda from Provincetown and Wellfleet. Mass. - Rep. Unit. St. Comm. Fish and Fisher. 1881 [1884]. p. 709, Tab. II, Fig. 12-16) von Provincetown. Ich werde daher die letztere Art wiederholt zum Vergleiche heranziehen.

Während an der hinteren Körperstrecke und am Vorderkörper die Segmente die gewöhnliche Form wie bei- Sylliden zeigen, d. h. ohne merkliche intersegmentale Einschnürungen sozusagen parallel- 
seitig aufeinander folgen und aneinander schliessen, sehen die Segmente der langen, mittleren Körperstrecke anders aus und zwar besonders ausgeprägt so am mittleren Teil dieser Strecke. Sie sind hier etwa 6-seitig bei extremster Ausbildung derart, dass sie länger als breit sind und sozusagen durch einen breiten Stiel hinten und vorn aneinander stossen. Eine ähnliche Segmentform, doch viel weniger extrem, ist bei $S$. convoluta vom Mittelkörper abgebildet. Der Kopf mit seinen Augen und Palpen gleicht sehr dem der $S$. convoluta, die Palpen sind am Grunde miteinander verbunden. Stirnaugen sind vermutlich vorhanden, doch nicht sicher zu entziffern. Abweichend von $S$. convoluta ist die Beschaffenheit der Kopffühler und Buccalcirren nebst den vordersten Dorsalcirren. Sie sind wie die übrigen Dorsalcirren und die Analcirren schwach Typosyllis-artig gegliedert und gegen das Ende zugespitzt, nicht ungegliedert und schwach gegen das Ende verdickt wie bei Syllides. Die hintersten Dorsalcirren sind ziemlich glatt.

Von der Beborstung der Parapodien ist nichts Bemerkenswertes zu sagen. Die komplexen Sichelborsten haben zweispitzige Sicheln abweichend von $S$. convoluta. Ventralcirren sind an den Parapodien wie dort vorhanden.

Der Pharynx ist kurz und reicht etwa bis ans 4te Parapodsegment. Er ist sehr dunkel, nahezu schwarz chitinisiert und auch bei stärkster Aufhellung nicht durchscheinend. Am Vorderrande ist er glatt und wird hier von farblosen, weichen Papillen umgeben. Ein solitärer Pharynxzahn ist nicht vorhanden, jedenfalls am Vorderende des Pharynx nicht. Ich glaube auch nicht, dass im Inneren des undurchsichtigen. Pharynx ein Zahn vorhanden ist. Der an den Pharynx anschliessende Muskelmagen ist kurz, von gestreckter Tonnenform und reicht bis ans 6te Parapodsegment. Er enthält etwa 25 bis 30 schlecht $z u$ unterscheidende Querreihen.

Ungefähr auf der hinteren Grenze des vorderen Längendrittels des Muskelmagens findet sich ein eigenartiges Organ, das analog auch bei $S$. convoluta vorkommt. WEBSTER und BENEDICT bilden es als ein nierenförmiges, mit der schwach konkaven Basis nach hinten schauendes radiär-gestreiftes Gebilde $a b$. Ich finde es bei beiden mir vorliegenden Würmern und nicht von genau gleicher Form bei beiden; durch seine dunkelbraune, chitinartige Färbung hebt es sich von dem blassen, bräunlichen Muskelmagen ab. Bei dem ganzen Wurm nimmt es etwa $3 / 5$ der Muskelmagenbreite in deren Mitte ein. Es erscheint hier als Ganzes bei gewisser Einstellung quer linsenförmig etwa und aus 2 deutlich von einander durch einen nach hinten verschmälerten, trapezischen Raum median getrennten Teilen bestehend. An dem anderen Wurm (Vorderende) ist die quere Linsenform des Organs besser ausgeprägt als bei dem ganzen Wurm. Man erkennt die Zweiteiligkeit des Organs. Jede Hälfte hat etwa die Form eines rechtwinkligen, mit der Hypothenuse nach vorn schauenden Dreiecks, beide Teile sind median durch einen gleich breiten, mässig schmalen Längsspalt von einander getrennt. Das verschiedene Aussehen des Gesamtorgans bei den 2 Würmern ist wohl so zu erklären, dass bei dem ganzen Wurm die beiden Hälften durch Druck weiter auseinander gepresst sind, während sie in dem Vorderende nahe an einander liegen. Was die physiologische Bedeutung dieses Gebildes betrifft, so vermute ich, dass es sich hierbei um chitinöse Verdickungen der Innenauskleidung des Muskelmagens handelt, die der Zerkleinerung und Vorbereitung der Nahrung vor ihrem Eintritt in den Mitteldarm dienen; man könnte hierbei an eine ähnliche Funktion wie bei der Innenauskleidung des Magens der körnerfressenden Vögel denken.

Hinter dem Muskelmagen schliesst sich ein kurzer Drüsendarm an, dessen Anhangsgebilde durch ihre bräunliche, dunklere Färbung sich abheben, er ist erheblich breiter als. der auf ihn folgende, gleichmässig breite eigentliche Mitteldarm.

In anbetracht der Beobachtung des eigentümlichen Organs im Muskelmagen dieser Würmer und gewisser anderer Ähnlichkeiten mit $S$. convoluta war ich anfangs geneigt, diese Tiere mit $S$. convoluta zu vereinigen. Dem steht indessen im Wege die Gliederung der vorderen Körperanhänge und deren abweichende Form und das Vorhandensein eines Drüsendarmabschnittes. Alkoholexemplare von S. longocirrata Oerst. zeigten übrigens in der Bildung der vorderen Körperanhänge das gleiche Verhalten wie die lebend und konserviert untersuchte $S$. convoluta. Ich kann demnach die Gliederung der vorderen Körperanhänge bei den Curaçao-Würmern nicht ohne weiteres auf die Einwirkung des Konservierungsmittels zurückführen. Ich nehme daher mit Vorbehalt für die 2 Curaçao-Würmer einen neuen Gattungs- und Artnamen an. S. convoluta war farblos mit braunem, gelblichem oder rötlichbraunem Darm; über eine so auffallende schwarze und ganz undurchscheinende Beschaffenheit des Pharynx im 
Sinne der Curaçao-Sylliden wird bei ihr garnichts erwähnt. Die Curaçao-Würmer, die an der vorderen Körperstrecke etwas dicker als am Mittelkörper sind - die Verdickung der Hinterenden bei den 2 Würmern ist wohl auf die Füllung mit Sperma zurückzuführen - sind in Alkohol matt gelblichgrau und undurchsichtig; vorn schimmern Pharynx und Magen schwarz resp. braun und am Hinterende das Sperma etwas schwärzlich durch die Körperwand.

Die komplexen Sichelborsten haben am Vorderkörper, wo sie zu ca. 10 pro Parapod auftreten, kurze schmale, an der Spitze schwach zweizähnige, ziemlich gerade Sicheln. In der hinteren Körperhälfte wird die Zahl der Borsten geringer, ihre Sicheln werden kürzer und breiter und der sekundäre Zahn ist stärker entwickelt als am Vorderkörper; ausserdem kommt hier noch eine obere, einfache, fein nadelförmige Borste hinzu. Sollte sich später auch die Errichtung einer neuen Gattung als unnötig erweisen, so bleibt doch die Zweizähnigkeit der Borstensicheln als Artunterschied von S. convoluta bestehen.

\section{? Autolytus (Proceraea) fasciatus Lnghns.}

Caracas-Bai, 1. V. 20.

Ein einziges, agames, hinten nicht ganz vollständiges Exemplar von ca. $14 \mathrm{~mm}$ Länge stelle ich mit Fragezeichen zu der vorstehenden Art. Die Segmente sind wegen der Verdrehung des Wurmkörpers schlecht zu zählen, 70-80 etwa sind wohl vorhanden. Die Grundfärbung ist dunkel graugelblich. An den vorderen $2 / 5$ etwa befindet sich dorso-median pro Segment ein auffallender schwarzer Querstrich, an einer Anzahl vorderster Segmente ist er nur blass bräunlich und nicht besonders auffallend. An dem langgestreckten, fadenförmigen Wurm sind die Dorsalcirren der Hauptkörperstrecke bräunlich und ganz kurz eiförmig-cylindrisch. Die Kopffühler sind nach Autolytus-Art lang, am 1sten Parapod ist rechts ein langer Dorsalcirrus erhalten. Hinter dem Kopf ist jederseits eine Bildung erkennbar, die ich für Epauletten halten ${ }^{*}$ muss. - Die Borsten entsprechen dieser Art, vereinzelt ist an den Parapodien die obere Borste mit dem langen einfachen Endabschnitt gut erhalten.

Der Muskelmagen enthält annähernd 55 Querreihen. Der braune Pharynx ist an der Stelle, wo die Zahnkrone sitzt, abgerissen und mehr nach hinten zurückgezogen. Die Zahl der Chitinzähne der Krone ist nicht genau auszumachen, es scheinen längere und kürzere Zähne vorhanden zu sein.

Dieser Autolytus gehört nach dem Längenverhältnis der Fühler und der Cirren an den verschiedenen Körpergegenden zur Untergruppe Proceraea und passt im allgemeinen zu Aut. fasciatus. Da die genaue Beschaffenheit der Zahnkrone des Pharynx nicht feststeht, teile ich das Tier mit einiger Reserve der zuerst von Madeira beschriebenen Art zu.

Fam. EUNICIDAE.

Eunice (Eriphyle) macrobranchia Schm.

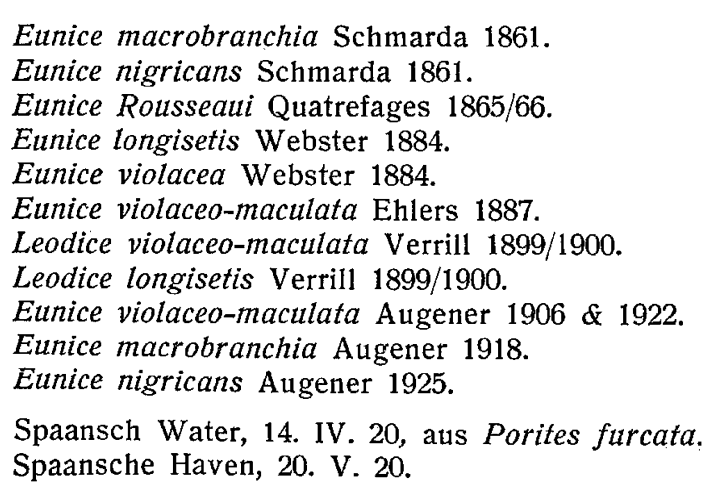

Diese Eunice hat mir in geringer Zahl vorgelegen, darunter in 2 vollständigen Exemplaren. Das vollständige Exemplar von Spaansch Water ist ca. $220 \mathrm{~mm}$ lang, an ihm sind die letzten 9 Ruder kiemenlos. Bei 4 Exemplaren beginnt die Kiemenzone 3-mal am 6ten, einmal am 7 ten Ruder. Kiemen aus der Strecke höchster Kiemenentwicklung haben 25 bis gegen 30 Fäden. Die Palpen sind mehr oder minder deutlich wieder geteilt. - Diese Würmer haben die dorsale Zeichnung der Eun. violaceomaculata Ehl. (1887). An dem vollständigen Wurm von Spaansche Haven - er ist ca. $230 \mathrm{~mm}$ lang, 
doch schwächer als das zuerst erwähnte Tier von Spaansch Water - ist bemerkenswert, dass das Tier z. T. in einer sicherlich von ihm selbst verfertigten, gelbgrauen Röhre steckte, welche äusserlich zunächst an die Röhren von Eun. filamentosa erinnert. Sie besitzt aber nicht die erhebliche Zähigkeit der filamentosa-Röhren, hat vielmehr eine leicht zerreissbare, papierartige Konsistenz.

Ich habe weiter vorn eine Reihe von Synonymen dieser Eunice angegeben, die den Namen macrobranchia zu führen hat. Bei Eun. macrobranchia kommt, wie ich neuerdings an deutsch-südwestafrikanischen Individuen derselben feststellen konnte, ebenfalls eine dorsale Zeichnung im Sinne der Eun. violaceo-maculata vor. Als Synonym betrachte ich auch die Eun. longisetis Webst. (1884) von Bermuda - leider stand mir kein Vergleichsmaterial zur Verfügung - eine Art mit geteilten Palpen und mit bis nahe ans Hinterende reichender Kiemenzone. Die Eun. violacea Gr. (Oerst.), eine ursprünglich aus dem Pazifik beschriebene Form, gehört mit den von WEBSTER ihr zugerechneten bermudischen Exemplaren jedenfalls auch zu macrobranchia. VERRILL hat (1899. [1900].) unter seinen Bermuda-Eunicen zwar Eun. violaceo-maculata von Eun. longisetis - er verwendet den Gattungsnamen Leodice, eine Auffassung, der ich mich nicht anschliessen kann - getrennt gehalten und schreibt beiden Arten ungeteilte Palpen zu. Unweigerlich hat aber Eun. violaceo-maculata bei entsprechender Konservierung 2-teilige Palpen. Nach der Maximalzahl ihrer Kiemenfäden hat andererseits Eun. longisetis - VerRILL gibt 7 bis $10 \mathrm{im}$ Maximum an - nahe Übereinstimmung mit Eun. mutilata Webst., die nach VERRILL selten mehr als 8-10 Fäden pro Kieme aufweist. Die Eunice von Curaçao, die ich in dieser Arbeit als Eun. mutilata angeführt habe und für diese Art halten muss, hat ungeteilte Palpen.

Eunice filamentosa Gr. (Oerst.)

Spaansch Water, 25. V. 20, und ohne Datum. Caracas-Bai, aus Korallen.

Diese Art wird vertreten durch ein kleineres Tier von Caracas-Bai, ferner durch ein grosses, nicht vollständiges Tier von Spaansch Water ohne Angabe des Datums.

Von Spaansch Water 25. V. 20. liegt ausser einem kleinen, in einem Röhrenstück eingeschlossenen Wurm ein sehr grosses Tier vor von ingesamt über $600 \mathrm{~mm}$ Länge.

Vorhanden ist hiervon ein Vorderende mit Kopf von ca. 93, eine lange, mittlere Körperstrecke von ca. 395, und ein längeres Hinterende von ca. $240 \mathrm{~mm}$ Länge, welche drei Teile wohl sicher einund demselben Wurm angehören. Hierzu gehören vermutlich noch 4 kurze Bruchstücke von zusammen etwa $175 \mathrm{~mm}$ Länge. An dem 8-9 mm maximalbreiten Vorderende steht die 1ste Kieme als einfaches, sehr kurzes Fädchen am 25ten resp: 26ten Ruder. Die vordersten Ruder des langen, mittleren Bruchstücks tragen lange, 3-fädige Kiemen wie die letzten Ruder des Vorderendes. - Die Röhre dieses grossen Wurmes hat Nebenäste wie EHLERS (1887) auch für die synonyme Eun. conglomerans angegeben hat.

Über die Synonymie dieser Eunice vergleiche man in meiner Westafrika-Arbeit (1918), in meiner Arbeit über westindische Typen (1925), und in meiner grossen Westindien-Arbeit. Die im warmen Indo-Pazifik verbreitete Eun. tubifex Crossl. kann ebenfalls verästelte Röhren haben und kann nunmehr mit Eun. filamentosa als Synonym vereinigt werden. Die Verbreitung von Eun. filamentosa ist danach circummundan in den warmen Meeren.

\section{Eunice schemacephala Schm.}

Eunice fucata Ehlers 1887

Eunice schemacephala Augener 1925.

Haiti, Port au Prince.

Caracas-Bai: 3. V. 20, unter Steinen am Ufer; 7. IV. 20, aus Maeandrina.

Von jedem der genannten Fundorte liegt ein Exemplar vor. Der vollständige, ca. $210 \mathrm{~mm}$ lange Wurm von Haiti hat ein vorn weiss berandetes Buccalsegment, der Vorderkörper ist oben ziegelrot. Die Kiemen beginnen am 5 ten Ruder und endigen mit etwa $2 / 5$ der Körperlänge. Eine Teilung der Palpen lässt sich in diesem Falle immerhin erkennen. Der Wurm von Caracas-Bai 3. V. 20 ist gleichfalls vollständig, ca. $74 \mathrm{~mm}$ lang. Er ist dorsal lebhaft braunrot, ohne dorsale weisse Färbung an einem der vordersten Rudersegmente, äusserlich der Eun. schemacephala höchst ähnlich. Eine Palpenteilung 
ist erkennbar. Die Kiemen - - sie haben im Maximum 4 höchstens 5 Fäden - beginnen 3- resp. 4-fädig am 5ten. Ruder und hören am 67ten Ruder etwa auf, hinter diesem Ruder lassen sich an einigen Rudern noch winzige Kiemenanlagen unterscheiden. Die Kiemenzone endet noch vor der halben Körperlänge, also weit vom Körperende entfernt.

Was die Borsten angeht, so habe ich 5 Ruder, von denen 4 dem Mittel- resp. Hinterkörper, 1 dem Vorderkörper entstammten, unter dem Mikroskop untersucht und in keinem Falle die Sicheln an den komplexen Borsten erhalten gefunden; ausserdem waren die hell, gelblich gefärbten Ventralhaken der Ruder an ihrer Spitze nicht normal erhalten.

Der Wurm von 7. IV. 20 endlich ist bei einer Länge von ca. $51 \mathrm{~mm}$ und einer Zahl von 107 Rudersegmenten hinten nicht ganz vollständig. Die Färbung ist dorsal schön ziegelrot, einzig am Hinterrande des Buccalsegments ist auf diesem eine schmale, weisse Querbinde entwickelt, auf der die Buccalcirren entspringen. Die Palpenteilung ist angedeutet. - Die Kiemen sind schwach entwickelt. Sie beginnen am 6ten Ruder einfädig und hören am 53ten Ruder 1-fädig auf. Im Maximum sind 2 Fäden pro Kieme vorhanden, die meisten Kiemen sind einfädig. - Ich habe die Borsten an zwei Rudern, von denen das eine vom Vorderkörper entnommen war, untersucht und fand auch in diesen Fällen nie -eine Borstensichel in situ erhalten und niemals die Ventralhaken am Ende gut erhalten. Die VentraIhaken sind auch an diesem Wurm gelblich, nicht schwarz.

An den bei Curaçao gesammelten Exemplaren dieser Palolo-Eunice ist von Interesse, dass der Wurm von 3. V. 20, unter Steinen am Ufer gefunden wurde, da doch der westindische Palolo dem Lebén im Korallenfels angepasst ist. Dass aber das fragliche Tier dem Palolo zugehört, dafür spricht ausser der äusseren Übereinstimmung der Verlust der Sicheln der Sichelborsten und die Beschädigung des Endes der ventralen Ruderhaken. - Ohne Frage hat Eun. schemacephala gewisse Ähnlichkeiten mit Eun. mutilata Webst., zumal mit mutilata-Exemplaren mit weit vor dem Körperende aufhörender Kiemenzone. Aber ich sah noch niemals, dass bei schemacephala eines der vordersten Rudersegmente weiss gefärbt ist, wie das bei mutilata die. Regel ist. Ferner kann ich an dem von mir gesehenen mutilata-Material von einer Palpenteilung nichts erkennen. Weiter sind bei mutilata die Borstensicheln keineswegs in Verlust geraten und die ventralen Ruderhaken sind mit Ausnahme ihrer hellen Spitze schwarz. Die Borstensicheln wie namentlich auch die ventralen Ruderhaken haben ein anderes Aussehen bei mutilata bezüglich ihrer zwei Zähne am Ende als bei schemacephala.

\section{Eunice mutilata Webst.}

Eunice mutilata Webster 1884.

Leodice mutilata Verrill 1899 (1900).

Eunice. barvicensis McIntosh 1885.

Caracas-Bai, 10. IV. 20, in der Wurzel von Gorgonia.

West-Punt, 14. V. 20.

Eun. mutilata wurde von WEBSTER nach einem einzigen Vorder- und einem einzigen Hinterende beschrieben, infolgedessen blieb vor allem Unklarheit über die Ausdehnung der Kiemenregion bestehen. Diese Unklarheit wurde auch durch VERRILL, der viele Individuen dieser Eunice von Bermuda vor sich hatte und einige kurze Bemerkungen über die Tiere gemacht hat, nicht beseitigt. Ich sehe mich daher veranlasst, ausführlicher auf das mir vorliegende Curaçao-Material einzugehen. Bedauerlicherweise habe ich kein einziges vollständiges Exemplar unter Händen gehabt.

Was das Material von Caracas-Bai anbelangt, so war dieses auf 2 Gläser verteilt, welche ich der Übersichtlichkeit halber mit römisch I) und II) bezeichnen will.

I). Das Material dieses Glases besteht aus 3 vorderen Körperstrecken mit Kopf und mehreren Fragmenten, darunter ein langes Hinterende mit intaktem Schwanzende. Bei 2 Tieren ist das 3te Rudersegment dorsal weisslich, viel heller als der Rücken davor und dahinter, bei dem 3ten Wurm ist das 3te Rudersegment kaum heller als seine Nachbarsegmente. An dem kürzesten Vorder- und dem kürzesten Hinterende ist dorsal und ventral eine feine grauliche Punktierung oder Sprenkelung vorhanden, namentlich deutlich an' dem Vorderende. Diese Sprenkelung dürfte wohl der grauen Sprenkelung, die WeBster von Eun. mutilata erwähnt hat, entsprechen.

a). Stärkstes und zugleich zweitlängstes Vorderfragment: ca. $52 \mathrm{~mm}$ lang und ca. $4,5 \mathrm{~mm}$ breit 
ohne Ruder, 100 Rudersegmente, Beginn der Kiemenregion am 6ten Ruder mit 3 resp. 4 Fäden pro Kieme. Maximalzahl der Kiemenfäden 7-9 pro Kieme. In der hinteren Hälfte 3 oder 4, zuletzt 1 oder 2 Fäden pro Kieme.

b). Längstes Vorderfragment, ca. $54 \mathrm{~mm}$ lang, doch schwächer als a), 132 Rudersegmente. Kiemenregion beginnt am 6ten Ruder mit 1 oder 2 ganz kurzen Fäden pro Kieme. Maximalzahl der Fäden 9 oder 10, vereinzelt 11 pro Kieme. Die Kiemen werden zuletzt 2- oder 1-fädig, die ca. 35 letzten Segmente sind kiemenlos.

c). Kürzestes Vorderfragment, ca. $17 \mathrm{~mm}$ lang, aber mindestens so stark wie a), 42 Rudersegmente. 1ste Kieme am 5ten Ruder, 2-fädig. Maximum der Kiemenfäden 8. Kiemen am letzten erhaltenen Rudersegment 4- oder 5-fädig. - Als Abnormität bei b) ist zu erwähnen, dass an ihm am 1sten Rudersegment rechts das Ruder fehlt ohne erkennbare Zeichen einer Verletzung.

d). Längstes Hinterende. $115 \mathrm{~mm}$ ca. lang. Ca. 198 Rudersegmente, von denen die ca. 178 vorderen noch Kiemen tragen. Die Kiemen sind zuerst 2- oder 3-fädig und bleiben so in den vorderen ca. $2 / 3$ dieses Hinterendes. Dann werden die Kiemen einfädig, die letzten Kiemen sind nur ganz winzige Stummel am Dorsalcirrus. Kiemenlos sind demnach annähernd die letzten 20 Rudersegmente.

e). An einem 2ten, kurzen Hinterende mit noch 49 Rudersegmenten sind die letzten 8-10 Rudersegmente kiemenlos. Da aber das Analsegment nebst den 4 letzten Rudersegmienten sich in unvollendeter Regeneration befindet, so wird sicherlich das normale Ende der Kiemeniregion noch nach weiter vorn zu vom Analsegment entfernt gewesen sein.: ...:

II). Das Material dieses Glases bèsteht abgesèhen .von sehr wenigen Fragmenten mitten aus dem Wurmkörper heraus aus 5 Vorderenden mit Kopf und 6 .Hinterenden mit Analsegment. Die Vorderenden zeigen keinen erheblichen Stärke-Unterschied. Das ungefähr stärkste _- unter den übrigen sind nur 3, die unbedeutend länger sind - ist ca. $45 \mathrm{~mm}$ lang und ca. $5 \mathrm{~mm}$ maximalbreit ohne Ruder. Bei 3 Vorderenden ist das 3te Rudersegment dorsal mehr oder minder ausgedehnt weisslich gefärbt, bei 2 Tieren das 3te und 4te Rudersegment teilweise so gefärbt. Alle 5 Vorderenden haben am letzten erhaltenen Rudersegment Kiemen.

a). 1ste Kieme am 6ten resp. 8ten Ruder 1-fädig. Maximum der Kiemenfäden 9 oder 10 pro Kieme. 65 Rudersegmente. - b). 1ste Kieme am 5ten Ruder 1- resp. 2-fädig. - c). 1ste Kieme am 5ten resp. 6ten Ruder 1- resp. 2-fädig. - d). 1ste Kieme am 6ten Ruder 2-fädig. - e). 1ste Kieme am 5ten resp. 6ten Ruder 2- resp. 3-fädig. - Als Abnormität bei a) ist zu erwähnen, dass 2 Segmente verdoppelt sind und zwar ist das eine nur links, das andere nur rechts und nur dorsal verdoppelt, also nur partiell. Ventral geht die Trennungsfurche vollständig durch nach beiden Körperseiten.

Von den Hinterenden habe ich die 3 längsten auf ihre Ausstattung mit Kiemen genauer untersucht. - f). Hinterende von ca. $170 \mathrm{~mm}$ Länge. Die vordersten Kiemen sind 4-fädig. Die letzte Kieme steht am 6. letzten Rudersegment, aber dahinter folgt noch ein unvollendetes Regenerat von ca. 18 kiemenlosen Rudersegmenten. -- g). Länge ca. $150 \mathrm{~mm}$. Vorderste Kiemen 3-fädig. Das Analende ist anscheinend normal, möglicherweise sind einige hinterste Rudersegmente weit vorgeschritten regeneriert. Kiemenlos sind die letzten ca. 14 Rudersegmente. - h). Länge ca. $220 \mathrm{~mm}$. Vorderste Kiemen 3-fädig. Kiemenlos sind hinten ca. 13 Segmente, doch scheinen diese weit vorgeschritten regeneriert zu sein. Ueber die 3 übrigen Hinterenden sei noch folgendes bemerkt. An dem 4ten Hinterende, dessen Analende normal ist, sind die ca. 25 letzten Rudersegmente kiemenlos. An dem 5ten Hinterende sind von den etwa 130 Rudersegmenten diè letzten ca. 115, also eine bedeutende Strecke, kiemenlos; möglicherweise ist ein kurzes Stück hinten weitgehend regeneriert. An dem 6ten Hinterende, an dem das Analende normal zu sein scheint, sind etwa die letzten 25 Rudersegmente kiemenlos. - Ueber die Färbung des Mittel- und Hinterkörpers an diesen kopflosen Hinterenden sei noch erwähnt, dass der lange Mittelund Hinterkörper einfarbig ist. Nur die hintersten Segmente sind auf ihrem vorderen Teile dorsal stärker oder schwächer weisslich, auf dem hinteren Teile braun. Der After ist weisslich, ausserdem braun berandet.

Das einzige Exemplar von Westpunt ist eine kleine, vollständige Eunice, die ich als junge Form zu Eun. mutilata stelle. Das. Tierchen ist mit ca. 73 Rudersegmenten ca. $14 \mathrm{~mm}$ lang. Auf der Dorsalseite zeigt sich die helle Punktierung wie sie auch bei grösseren Individuen beobachtet wurde. Das 3te Rudersegment ist dorsal weiss und hebt sich so sehr scharf von den Nachbarsegmenten ab. Die Kiemen beginnen am 7ten Ruder 1- resp. 2-fädig und endigen am 27ten Ruder 1-fädig. Die 
Maximalzahl der Kiemenfäden beträgt 2. Es zeigt sich an diesem jungen Tier, dessen Borstenformen ganz mit denjenigen grösserer Individuen übereinstimmen, dass die Kiemenzone hier abweichend von ihrer Ausdehnung bei grossen Exemplaren, auf eine kurze vordere Körperstrecke beschränkt ist. Diese Erscheinung kommt ja auch bei anderen Eunice-Arten vor.

Was den Kopf dieser Eunicen betrifft, so ist bei allen von mir untersuchten Individuen der Kopf vorn median tief eingeschnitten und die Palpen sind ungeteilt. Die Fühler dieser Tiere sind ungegliedert, glatt oder unregelmässig quer gefurcht. Die ventralen Haken der Ruder sind mit Ausnahme ihrer hellen Spitze wie die Ruder-Aciculae schwarz. Ihr sekundärer Zahn ist stärker, ausserdem bei guter Erhaltung etwas länger, zum mindesten doch ebenso lang wie der Endzahn.

Meine Feststellungen über die Entwicklung der Kiemen und die Ausdehnung der Kiemenregion an dem Curaçao-Material fasse ich folgendermassen zusammen. Die Kiemen beginnen in der Regel am 5ten oder 6ten Rudersegment. Die Maximalzahl der Fäden pro Kieme beträgt 7-9, selten 10-11. Auch die stärkst entwickelten Kiemen lassen, wenn man sie dem Körper andrückt, einen grossen Teil der Dorsalseite, etwa $3 / 5$ derselben, unbedeckt. Die Dorsalcirren sind sehr viel kürzer als z. B. die stärkst entwickelten Kiemen. Sie können - ich spreche hierbei immer von den stärkst entwickelten Kiemen ungefähr so lang wie die mittleren. Kiemenfäden, aber auch viel kürzer als diese sein. Über die hintere Grenze der Kiemenregion ist zu sagen, dass diese in der Regel bis nahe an das Körperende heranreicht und die etwa 20-25 letzten Segmente freilässt. Das von mir beobachtete Beispiel eines viel früheren Aufhörens der Kiemen (vgl. l b) ist wohl als Ausnahme von der Regel zu betrachten und kann auch bei anderen Eunice-Arten mit für gewöhnlich bis weit nach hinten reichender Kiemenregion vorkommen. - Von den Buccalcirren endlich ist zu sagen, dass sie viel kürzer als das Buccalsegment, nur halb so lang wie dieses sein können, in anderen Fällen mindestens so lang wie dieses sind. Ich habe 2 Fälle von Abnormițät an den Buccalcirren feststellen können. In dem einén Falle war der linke Buccalcirrus normal, der rechte bestand aus 2 gleich langen, starken Fäden. Bei einem anderen Wurm fehlten beide Buccalcirren, ohne dass eine Verletzung oder Abrissstelle erkennbar war.

Aus der Untersuchung der herauspräparierten Kiefer eines grösseren Wurmẹs ergibt sich, dass die Kiefer im allgemeinen zu McInTosh's Angabe über die Kiefer der Eun. barvicensis passen. Vom Oberkiefer seien hier die Zahnzahlen der Stücke II-IV verzeichnet. Es haben: II) 1. 4, r. 5 Zähne; III) 1. 7, r. 8 (?9); IV) 1.5 oder 6 , von denen die zwei lateralen Zähne ziemlich gross und gut entwickelt sind. An den braunschwarzen Unterkiefern passt die Form zu dem linken Unterkiefer in MclNTOSH's Abbildung von Eun. barvicensis. Die seitlichen Ränder der Unterkieferstäbe sind merklich heller, bräunlich, und in der gleichen Färbung zieht sich je von der Mitte des Schneidenrandes ein schmaler, keilförmiger Streif nach hinten gegen den Seitenrand der Stäbe.

Eun. mutilata hat viel Ähnlichkeit mit Eun. coccinea Gr., aber eine weiter nach hinten reichende Kiemenregion. Die Unterschiede von der äusserlich ähnlichen Eun. schemacephala habe ich bei dieser hervorgehoben. Bei schemacephala ist u. a. der sekundäre Zahn an den ventralen Ruderhaken, falls er überhaupt erhalten ist, auch bei bester Erhaltung erheblich kürzer, auch schwächer als dèr Endzahn. Ueber Eun. longisetis Webst., die in dem Beginn der Kiemenregion und der Zahl der Fäden der starken Kiemen der Eun. mutilata höchst ähnlich ist und bei der auch eines der vordersten Rudersegmente weiss gefärbt ist, kann ich leider nicht aus eigener Anschauung urteilen. Nach VerRILL (1899 [1900].) soll Eun. longisetis ungeteilte Palpen haben, doch lässt die eigenartige, dorsale Zickzack- oder Netzzeichnung, von der VerRILl spricht, einen leicht an die entsprechenđe Rückenzeichnung der Eun. violaceo-maculata Ehl. und unwillkürlich an nähere Beziehungen der Eun. longisetis zu der letzteren denken. - Eun. barvicensis McInt. ist wohl mit mutilata identisch. Ihre Beschreibung wurde nach sehr dürftigem, schlecht erhaltenem Material gemacht und enthielt keine genaue Angabe über die hintere Begrenzung der Kiemenregion.

\section{Eunice gagzoi Aug. (Textfig. 4).}

Spaansch Water: 8. IV. 20, von Mangrove-Wurzeln; 25. V. 20.

Diese nach wenigen Individuen aus Westindien von mir beschriebene, kleine Eunice habe ich von Curaçao in ungefähr 25 Exemplaren wiedergefunden, von denen etwa 20 am 25. V. 20. gesammelt 
wurden. Bei wenigen Exemplaren ist der Vorderkörper oben gerieselt und gepunktet, bei zweien das Buccalsegment oben ausgedehnt weisslich gefärbt. Die meisten Exemplare sind graugelblich-fleischfarben, schwach rostgelblich mitunter dunkler d. h. bräunlich, deutlich oder schwach irisierend. Die Maximallänge beträgt ca. 20 bis $29 \mathrm{~mm}$. Mehrfach war das Körperende hinten in Regeneration. Am normalen Analsegment sehe ich nie mehr als 2 Analcirren, die etwa so lang sind wie die 3 letzten Segmente. Am Kopf ist der mediane Einschnitt vorn stets deutlich, die Palpen sind immer ungeteilt. Bei den Borsten gelang es mir jetzt die sehr schwer in freie Lage zu bringenden Kammborsten an einem Parapod vom Mittelkörper freizubekommen. Von 3 an diesem Parapod stehenden Kammborsten war eine gut in Profillage und hat am Endspatel ca. 15 Randzähne, von denen der äusserste jederseits, besonders der eine, merklich länger als die übrigen ist. Der starke ventrale Acicularhaken der mittleren und hinteren Parapodien ist bei guter Erhaltung am Ende mit einer hyalinen, abgestutzten Entscheide versehen.

Was das Vorhandensein von Kiemen angeht, so habe ich eine Reihe von Exemplaren daraufhin geprüft, wobei die Intaktheit des hinteren Körperendes Voraussetzung ist. So finden sich an einem Wurm vom 8. IV.20. an den 25 bis 30 letzten Parapodien einfädige Kiemen, die zwar an sich kurz, doch bei maximaler Entwicklung viel länger als die zugehörigen Dorsalcirren sind. Ihr genaues erstes Auftreten ist nicht feststellbar. Bei einem anderen Wurm sind am Hinterende vereinzelt kurze, 1-fädige Kiemen zu erkennen. Bei einem ca. $20 \mathrm{~mm}$ langen Wurm stehen Kiemen an einigen 30 hintersten Segmenten und sind im Maximum $1 / 4$ bis $1 / 3$ so lang wie der Körper breit. Hingegen hat u. a. eines der grössten Individuen von ca. $29 \mathrm{~mm}$ Länge keine erkennbaren Kiemen. Man kann daher nicht sagen, dass als Regel bei den grösseren Exemplaren Kiemen auftreten, während sie bei den kleineren fehlen.

Das vorliegende reichere Material dieser kleinen Eunice hat bestätigt, dass es sich um eine Art mit kurzen, ungegliederten Fühlern, mit Kammborsten und nicht-schaufelförmigem Unterkiefer handelt. Dass diese kleinen Tiere den Jugendzustand einer grösseren westindischen Eunice darstellen, dafür habe ich auch jetzt keinen Anhaltspunkt erlangt. Welche andere Eunice könnte es denn sein? Von den von Dr. v. D. HoRST ebenfalls in Spaansch Water gesammelten Eunicen könnte ganz abgesehen von der

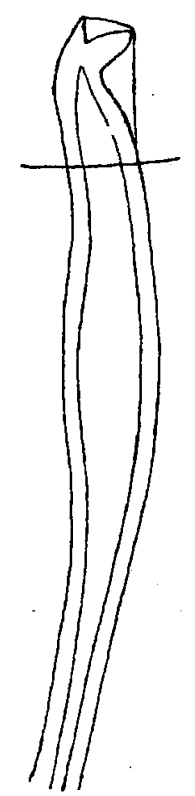

A

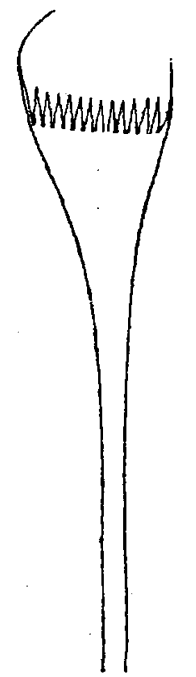

B

Fig. 4. Eunice gagzoi Aug. A. Ventraler Haken von einem mittleren Parapod. Profil. $320 \times$. B. Kammborste. Desgl. Flächenansicht. $600 \times$. von vornherein ausgeschlossenen Eun. siciliensis nur die Eun. filamentosa herangezogen werden. Aber Eun. gagzoi hat abweichend von letzterer auch am Vorderkörper so am 2ten Parapod, stark 2-zähnige, kurze Borstensichein von der gewöhnlichen bei den Eunicen auftretenden Bildung. Ich bleibe einstweilen bei meiner früher geäusserten Ansicht, dass Eun. gagzoi ein mit Kiemen ausgestatteter Nicidion kinbergi Webst. (brevis Ehl.) ist.

\section{Eunice vittata d. Chiaje.}

Caracas-Bai, aus Spongien.

Bei den 2 vorhandenen Exemplaren beginnen die Kiemen am 3ten Rudersegment und endigen bei dem einen am ca. 41 ten, bei dem anderen am 47 ten Rudersegment. Die Gliederung der Fühler ist bei dem einen Wurm deutlich und lang; bei dem 2ten Wurm, bei dem die Fühler stärker gedehnt sind, zeigt sich das viel undeutlicher.

\section{Eunice siciliensis Gr.}

Spaansch Water, 29. IV. 20, aus Siderastraea.

Caracas-Bai, 7. IV. 20, aus Maeandrina.

Diese circummundan in den tropischen und subtropischen Meeren verbreitete Art wurde in wenigen Exemplaren gesammelt. 
Nicidion kinbergi Webst.

Nicidion brevis Ehlers 1887.

Nicidion kinbergi Hoagland 1919.

Spaansch Water, aus Porites furcata.

Ausser einèm im gleichen Glase liegenden Hinterende, das vermutlich dieser Art angehört, sah ich ein vollständiges Tier von ca. $33 \mathrm{~mm}$ Länge, mit 153 Segmenten. Etwa das vordere Drittel des Körpers ist dorsal hell rötlich-braun, ohne anderweitige Zeichnung, weiter hinten verblasst die Färbung in ein graurötliches Weiss. - Am Analsegment stehen 2 kurze, ungegliederte Analcirren. - Die Fühler zeigen so etwas von Querringelung, keineswegs aber eine deutliche Gliederung. - Die Borsten entsprechen dieser Art.

Nach sorgfältiger Untersuchung war festzustellen, dass von Kiemen nichts vorhanden ist. WEBSTER's unvollständiges Originalexemplar von Bermuda hatte bei einer Länge von $14 \mathrm{~mm}$ noch 70 Segmente. Der $N$. brevis Ehl. von Westindien passt nach seiner Zahl von 127 Segmenten im Verhältniss zu seiner Länge von $22 \mathrm{~mm}$ zu dem Curaçao-Tier. Wie ich bei Eun. gagzoi Aug. auch in meiner grossen Westindien-Arbeit gesagt habe, betrachte ich bis auf weiteres $N$. kinbergi als eine kiemenlose Form der Eun. gagzoi.

$$
\text { Lysidice ninetta. Aud. \& Edw. }
$$

Lysidice brachycera Augener 1925.

Caracas-Bai: 2. und 13. IV. 20, aus Korallen; in der Wurzel von Gorgonia; 7. IV. 1; 25. V. 20.

Diese Lysidice hat mir in 6 Exemplaren vorgelegen, von denen das Tier aus der Wurzel von Gorgonia ein Weibchen mit Eiern ist. An dem Wurm vom 2. IV. 20 hafteten Bröckchen zerriebenen Korallenkalkes ziemlich fest an.

Bei 5 Exemplaren sind wie bei europäischen Vertretern der Art alle Fühler, auch der Mittelfühler kürzer, z. T. erheblich kürzer als der Kopf. Nur bei dem Wurm vom 2. IV́. 20 sind sie etwas länger, d. h. die paarigen etwa kopflang, der Mittelfühler ètwas länger als der Kopf.

Ich stelle jetzt diese westindischen Lysidicen, die an sich den Namen L. brachycera Schm. (1861) zu führen hätten, nach Aufklärung der letzteren Art mit dieser zusammen zu L. ninetta Aud. \& Edw., einer im Atlantik von Norden nach Süden sehr weit verbreiteten Art, da ich keinen Unterschied von L. ninetta finden kann.

Betreffs der Verbreitung im Südatlantik ist bemerkenswert, dass diese Art, nachdem ihr Vorkommen an Westafrika:(1918) von mir verzeichnet werden konnte, auch an Deutsch-Südwestafrika vorkommt. Das Hamburger Zoologische Museum erhielt inzwischen von Swakopmund ein schönes, grösseres Exemplar.

\section{Lumbriconereis impatiens Clap.}

Spaansche Haven, 20. V. 20.

Von dieser Lumbriconereis sah ich ein einziges ansehnliches Exemplar von düster bräunlicher Färbung und einer Maximalbreite ohne Ruder von ca. 2,5 mm. Der Wurm ist in mehrere Stücke zerbrochen, das Analende ist nicht erhalten. Ein längeres Vorderende mit Kopf ist ca. $125 \mathrm{~mm}$ lang, ausserdem liegen noch mehrere Bruchstücke vom Mittelkörper von zusammen ca. $104 \mathrm{~mm}$ Länge vor. Das Tier muss danach total mehr als $229 \mathrm{~mm}$ lang gewesen sein.

Der kegelförmige Kopf ist wie bei L. impatiens, robusta und parvo-pedata gestaltet. -- Über die Verteilung der am ganzen Körper einfachen Haken der Ruder ist folgendes auszuführen. Die Haken beginnen zum mindesten an einem der vordersten Rudersegmente, vermutlich schon am ersten Rudersegment. Am 5ten Ruder finde ich unter dem Mikroskop neben 4 oder 5 gesäumten Borsten einen einzigen gerade aus dem Ruder herauskommenden Haken. Am 20ten Ruder findet sich neben 2 oder 3 gesäumten Borsten ein Haken. Haken aus der Mitte des $125 \mathrm{~mm}$ langen Vorderendes finden sich $\mathrm{zu}$ 2 oder 3 am Ruder ohne Begleitung von gesäumten Borsten. Sie haben keine deutlichen Zähne am Scheitel, allenfalls kann man am oberen Ende des Hakenkopfes einen Zahn unterscheiden, davor eventuell noch einen 2ten Zahn. 
Der Kieferapparat passt in seiner Form zu L. impatiens. Der Oberkiefer verhält sich folgendermassen: I) Zange; II) 1. und r. 4 Zähne; III) 1-zähnig; IV) 1-zähnig. Ich finde diese ansehnliche Lumbriconereis nach ihrer Kopf- und Kieferbildung und der Verteilung der überall einfachen Ruderhaken so weit mit $L$. impatiens übereinstimmend, dass ich sie dieser zuordne. Von den aus dem WestindienMeer beschriebenen Lumbriconereis-Arten sind wahrscheinlich die 2 folgenden identisch mit L. impatiens. - Erstens ist das L. robusta Ehl., eine grosse Art von ca. $5 \mathrm{~mm}$ Breite. Kopfform und Kieferbildung stimmen mit den entsprechenden Organen bei meinem Tier überein. Die Haken sind einfach, doch fehlt bei EHLERS eine Angabe darüber, wo ungefähr zuerst am Körper Haken auftreten. - In der kurzen Beschreibung von L. parvo-pedata Treadw., einer gleichfalls grossen Art, deren Kopfform gut zu meinem Tier passt, fehlt jegliche Angabe über die Form der Kiefer. Die stets einfachen Haken wurden neben gesäumten Borsten zu mehreren schon am 2ten Ruder beobachtet.

\section{Lumbriconereis floridana Ehl.}

Spaansch Water: 14. IV. 20, aus Porites furcata; 25. V. 20.

Wenige junge, dünne, unvollständige Exemplare - eines von ihnen ist z. B. ca. $16 \mathrm{~mm}$ lang vertreten diese Art. - Die komplexen Haken des Vorderkörpers treten vom 1sten Ruder an auf, z. B. bei einem Exemplar in Einzahl neben gesäumten. Borsten bis zum 10ten Ruder incl.; vom 11ten Ruder an sind nur 2 einfache Haken pro Ruder vorhanden. Die Kopfform ist bei dieser Art mehr oder weniger stumpf eiförmig, in einem Falle vorn sogar flach abgerundet.

Diese düșter bräunlich gefärbten Würmer haben viel Ähnlichkeit mit der L. gracilis Ehl. $(1864 / 68)$ des lusitanischen Bezirks, die westindische Art weicht aber von letzterer durch die Zweizähnigkeit von Oberkieferstück III ab.

Aracoda iricolor Mont.

Aracoda multidentata Ehlers 1887.

Spaansch Water, 3. IV. 20, aus Porites furcata.

Spaansche Haven, 20. V. 20.

Von den wenigen Exemplaren dieser Art ist ein vollständiges Tier ca. $50 \mathrm{~mm}$ lang und hat am Analsegment 4 kurze Analcirren, von denen die unteren ca. $1 / 3$ so lang wie die oberen sind. Das grösste Exemplar ist in 2 Teile zerbrochen, die zusammen ca. $122 \mathrm{~mm}$ lang sind, und vermutlich einem vollständigen Wurm entsprechen.

Das grösste Tier zeigt bei näherer Üntersuchung gute Übereinstimmung mit Ar. iricolor, so in der Kopfbildung mit den 4 Augen, in der Beschaffenheit der Borsten und in der Zahl und Bezahnung der Oberkieîerstücke. In den Rudern liegen mehrere helle, zartere Aciculae, zu denen sich an den hinteren Rudern zu unterst noch eine ebenfalls helle, stärkere Acicula hinzugesellt.

Ich hatte diese Aracoda-Art früher unter dem Namen der westindischen Ar. multidentata Ehl. (1887) aufgeführt, bin aber später zu der Auffassung gelangt, dass Ar. multidentata nicht von Ar. iricolor zu trennen ist, was ich bereits in einer anderen Arbeit ausgesprochen habe. Die Verbreitung ist sehr ausgedehnt und erstreckt sich über die West- und Osthalbkugel.

\section{Oenone fulgida Sav.}

Spaansch Water, 7. und 14. IV. 20, aus Porites furcata.

Diese im Westindien-Meer verbreitete Wurmform ist mit 6 Exemplaren in der Sammlung vertreten. Es sind kleinere Tiere mit Ausnahme eines stattlich grossen von ca. $215 \mathrm{~mm}$ Länge.

Fam. STAuronereidae.

Stauronereis angolana Aug.

Spaansch Water: 15. und 25. V. 20, aus Porites furcata; 5. V. 20, aus Korallen. Spaansche Haven.

Von den wenigen Exemplaren dieser Art sind die 3 grössten vollständig ca. 36 resp. $40 \mathrm{~mm}$ lang und von düster brauner Färbung resp. bräunlich-fleischfarben. Kleinere Individuen, so von 15 und 
$18 \mathrm{~mm}$ Länge, sind zart weiss-bräunlich, ein 3tes ist düster grau-bräunlich. Ein weiteres kleineres Tier - es steckte zwischen den groben Hartkörpern auf einer Loimia-Röhre - war in Formolkonservierung zart fleischfarben, am Hinterkörper mehr graugelblich.

An 2 mittleren Rudern eines kleineren Wurmes finde ich 8-10 Dorsal- und 12-14 Ventralborsten. Dorsale Gabelborsten fehlen dem Charakter dieser Art entsprechend. An dem genauer untersuchten Unterkiefer eines kleineren Wurmes finden sich jederseits der Schneiden 2 resp. 3 freie Chitinkörner; die Schneiden haben etwa 6 Zähne. - Die Fühler sind so lang oder länger als die Palpen und lassen eine Gliederung nur bei genauer Untersuchung erkennen, was mit dem Erhaltungszustande und der Art der Konservierung zusammenhängen mag. Das Nuchalorgan ist ganz deutlich.

Circummundan und im Atlantik weit verbreitete Art.

Fam. Glyceridae.

Glycera tessellata Gr.

Glycera tessellata Horst 1922.

Spaansche Haven: 17. IV. 20; 6. und 20. V. 20; 16. IV. 20, aus Sand ausgesiebt; 17. IV. 20, Riff.

Caracas-Bai : 10. V. 20, aus Spongien; 25. V. 20

Curaçao, 1920

Diese bereits von HoRsT für Curaçao angegebene Glycera gehört dort zu den häufigeren Polychaeten, da ich mehr als 30 Exemplare von verschiedener Grösse unter Händen hatte.

Es sei hier hervorgehoben, dass in keinem Falle eine dorsale tessellata-Zeichnung erkennbar war mit Ausnahme eines einzigen, kleinen Wurmes von Spaansche Haven 20. V. 20., bei dem eine solche Zeichnung schwach entwickelt war.

Glycera sphyrabrancha Schm.

Glycera sphyrabrancha Augener 1925.

Spaansche Haven, Riff.

Es liegt nur ein einziger Wurm vor, ein grösseres Tier von ca. $100 \mathrm{~mm}$ Länge, dem aber Vorder- und Hinterende fehlen. Die Färbung ist matt bräunlich, mit etwas Metallglanz; am Vorderkörper dorsal eine schwache, feine, dunklere Längstieselung. - Die mit grosser, einfacher, dorsaler, fixierter Kieme ausgestatteten Ruder entsprechen in ihrer Form durchaus denjenigen der Gl. sphyrabrancha, so dass ich keine Bedenken hege, diesen Wurm der genannten Art zuzuordnen.

Die Verbreitung dieser Glycera ist circummundan, ich konnte sie (1924) für Deutsch-Neuguinea feststellen. Mit Berücksichtigung der Häufigkeit und weiten Verbreitung der Gl.tessellata im WestindienMeer ist es auffallend, dass so sehr wenig Material von Gl. sphyrabrancha bisher in diesem Gebiet gesammelt wurde.

Fam. SPIONIDAE.

Scolecolepis vanderhorsti n. sp. (Textfig. 5.)

Spaansche Haven, 6. V. 20. und 16. IV. 20, aus Sand ausgesiebt.

Diese Spionide ist durch wenige Vorderenden, ferner ein Hinterende und verschiedene Bruchstücke ohne Kopf und Schwanzende vertreten. Die Färbung ist dunkel gelbbraun mit weisslichen Körperanhangsorganen. Die Kiemen sind mit einem zarten, braunschwarzen, längsmedianen Streifen geziert, der an der Kiemenbasis fleckartig erweitert ist, so dass die Würmer von der Seite betrachtet eine Reihe segmentaler dunkler Flecken erkennen lassen. Am Körper hafteten, denselben röhrenartig umschliessend, Fetzen geronnener Schleimmenbran, die aussen mit Korallensand beklebt waren.

Der Habitus dieser Würmer ist wie bei den Scolecolepis-Arten langgestreckt, der leicht zerbrechliche Körper ist stark abgeplattet und hat ansehnlich hohe Segmentzahlen. Das längste Vorderende, ca. $77 \mathrm{~mm}$. lang und ca. $3 \mathrm{~mm}$. maximalbreit, enthält zum mindesten 250 Segmente. Buccalcirren waren in keinem Falle erhalten.

Der Kopf ist mit wohlentwickelten, seitlichen Kopffortsätzen nach Scolecolepis-Typ versehen und trägt hinten jederseits eine halbmondförmige Ocellengruppe. Hinter dem Kopfe erstreckt sich ein mediodorsaler Nuchalwulst bis ans 2te Segment nach hinten. 
Die Ventralparapodblätter haben nichts Besonderes an sich und haben einen einheitlichen, freien Rand ohne Einschnitt. Die Dorsalparapodblätter nehmen vom 1sten Segment an anfangs an Länge $\mathrm{zu}$, werden aber noch innerhalb des vorderen Körperlängendritteḷ wieder kürzer und kleiner und sind am hinteren Körperdrittel schliesslich nicht mehr erkennbar.

Kiemen treten am dorsalen Parapodast vom 1 sten Segment an auf bis zum Hinterende und die 1 ste Kieme ist schon ziemlich gross, doch nur wenig länger als das Dorsalblatt und kaum oder höchst unbedeutend kürzer als die 2te Kieme. Die Kiemen

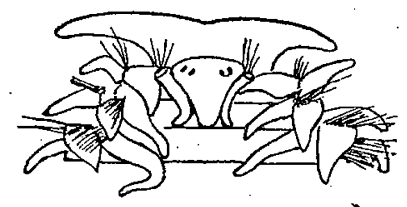

A

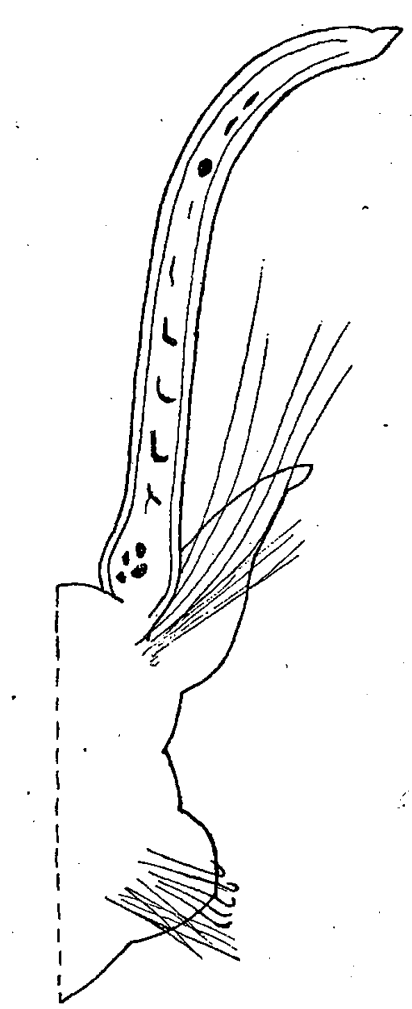

$\mathrm{D}$

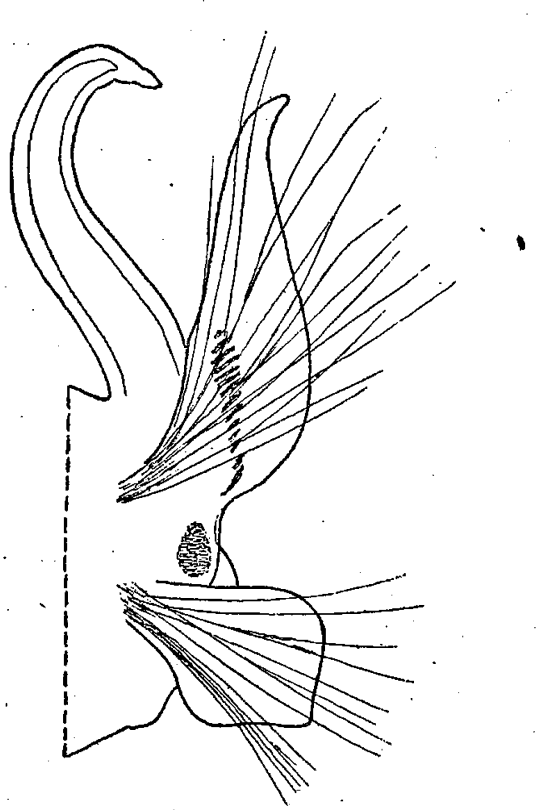

B

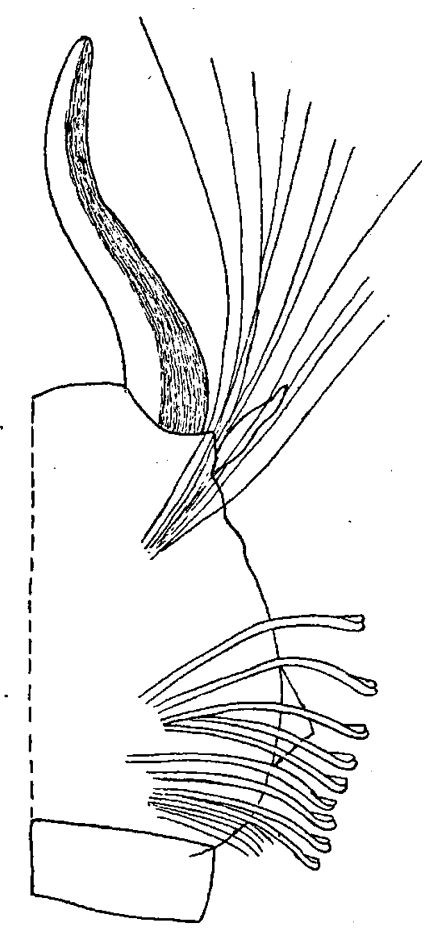

$\mathrm{E}$

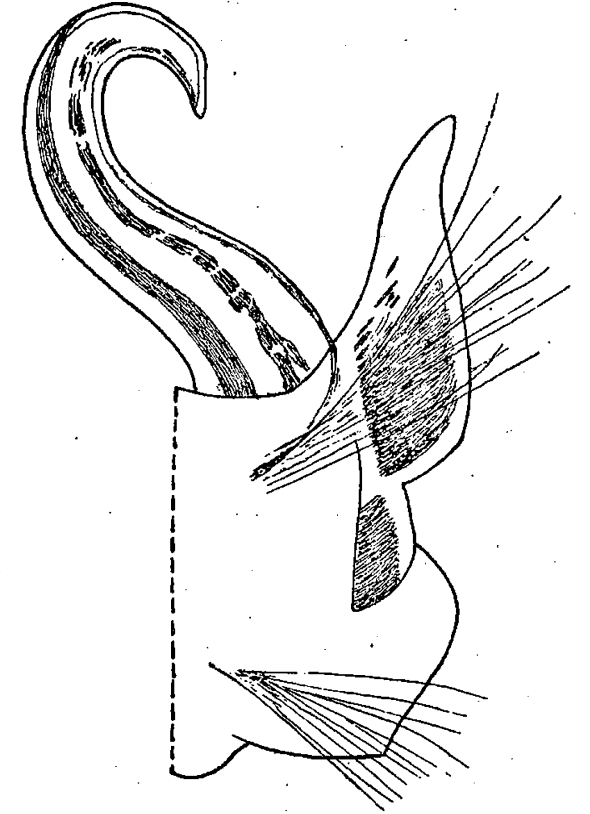

C

Fig. 5. Scolecolepis vanderhorsti n. sp. A. Vorderende. Von oben. $23 \times$. B. 5tes Parapod. Von vorn. $56 \times$. C. 30 tes Parapod. Desgl. $56 \times$. D. Ca. 80tes Parapod. Desgl. $56 \times$. E. Ca. 240tes Parapod. Desgl. $56 \times$. F. Ventraler Haken vom Hinterkörper. [Ca. 240tes Parapod]. Profil. ca. $900 \times$.

erreichen bald ihre grösste Länge, sie sind dann $2 \frac{1}{2}-3$ mal so lang wie das Dorsalblatt und reichen quergelegt noch etwas über die Längsmediane des Rückens hinüber, so z. B. in der Gegend des 25ten bis 30ten Segments. Eine Strecke lang bleiben die Kiemen erheblich lang, werden aber noch im vorderen Körperdrittel wieder kürzer und nehmen nach hinten zu immer mehr an Länge und Stärke ab. Die Kiemen sind überall gänzlich frei vom Dorsalparapodblatt, zuletzt sind sie äusserst zart und kurz und an wenigen hintersten Segmenten mögen sie ganz fehlen. 
An dem einzigen vorhandenen Hinterende sind am Analsegment 2 Analcirren vorhanden resp. erhalten; sie sind kurz, aus verbreiterter Basis fadenfein verjüngt, der eine entspringt links seitlich hinten, der andere in der Mitte hinten am Analsegment. Vielleicht ist durch Verdrückung des Analsegments die symmetrische Inserierung dieser Cirren verschoben, oder auch es sind nicht alle ursprünglich vorhanden gewesenen Cirren mehr erhalten.

Die Beborstung der Parapodien besteht aus Haarborsten und Haken. Am Dorsalast finden sich nur Haarborsten, so auch in der Gegend des 240ten-250ten Segments. Haken kommen nur am Ventralast vor und zeigen sich zuerst zwischen dem 70ten und 80ten Parapod. In der Gegend des 80ten Parapods z. B. sind 5 oder 6 Haken vorhanden ausser langen Haarborsten und einem am untersten Ende des Borstenfächers stehenden Bündel kurzer, kräftiger Haarborsten. In der Gegend des 240ten-250ten Segments finden sich die entsprechenden 2 Haarborstenformen ausser 9 Haken. Die Haken sind im Profil am Ende 3-zähnig, der sekundäre Zahn ist viel kürzer und schwächer als der Hauptzahn, der tertiäre ganz unbedeutend.

Diese Spionide stimmt im Habitus, der Kopfform und dem Verteilungsmodus der Borsten und Haken mit den besser bekannten Arten der Gattung Scolecolepis überein, weicht aber von diesen durch das gänzliche Freibleiben der Kiemen von den Dorsalparapodblättern ab. Aus diesem Grunde die Curaçao-Tiere von Scolecolepis generisch zu trennen, unterlasse ich bis auf weiteres. Der bis vor kurzem für die Spioniden der hier in Frage stehenden Gruppe gebräuchlich gewesene Name Scolecolepis ist von SöDERSTRÖm (1920) durch den Namen Nerine ersetzt worden, worin ich diesem Autor wegen der dadurch hervorgerufenen Verwirrung in der Gattungsbezeichnung der Spioniden nicht folge.

Poecilochạetus serpens Allen.

Spaansch Water, 19. IV. 20, aus Porites furcata.

Das einzige Exemplar ist ein in 3 Teile zerbrochener Wurm von ca. $82 \mathrm{~mm}$ Länge und ca. $2 \mathrm{~mm}$ Maximalbreite. Während das Vorderende gut erhalten ist, ist das Hinterende verstümmelt. Die Segmentzahl beträgt ungefähr 237. Am Hinterende dürfte an der vollständigen Länge wohl nur wenig fehlen. Die Färbung ist unrein düster-bräunlich, am vorderen Körperende reiner und heller braun. Die Bauchmarklinie ist merklich heller als die übrige Bauchfläche. - Der Wurm ist ein Weibchen mit zahlreichen Eiern.

Am Vorderkörper finde ich die gleichen Verhältnisse wie bei britischen Exemplaren. Der Kopf mit den kleinen Augen und dem unpaaren Fühler ist genau wie dort. Die Buccaltentakel sind abgefallen. Nicht erhalten sind ferner von den 3 langen, dick-fadenförmigen, dorsalen Anhängen hinter dem Kopf die paarigen. Diese Anhänge - sie werden von ALLEN als Nuchalorgane aufgefasst - gehören, soweit ich an diesem einen Tier feststellen kann, dem 1sten Segment (Buccalsegment) an. - Die 2 kurzen, vorderen Körperregionen enthalten wie bei der europäischen Form in der 1sten Region 6, in der 2ten 7 Segmente. - Von den als Kiemen bezeichneten Parapodanhängen vermag ich an dem westindischen Alkoholtier, das wegen seiner Zerbrechlichkeit zu schonen ist, nichts genaueres zu erkennen.

Der vorliegende Wurm ist viel segmentreicher und länger als die britischen Exemplare. Bemerkenswert ist auch die Auffindung in Korallen, während die europäische Form im Sande lebt. Die Feststellung der merkwürdigen Spionide im Westindien-Meer ist von grossem Interesse. Das Verbreitungsgebiet dieser Art ist demnach weit ausgedehnt von der Borealen Region bis in die Tropenregion des Atlantik, sicherlich aber wohl extra-arktisch. Wie ich vermute, kommt das Tier noch in anderen Teilen des Atlantik-Gebiets vor.

Verbreit.: Britische und Skandinavische Meeresteile. Nordsee. Die erwachsene Wurmform, deren Larve schon weit früher aufgefunden wurde, wurde von Allen bei Plymouth im Sande entdeckt und 1904 beschrieben.

\section{Fam. SACCOCIRRIDAE.}

Saccocirrus major Pier.

Caracas-Bai, 3. V. 20, unter Steinen.

Von der äusserst artenarmen Gattung Saccocirrus sah ich einen einzigen vollständigen Wurm, ein geschlechtsreifes Weibchen mit Eiern, von gelbbräunlicher Färbung. Der sehr gestreckte, ungefähr 
$19 \mathrm{~mm}$ lange Wurm hat die Stärke eines dicken Nähfadens; die Segmente lassen sich nicht gut zählen, es sind über 100 .

Der kleine Kopf mit jederseits einem ziemlich grossen Auge, wie die langen Buccalcirren hinter demselben, entsprechen ganz der Gattung. - Die Analanhänge haben je 11 oder 12 Randpapillen.

Die Beborstung ist die der. Gattung. Es treten pro: Parapod 4 oder 5 kürzere und längere Spatelborsten auf, mit 3-zähniger Spitze. Ausserdem 1 oder 2 haarförmig aussehende, sehr feine Borsten, die $1 \frac{1}{2}-2$ mal so lang wie die Spatelborsten sind. Ich habe auch mit sehr starken Vergrösserunger nicht ausmachen können, wie die Endspitze dieser feinen Borsten beschaffen ist.

Dieser Wurm passt in der Zahl der Papillen der Analfortsätze vollkommen zu S. major (PIẸRANTONI 1907). Auch die Färbung passt, da Weibchen dieser Art weiss oder gelblich sind. Die europäischen Tiere dieser Art werden allerdings sehr viel grösser als das westindische und sind geschlechtsreif von Anfang Frühling bis Anfang Sommer, was wiederum zu dem Verhalten des westindischen Tieres passt. Ich nehme daher bis auf weiteres an, dass $S$. major im westindischen Tropenmeer bei einer viel geringeren Grösse geschlechtsreif wird. Nach seiner Grösse würde das Curaçao-Tier viel besser zu $S$. papillocercus Bobr. passen, allein diese Art hat nur halb so viele Analanhangspapillen, ausserdem eine abweichende Färbung und eine ganz andere Geschlechtsreifezeit.

Fam. OPHELIIDAE.

Armandia maculata Webst.

Spaansch Water, 3. IV. 20 und 13. V. 20, unter einem Stein.

Spaansche Haven, 20. V. 20.

Caracas-Bai, 10. V. 20, aus Spongien.

Diese Würmer lagen mir in 8 Exemplaren von verschiedener Grösse vor. Die grösseren Individuen, bis ca. $36 \mathrm{~mm}$ lang, sind schokolade-braun mit einer Spur Fleischfarbe oder auch braungelblich oder zart rötlich-graubräunlich. Bei 6 grösseren Exemplaren finde ich stets 29 Borstensegmente. Am Analrohr des grössten Wurmes stehen ca. 22 Randpapillen, bei 2 weiteren grösseren Exemplaren finden sich ca. 24-26 solche Papillen, von denen in dem einen Falle die unterste jederseits viel länger und stärker als die übrigen ist. Von 2 kleinen Exemplaren bis ca. $11 \mathrm{~mm}$ Länge - sie sind graugelblich hat das grössere, soweit erkennbar, ebenfalls 29 Borstensegmente. Die Analrohrpapillen sind viel geringer an Zahl als bei den grossen Exemplaren, es mögen 8-10 sein. - Die Analkieme ist vorhanden, ebenfalls sind die sog. Seitenaugen doch z. T. erkennbar. Bei den 4 Individuen vom 3. IV. 20. sind die letzten Borstensegmente kiemenlos. Ich habe diese weit verbreitete Art schon an anderer Stelle für das Westindien-Meer feststellen können.

\section{Polyophthalmus floridanus Aug.}

Caracas-Bai: 1. V. 20 und 3. V. 20, unter Steinen am Ufer; 10. V. 20, aus Spongien.

Die 3 von mir gesehenen Exemplare dieser kleinen Wurmform sind 9-10 mm lang und einfarbig graubräunlich, dunkel graugelblich oder braungelb. Nur bei dem einen Wurm (3. V.20.) ist am Vorderund Hinterende etwas schwärzliche Färbung zu erkennen. Bei einem Wurm erkenne ich unter der Lupe. in Alkohol sicher 11 Paar Seitenaugen.

Alle von mir bisher gesehenen westindischen Polyophthalmus waren mehr oder weniger dunkel gefärbt und dabei ungefleckt, d. h. sie zeigten nicht die typische, braune Fleckung auf hellem Grunde wie bei $P$. pictus Duj. Es mag aber sein, dass die Untersuchung eines grösseren Materials der westindischen Form doch dazu führen wird, letztere als Varietät mit $P$. pictus zu vereinigen.

\section{Fam. Capitellidae.}

Dasybranchus caducus Gr.

Spaansch Water: 17. IV. $20 ; 4$. V. 20.

Spaansche Haven: 16. IV. 20, 17. IV. 20, 6, V. 20 und 20. V. 20, aus Sand ausgesiebt.

Caracas-Bai, 5. V. 20.

Von diesem Dasybranchus, den ich in wenigen Individuen bereits früher aus Westindien sah, 
lagen mir 15-20 Exemplare voń verschiedener Grösse vor. Mit Ausnahme eines kleineren vollständigen Wurmes von ca. $125 \mathrm{~mm}$ Länge sind alle mehr oder weniger zerbrochen. Das bei weitem stärkste Tier ist ein Vorderende von 9-10 mm Maximalbreite. Am Körper - die Würmer sind mehr oder minder spiralig eingerollt - haften hier und da zarthäutige Schleimfetzen mit etwas Fremdkörperbelag aussen.

Der Kopflappen, der, je nachdem er mehr ausgestreckt oder mehr eingezogen ist, ein etwas verschiedenes Aussehen hat, ist gerade so gestaltet wie bei mediterranen $D$. caducus. Bei kleinen Exemplaren erkennt man an seiner Basis jederseits eine Ocellengruppe.

Kiemen waren streckenweise ausgestülpt, so bei den Tieren vom 6. V. 20. Ich zählte an der Kieme eines grösseren Wurmes mindestens 20 Nebenäste resp. Fäden.

Was die als Thoraxregion aufzufassende vordere Körperstrecke betrifft, so besteht sie ausser dem nackten Buccalsegment stets aus 13 nur mit Haarborsten ausgerüsteten Segmenten wie bei europäischen Tieren der Art. Eine hintere, äussere Grenze an der Thoraxregion, die nach theoretischer Überlegung hinter dem letzten Haarborstensegment erkennbar sein müsste, befindet sich an einzelnen Exemplaren allerdings einigermassen deutlich hinter dem letzten Haarborstensegment. Bei anderen Individuen wieder befindet sie sich hinter dem 11 ten Borstensegment mehr oder minder deutlich. Bei gewissen Exemplaren sind die Thoraxsegmente bis zum letzten Thoraxsegment dunkler als die dann beginnende Abdomenregion, während wieder bei anderen - es sind Tiere mit äusserer Thoraxgrenze hinter dem 11 ten Haarborstensegment - das 12te und 13te Haarborstensegment heller als sonst, mehr den folgenden Abdominalsegmenten ähnlich sind. Es entsprechen die hier kurz angegebenen Verhältnisse bezüglich der letzten Thoraxsegmente der Angabe von EIsIg (1887. p. 169), dass die 2 letzten Thoraxsegmente in ihrem Aussehen den Abdominalsegmenten ähnlich sind. - Nach Eröffnung des stärksten Vorderendes vom Rücken her ergab sich, dass das sog. Septum in Thorax zwischen dem 11 ten und 12ten Haarborstensegment verläuft genau wie bei mediterranen Tieren von $D$. caducus (vgl. EISIG 1887). Ich bezeichne sonach auch die Curaçao-Tiere dieser Art als $D$. caducus in der Überzeugung, dass sie sich nicht von europäischen Exemplaren desselben unterscheiden.

\section{Heteromastides bifidus Aug.}

Heteromastides bifidus Augener 1924.

Caracas-Bai, 25. v. 20.

Ich sah von dieser kleinen Capitellide nur ein einziges Exemplar von hell graulicher Fleischfarbe. Es ist bei voller Erhaltung ca. $11 \mathrm{~mm}$ lang, mit annähernd 50 Segmenten. Dieser Wurm ist grösser als das einzige Originalexemplar von Südwest-Australien (1914), woraus die höhere Segmentzahl zu erklären ist.

Im übrigen passt das Curaçao-Tier gut zu dem Original. Der Kopf, der hinten jederseits Ocellen trägt und in seinen hinteren Ringel zurückgezogen ist, ist vorn stumpfer abgerundet als bei dem Original, was wohl durch einen etwas anderen Kontraktionszustand zu erklären ist. - Am Thorax sind die Grenzen der vordersten Segmente verwischt, ich glaube trotzdem, dass 13 Thoraxsegmente vorhanden sind, von denen 12 mit Haarborsten versehen sind. Soweit ich an diesem Tier feststellen kann, finden sich an der Thoraxregion nur Haarborsten, was bei dem Original wohl auch der Fall gewesen sein wird. Die abdominalen Haken entsprechen denen des Originals, sie haben im Profil 3 Zähne am Hakenkopf, ein 4tes Zähnchen ist zweifelhaft. - Das Analsegment mit seinen 2 Fortsätzen passt gut zu demjenigen des australischen Wurmes.

Die Verbreitung dieser kleinen Capitellide scheint nach dem Funde von Curaçao sehr ausgedehnt zu sein.

Fam. ARICIIDAE.

$$
\text { Scoloplos (Naidonereis) laevigata Gr. }
$$

Spaansche Haven, 17. IV. 20, Riff.

Kleine Lagune bei Caracas-Bai, 26. IV. 20.

Von Caracas-Bai ist nur ein Vorderende vorhanden, von Spaansche Haven ein zerbrochenes, grösseres Exemplar von dunkel gelbbrauner Färbung. Der Kopf ist bei diesem Wurm wie üblich vorn 
stumpf gerundet. Die 1ste Kieme steht am 6ten Parapodsegment; die 1ste Körperregion umfasst ca. 25 Parapodsegmente.

Scoloplos treadwelli Eisig.

Aricia cirrata Treadwell 1900/1902

Scoloplos treadwelli Eisig 1913/14.

Spaansch Water, 17: IV. 20.

Das einzige Exemplar ist ein vollständiger Wurm von ca. $55 \mathrm{~mm}$ Länge. Die Segmentzahl beträgt über 200, wegen der starken Verkrümmung des Tieres sind die Segmente schlecht zu zählen. Am Körper haften häutige Röhrenfetzen. Die Färbung ist am Vorderkörper dunkelbräunlich, in der Mitte und hinten heller als vorn. Der Kopf hat die spitz kegelförmige Gestalt wie bei den echten Scoloplos. Das Analsegment trägt 4 fadenförmige Analcirren, von denen die 2 mittleren kurz, viel kürzer als die seitlichen Cirren sind.

Die 1ste Körperregion ist hinten deutlich abgesetzt und entspricht mit ihrer hinteren Grenze dem Beginn der Kiemenregion. Die kompress-lanzettlichen Kiemen beginnen am 19ten Borstensegment und sind zuerst viel grösser als das Dorsalparapodblatt, etwa 3mal so lang wie das letztere. Rasch sinkt dann die Kiemenlänge auf das 2-fache der Länge des Dorsalblattes herab, ungefähr auf halber Körperlänge ist die. Kieme nur noch eben so lang wie das Dorsalblatt, an den hintersten Segmenten wird das Dorsalblatt kürzer als die Kieme.

An voll entwickelten Parapodien vom vorderen Mittelkörper hat der Ventralast eine kurze, kegelförmige, stumpfe Papille unten am Ende, beide Äste sind mit einer Acicula versehen. Die thoracalen Ventralparapodien haben keine Papillen im Sinne der echten Aricien.

Was die Borsten betrifft, so fand ich an 2 Präparaten aus der kiemenlosen 1sten Region alle Borsten abgebrochen; ventral kommen u. a. starke braune Haken vor. An Parapodien vom vorderen Mittelkörper finden sich dorsal oben Haarborsten des gewöhnlichen Typs. Ob an den Dorsalparapodien Gabelborsten vorkommen, ist zweifelhaft. Ich habe mehrere Dorsalparapodien von der Mittelkörperregion daraufhin untersucht, doch Gabelborsten nicht sicher feststellen können. Abgebrochene Haarborsten täuschten öfter Gabelborsten vor. Ihr etwaiges Vorhandensein wäre an reichlicherem Material noch zu bestätigen. Am Ventralast der Parapodien der postthoracalen Körperstrecke stehen nur Haarborsten.

Ich nehme an, dass dieser Scoloplos die von TREADWELl als Aricia cirrata beschriebene Ariciide von Porto Rico ist, deren Name von EISIG in Scoloplos treadwelli umgewandelt wurde, da bereits eine Aricia cirrata, die gleichfalls der Scoloplos-Gruppe angehört, früher von EHLERS (1897) aufgestellt wurde. Nach TREADWell beginnen die Kiemen am 13ten und 17ten Segment, und der Thorax endet am 14ten, 17ten und 20ten Segment; das vorliegende Tier würde mit seiner Thoraxlänge daher zu dem letztgenannten Fall passen. Nach TREADWELL sollen vereinzelte Dorsalparapodblätter verzweigt sein, was auch an dem Curaçao-Tier vorkommen mag; an zahlreichen, untersuchten Dorsalparapodien habe ich nichts dergleichen gesehen. Diese Ariciide ist gewiss weiter verbreitet im Westindien-Meer.

\section{Fam. CiRRATulidae.}

Cirratulus melanacanthus Gr.

Caracas-Bai : 11. V. 20, aus Spongien; 6. und 13. V. 20, aus Sand; 6. V. 20.

Vom 11. V. 20. liegt ein einziges, ca. $24 \mathrm{~mm}$ langes, vollständiges Tier vor, vom 13. V. 20 . waren fast nur Vorderenden etlicher Individuen erhalten.

Caracas-Bai, 25. V. 20.

Cirratulus punctatus Gr. (Oerst.)

Dieser in wenigen Exemplaren gesammelte Cirratulus ist kenntlich an seinem schwarzgefleckten Körper und den in der gleichen Farbe quergebänderten Cirren am Vorderende. Bei mehreren Tieren ist am Hinterende ein kurzes Regenerat vorhanden, das durch seine hellere Grundfarbe und schwach entwickelte schwarze Zeichnung auffällt. 
Fam. MaLdanidae.

Praxillella spec.

Spaansche Haven.

Ich führe uñter diesem Name ohne nähere Erörterung der Vollständigkeit halber das Vorderende eines kleinen Wurmes mit noch 10 Borstensegmenten auf. Es ist ein Tier mit flacher Kopfscheibe und mit Kopfsäumen. Es ist kein Hautkragen an einem der vorderen Segmente entwickelt. Ventral stehen an den Segmentflanken Haken und zwar vom 1sten Borstensegment an.

Maldanidarum gen. et. spec.

Spaansche Haven, 20. V. 20.

Ich sah nur das Hinterende eines grossen Wurmes von ca. $240 \mathrm{~mm}$ Länge, mit noch 9 Segmenten. Die zugehörige, teilweise erhaltene Röhre besteht aus Korallensand und ist dickwandig, doch ziemlich leicht zerbrechlich. - Von den Segmenten sind ausser 5 Borstensegmenten 3 nackte Präanalsegmente und das Analsegment erhalten. Das Analsegment ist trichterförmig, ähnlich demjenigen von Nicomache u.s. w., und ist mit 21 Analcirren ausgestattet, von denen ein kleiner Teil äusserst kurz, papillenartig ist. Ventro-median ist kein besonders verlängerter Anälcirrus vorhanden, auch sonst keine besonders. lange fadenförmige Analcirren. Hautkragen sind an diesem Hinterende nicht entwickelt.

\section{Nicomache antillensis Aug.}

Nicomache antillensis Augener 1922.

Caracas-Bai : 23. IV. 20, von Korallen; 8. V. 20.

Spaansch Water, 17. IV. 20.

Abgesehen von einigen Bruchstücken ohne Kopf und Hinterende vom 8. V. 20., die offenbar dieser Art angehören, konnte ich ein Vorderende von Spaansch Water und 4 Vorder- und 4 Hinterenden nebst 3 Bruchstucken vom Mittelkörper vom 23. IV. untersuchen. Erhaltene Röhrenteile bestehen aus Korallensand und anderen Hartkörpern und sind ziemlich fest.

Ein Vorderende vom 23. IV. 20. mit noch 10 Borstensegmenten ist ca. $30 \mathrm{~mm}$ lang. Der Vorderkörper bis zum 3ten Borstensegment incl. ist graulich-fleischfarben, so auch die letzten 2 erhaltenen Segmente; die übrigen Segmente sind lebhaft braun mit grauweissem Drüsengürtel. Ebenso gefärbt ist das einzige Vorderende von Spaansch Water, das mit noch 11 Borstensegmenten ca. $26 \mathrm{~mm}$ lang und ca. 2,5 mm breit, ungefähr ebenso stark wie das vorhergehende Vorderende ist. Bei anderen Tieren kann die Färbung bis zum 3ten Borstensegment incl. düster bräunlich sein, wie auch sonst die Färbung noch dunkler sein kann als vorher beschrieben.

Im Allgemeinen ist über diese Würmer noch folgendes zu sagen. Wie bei dem Original finde ich stets 2 nackte Präanalsegmente und 3 vorderste Borstensegmente mit wenigen ventralen, glatten Stacheln jederseits ventro-lateral. Ocellen an der Oberlippe konnte ich bei mehreren untersuchten Individuen ebenfalls nicht auffinden. An 3 Vergleichsexemplaren fanden sich am 1sten Borstensegment 3, 5, 4, am 2ten Borstensegment 5, 4, 3, am 3ten Borstensegment 4, 5 resp. 6, 4 resp. 5 glatte Stacheln pro Stachelgruppe. - Die normalen Ventralhaken der mittleren Segmente haben im Profil 7 oder 8 Zähne über dem Hauptzahn. - Von Analcirren finden sich an den 4 erhaltenen Analsegmenten 18, 22, 16, 13 (2 davon besonders breit). Die Cirren sind ziemlich gleich lang, nur ausnahmsweise ist einer viel kürzer als die übrigen. Medio-ventral ist in keinem Falle ein besonders langer Cirrus entwickelt.

Ich war bei der Untersuchung des Originals zu dem Schlusse gelangt, dass die 2 Bruchstücke desselben einem vollständigen Wurm entsprächen, von dessen Segmenten 19 Borstensegmente, 2 nackte Präanalsegmente sind. Dieselben Segmentzahlen ergeben sich, wenn man die verschiedenen Vorder- und Hinterenden von Curaçao zusammenzupassen sucht. In diesem Sinne ergibt von den Caracas-Bai-Tieren ein Vorderende mit noch 14 Borstensegmenten zusammen mit einem Hinterende mit noch 5 Borstensegmenten gleichfalls 19 Borstensegmente u.s w. Die gleiche Gesamtsegmentzahl liefert ein Vorderende mit 10 Borstensegmenten zusammen mit einem Hinterende mit 9 Borstensegmenten. 
Fam. TEREBELlidAe.

Leprea (Terebella) lapidaria Kähl.

Westindien. (BOEKE leg.).

Diese von mir bereits aus der Sammlung KüKENTHAL \& HARTMEYER für Westindien aufgeführte Terebellide ist durch ein vollständiges, doch erweichtes, gedehntes, verblasstes Exemplar von ca. $55 \mathrm{~mm}$ Länge vertreten. Von den Charakteren dieser Art seien erwähnt die 3 Paar Kiemen und das Auftreten von Dorsalborsten bis nahe ans Hinterende.

Leprea (Terebella) reticulata Ehl.

Spaansche Haven.

Spaansch Water: 15 . V. 20 und 17. IV. 20, 5. V. 20, aus Korallen; 8. IV. 20, von Mangrove-Wurzeln. Caracas-Bai, 10. und 11. IV. 20, aus Spongien.

L. reticulata hat $\mathrm{mir}$ in 15 bis 20 Exemplaren von Curaçao vorgelegen, und z. T. mit viel grösseren Individuen als EHLERS sie sah. In Formol konservierte Tiere sehen mehr oder weniger schön zart fleischfarben aus.

Das grösste von mir gesehene Tier ist das einzige in Caracas-Bai 11. V. 20. gesammelte, ein in zwei Teile zerbrochener, vermutlich doch vollständiger Wurm. Die Segmentzahl beträgt bei einer Länge von ungefähr $96 \mathrm{~mm}$ über 100, von denen 39 Haarborstensegmente, ungefähr 63 reine Hakensegmente sind. Kopfocellen konnte ich nicht erkennen. Das 2te Kiemensegment trägt seitlich an den oberen 2/3 seiner Höhe. einen dicklichen, schwach scheuklappenartigen Wulst. Von Bauchschildern sind am Thorax 12 oder 13, wohl 13 vorhanden. - Ein weiteres vollständiges Tier von ca. $28 \mathrm{~mm}$ Länge hat ca. 36 Haarborstensegmente. Ein 3tes kleineres Tier hat 27 Haarborstensegmente. Ein 4tes, unvollständiges Tier mit noch 20 reinen Hakensegmenten und von ca. $35 \mathrm{~mm}$ Länge hat 37 Haarborstensegmente. Ein erheblich kleineres Exemplar als das vorhergehende hat 25 Haarborstensegmente. Die Zahl der Haarborstensegmente mag danach mit der Grösse der Würmer etwas zunehmen.

Von Kiemen sind normalerweise 3 Paar vorhanden. Sie sind buschig, mit kurzem, nacktem Basalstiel versehen. Die 2te Kieme entspringt tiefer als die 2 anderen. Bei dem grössten Wurm ist rechts die 2te Kieme die grösste von allen, grösser als die 3te, während links Kieme 2 und 3 so gut wie gleich gross sind. Wenn weniger als 3 Paar Kiemen vorhanden sind, mögen Kiemen schon während des Freilebens oder aber beim Abtöten in Verlust geraten sein, so bei Tieren vom 8. IV. 20. Das Auftreten der einseitig fein gebärtelten Leprea-Borsten in den Haarborstenbündeln und die dorsale Körper-Retikulierung am Vorderende der Würmer vervollständigen das Bild dieser Terebelliden. Die deutliche Erkennbarkeit der Retikulierung ist von dem Erhaltungszustande der Würmer abhängig und zeigt sich im Bereiche der 9 oder 10 ersten Borstensegmente.

Mehrfach waren die Röhren erhalten. Sie sind ziemlich starr und widerstandsfähig, und auf sehr zarthäutiger organischer Innenschicht mit einer dicken, weiss-grauen oder schmutzig-grauen Schlammschicht bekleidet; in ihrem Aussehen erinnern sie an Maldaniden-Röhren. Von den in Caracas-Bai aus Spongien gefundenen Würmern steckte einer auch in einer solchen Schlammröhre. Mit Schwammnadeln bekleidete Röhren wurden nicht beobachtet. Die bei einzelnen Exemplaren mehr oder minder zahlreich in die Haut eingespiesst gefundenen feinen Schwammnadeln haben sich wohl beim Herausholen der Tiere zwischen den Spongien in den Körper eingebohrt.

\section{Loimia turgida Andr.}

Spaansch Water: 3. und 26. IV. 20 und 15. V. 20;4. V. 20.

Caracas-Bai: 19. V. 20; 23. IV. 20, von Korallen; 10. V. 20, aus Spongien.

Diese stattliche Terebellide lag mir von den einzelnen Fundorten in einzelnen oder ganz wenigen Individuen vor von recht verschiedener Grösse. In Formol konservierte Exemplare sind dunkel fleischfarben und ihre Tentakel blass fleischfarben, Alkoholexemplare sind mehr bräunlich als Formol-Exemplare, mit weiss-bräunlichen Tentakeln. Niemals sah ich am Körper und den Tentakeln dunkle Zeichnung im Sinne anderer Loimia-Arten, während von ANDREws (1891) eine solche für die Tentakel angegeben wird. 
Diese Würmer haben stets 17 Haarborstensegmente. - Ein Wurm von ca. $132 \mathrm{~mm}$ Länge ist ca. $9 \mathrm{~mm}$ maximalbreit. Ein solcher von ca. $183 \mathrm{~mm}$ Länge hatte lang ausgestreckte Tentakel, deren Länge $1 / 3$ der Körperlänge gleichkommt. Dieser Wurm hat 130 bis 140 reine Hakensegmente, an denen zuweilen auf einer Seite oder auf beiden Seiten die Hakenflösschen nicht entwickelt sind. Ein etwa $185 \mathrm{~mm}$ langes Tier hat ca. 135 reine Hakensegmente. An einem grossen ca. $15 \mathrm{~mm}$ breiten und ca: $92 \mathrm{~mm}$ langen Wurm besteht das Abdomen aus 35 normalen Abdominalsegmenten und einem hinteren Regenerat. - Haken aus den Doppelreihenpolstern grosser Tiere haben " 5 Zähne an der Schneide, oft sind auch nur 4 erkennbar.

Über die Zahl und Gestaltung der thoracalen Bauchschilder ist folgendes zu sagen. Ich habe sie an 11, allen hierfür geeigneten Individuen, untersucht, es waren überwiegend grosse Exemplare. Danach ist die Normalzahl der Bauchschilder als 15 festzustellen, innerhalb deren die Bauchschilder ihrer verschiedenartigen Ausbildung nach in 3 aufeinander folgende Gruppen zu teilen sind. Die erste Gruppe enthält - ich rechne wie sonst Bauchschilder vom 1sten Borstensegment an als vorhanden stets 10 ungeteilte Bauchschilder, die zweite Gruppe 2 quer-zweigeteilte, die dritte Gruppe 3 zum mindesten quer-dreigeteilte Bauchschilder. Mitunter ist in der dritten Gruppe noch ein 16ter Bauchschild erkennbar. Zuweilen sieht es so aus, als ob der Gruppe 2 mehr als 2 Bauchschilder angehörten auf Kosten der dritten Gruppe. Ausnahmsweise ist das 15te Bauchschild nicht sicher unterscheidbar. Es mögen ja nun tatsächliche Variationen in der Zahl und Ausbildung der Bauchschilder vorkommen, was schwer zu entscheiden ist. Im Allgemeinen bin ich der Ansicht, dass anscheinende Abweichungen von der Norm, so speziell auch die Tatsache, dass die Bauchschilder der dritten Gruppe in mehr als 3 Teile geteilt erscheinen, auf einen verschiedenen Konservierungs-, Spannungs- und Erhaltungszustand der einzelnen Individuen zurückzuführen sind. In der hohen Zahl der thoracalen Bauchschilder passt diese atlantische Art gut $z u$ der indo-pazifischen L. annulifilis Gr. (WILLEY 1905) von Ceylon. Da aber das Original von GRUBE nicht mehr kontrollierbar ist, und mir sonst nur ein einziges zu der L. annulifilis im Sinne Willey's zu stellendes indo-pazifisches Exemplar unter die Hände gekommen ist, benenne ich die westindische Loimia bis auf weiteres als L. turgida Andr.

Vor ' den erhaltenen Röhren ist die längste vorhandene ca. $220 \mathrm{~mm}$ lang und ca. $17 \mathrm{~mm}$ breit. Die Röhren sind Thelepus-artig, rauh und schwer. Der. Aussenbelag besteht aus gariz überwiegend dunkelfarbigen Steinchen bis zu ziemlich grober Grösse. Eine Röhre war aussen mit kleinen, weissen Hartkörpern beklebt, und an dem in ihr steckenden Wurm war ein ansehnlicher Endabschnitt ganz nach vorn umgeschlagen, was wohl als Beweis für die Bewegungsfähigkeit dieser Würmer in ihren Röhren anzúsehen ist. Diese im Westindien-Meer und im Subtropen-Gebïet Nordost-Amerikas verbreitete Art ist von mir (1922) versehentlich nach einem einzelnen Tier als Lanice haitiana neu beschrieben worden, was ich in meiner grossen Westindien-Arbeit inzwischen berichtigt habe.

\section{Nicolea bilobata Gr. var. antillensis Aug.}

Spaansch Water, 3. IV. 20 und 25. V. 20.

Diese in etwa 20 Exemplaren erbeuteten Würmer sind in Formol fleischfarben-bräunlich mit etwas hellerer Unterseite und abweichend von Nicolea cetrata Ehl. nicht langgestreckt. Die 2 grössten Individuen sind etwa 36 und $38 \mathrm{~mm}$ lang, bei einer Zahl von 70 Abdọminalsegmenten im 2ten Falle.

Die Zahl der Kiemen (2 Paar), die Hakenstellung am Thorax, die grossen Flankenlappen am 2ten Kiemensegment entsprechen dieser Art. An den mit deutlichem Schutzpolsterfortsatz versehenen Haken erkenne ich wie früher in der 2ten Ordnung der Zähne an der Schneide nur einen einzigen Zahn, die Zähne noch höherer Ordnung sind schlecht auseinander zu sondern nach ihrer Stellung.

Die leicht zerreissbaren Röhren sind aussen mit Schlamm besetzt.

Thelepus setosus Qf.

Spaansch Water: 3,12 und 26 . IV. $20 ; 25$. V. $20 ; 7,13$, 14. IV. 20 und 5. V. 20 , aus Porites furcata. Spaansche Haven, 11. V. 20.

Caracas-Bai, 19. IV. 20 und 5. V. 20, aus Korallen

Thelepus setosus, der bei Curaçao offenbar verbreitet ist, war von den einzelnen Fundorten immer nur in 1 , höchstens 2 Exemplaren eingesammelt. An einem Wurm war ein Stück der Röhre 
erhalten, die die für Thelepus bekannte, ziemlich feste Konsistenz hat; aussen auf ihr sass u. a. eine Kalkbryozoën-Kolonie.

Was die. Zahl der mit Dorsalborsten ausgestatteten Segmente betrifft, so habe ich selbige bei 6 Exemplaren festgestellt. Sie beträgt: 53, 48, ca. 47, 45, 41, 39. Einer der grössten Würmer, total ca. $80 \mathrm{~mm}$ lang, hat 45 , ein total ca. $65 \mathrm{~mm}$ langer 41 . Haarborstensegmente. Am hinteren Ende der Haarborstenzone können noch innerhalb derselben zuweilen Segmente ohne Haarborsten vorkommen.

Terebellides stroemi M. Sars.

Spaansch Water: 3. IV. 20; 17. IV. 20.

Diese kosmopolitische Art, die ich schon zweimal früher aus dem Westindien-Meer aufführen konnte, habe ich in einer kleinen Zahl von z. T. schön erhaltenen Individuen gesehen, von bis 40-48 mm Länge.

Diese westindischen Terebellides haben in Übereinstimmung mit meinen früheren Feststellungen sicher 18 Segmente mit dorsalen Haarborsten. Die Haarborsten des 1sten Borstensegments bilden ein recht kleines, oft schwer zu erkennendes, doch bei genauer Untersuchung feststellbares Bündel.

Ein Wurm steckte in einer leicht zerreissbaren, mit Schlamm bekleideten Röhre, ein anderer in einem Stück von einer solchen Röhre.

Fam. SABEllidaE.

Sabellastarte magnifica Shaw.

Spaansch Water: 7, 13. IV. 20, aus Porites furcata; 5. V. 20, aus Korallen; 3, 17, 29. IV. 20; 25. V. 20 Caracas-Bai, 7. IV. 20, aus Maeandrina.

Bei dieser grossen, von den einzelnen Fundorten meistens in wenigen Individuen vorliegenden Sabellide, fand ich 8, zuweilen nur 7 Thoraxborstensegmente. Ein röhrenloser Wurm von ca. $59 \mathrm{~mm}$ Länge hat ca. 50 Strahlen pro Kieme, ein ebenfalls röhrenloser, ca. $76 \mathrm{~mm}$ langer und ca. $14 \mathrm{~mm}$ breiter, ca. 54 Strahlen pro Kieme. Von aus ihrer Röhre entnommenen Exemplaren besass ein ca. $101 \mathrm{~mm}$ langer und ca. $12 \mathrm{~mm}$ breiter Wurm ca. 71 Strahlen pro Kieme; an der Röhre klebten aussen Korallenstücke und eine kleine Muschel. Ein 2tes derartiges Tier hat bei einer Länge von ca. $91 \mathrm{~mm}$ und einer Breite von 7-8 mm etwa 51 Strahlen pro Kieme. Ein 3tes derartiges Tier war ca. $62 \mathrm{~mm}$ lang und ca. $9 \mathrm{~mm}$ breit, mit ca. 54 Strahlen pro Kieme. Bei den Längenangaben ist die Kiemenkrone nicht mitgerechnet.

Was die Länge der Röhren angeht, so lässt sich folgendes darüber sagen. Der Wurm von $91 \mathrm{~mm}$ Länge steckte in einer Röhre von ca. $180 \mathrm{~mm}$ Länge, zu deren Länge gewiss noch ein lose im Glase liegendes Röhrenstück von ca. $77 \mathrm{~mm}$ gehörte, sodass sich eine totale Röhrenlänge von ca. $257 \mathrm{~mm}$ Länge ergeben würde. Dieses ist die längste Röhre, die ich gesehen habe; ob und wie weit sie vollständig erhalten war, kann ich nicht entscheiden. Eine andere Röhre, einen grossen Wurm enthaltend, ist ca. $180 \mathrm{~mm}$ lang, aber am unteren Ende jedenfalls nicht vollständig erhalten. Am Vorderende dieser Sabellidenröhren ist die innere organische Auskleidung eine Strecke lang nur ganz zart und bräunlich, nach hinten zu wird sie zäher und dicker.

Die Sabella splendida Kbg. (1867) von Guadeloupe ist nach K. E. Johansson (1925) eine Sabellastarte und daher als Synonym mit $S$. magnifica zu vereinigen.

Auf die durch ihre Grösse und Häufigkeit auffallende S. magnifica bezieht sich wohl zum mindesten teilweise die Bemerkung von Fr. Doflein in seinem Buche (Von den Antillen zum fernen Westen. 1900. p. 83. VII. Kap. Die Küsten von Martinique und ihre Tierwelt.): Indem wir vorwärtsfuhren, zogen sich ganze Wälder von Seeanemonen und Röhrenwürmern blitzartig vor dem Schatten unseres Bootes zurück.

\section{Sabella melanostigma Schm.}

Spaansch Water: 3. IV. 20; 1. vi: 20.

Caracas-Bai: 3. V. 20, unter Steinen am Ufer; 13. V. 20, aus Korallen; 19. IV. 20. und 25. V. 20.

Von dieser in der Curaçao-Sammlung mit einer ganzen Anzahl von Individuen vertretenen Art 
liegen auch Röhren vor. Röhren vom 13. V. 20. sind aussen mit grauweissem Schlamm beklebt. Von den Röhren vom 19. IV. 20., die z. T. an Spongien hafteten, ist eine, die einen nur etwa mittelgrossen Wurm enthält, bei wohl so gut wie vollständiger Erhaltung ca. $80 \mathrm{~mm}$ lang. Röhren vom 3. IV. 20. sind mit dunklem Schlamm beklebt und ausserdem mit allerlei anderem Material, wie Stücken von Algen, Bryozoën etc. Als äusseres Beklebematerial wird daher von den Würmern solches verwendet wie es jeweils am Standorte der Tiere vorhanden und $z u$ erreichen ist.

Grosse Exemplare sind ca. 35-50 mm lang, mit 17-20 Strahlen pro Kieme, während bei einem kleinen Wurm z. B. nur 11 Strahlen pro Kieme vorkommen. Die Färbung ist je nach der Konservierungsmethode verschieden, so bräunlich in verschiedener Abstufung oder auch zart rötlich-graugelb mit oder ohne braun am Vorderkörper. Am Collare können auffallende dunkle Flecken auftreten. Charakteristisch sind die 2 Längsreihen segmentaler dunkler Flecken, die die immer mehr oder weniger hell bleibenden, die Borsten und Haken tragenden Partien wie 2 Nähte am ganzen Körper einrahmen; am Hinterkörper können diese Flecken kurz-querstrichförmig werden. - Die Thoraxsegmentzahl beträgt bei 14 Individuen: 2 mal 10;2 mal 11; 3 mal 12; 4 mal 13,1 mal 14;1 mal 15; 1 mal 13 resp. 15 .

Kiemenstrahlocellen treten in 2 oder 3 Paaren pro Strahl auf. Die Ocellen jedes Paares liegen öfter vor einander durch einen Zwischenraum getrennt, statt neben einander. Es kommen auch öfter 3 Ocellen in einer Ocellengruppe vor, von denen eine auf der einen Strahlseite liegt, während die 2 anderen auf der entgegengesetzten Seite getrennt von und über einander am Strahl liegen.

Bei einem grossen Exemplar ist das. Vorderende in Regeneration. Es sind hier 8 resp. 9 Thoraxsegmente schon ziemlich normal wieder entwickeit. Das Collare ist weniger weit vorgeschritten, so ventral noch kürzer als normal. Die 13 oder 14 Strahlen pro Kieme sind geringer an Zahl als bei gleich grossen, normalen Individuen, ca. $1 / 4$ so lang wie der Körper und kaum $1 / 2$ so lang wie bei normalen Tieren. An den längsten Strahlen steht ein unteres Ocellenpaar, vereinzelt noch ein 2tes Paar nahe der Spitze.

Als jüngeres Synonym ist mit $S$. melanostigma zu vereinigen die $S$. cornuta Kbg. (1867) von St. Barthélémy, die nach E. K. JoHANSSON (1925) mit der Beschreibung der S. mélanostigma von EHLERS (1887) übereinstimmt.

Caracas-Bai, 5. und 29. V. 20.

Sabella bahamensis Aug.

Diese kleine Sabellide hat mir in einer Anzahl von Exemplaren vorgelegen, die alle in ihre Röhren eingeschlossen waren. Die Röhren, wie die früher (1922) von mir gesehenen, mit grauweissem Schlamm bekleidet, stehen gesellig zusammen, so an einem toten Korallenstück, zwischen Spongien und anderen Organismen. Die Färbung ist gelbbraun oder braun - an den verschiedenen Körperteilen heller oder dunkler - bis hell schokoladebraun. Hakenwülste und Parapodien sind hellfarbig, ebenso die Kiemenstrahlfäden, Kiemenstrahlen aussen braun, Kiemen ohne andersfarbige Querbinden; Collare breit grauweiss besäumt.

Diese Würmer sind im Maximum 20 bis $25 \mathrm{~mm}$ incl. Kiemen lang. Die Anzahl der Thoraxsegmente beträgt in 6 Fällen 5 mal 12, in einem Falle vielleicht 11. Die Zahl der Kiemenstrahlen war bei 6 Individuen - es handelt sich hierbei immer um grössere Exemplare -3 mal 11 und 3 mal 12 pro Kieme. Wenn ich früher der Ansicht war, dass dem Collare dieser Sabellide ein seitlicher Einschnitt nicht zukomme, so bin ich in diesem Punkte jetzt zu einer anderen Anschauung gelangt. Ich nehme jetzt an, dass doch ein seitlicher Einschnitt vorhanden ist, der unter hierfür besonders günstigen Spannungsverhältnissen so gut wie ausgeglichen sein kann. Diese Würmer sind im Westindien-Meer offenbar weiter verbreitet.

Anm. Über die Bildung vegetativer, abdominaler Knospen bei S. bahamensis.

Um diese Erscheinung zu untersuchen, habe ich eine Anzahl Exemplare aus ihren Röhren herauszulösen versucht - leider war kaum ein einziges Tier ohne Röhre abgetötet - was sich insofern schwierig gestaltete, als häufig der Wurmkörper mehr oder weniger mit der Innenwand der Röhre verklebt war. Immerhin gelang es mir, einige Exemplare mit dem Funddatum 29. IV. 20. mit unbeschädigtem Hinterende herauszupräparieren.

Bei mindestens 6 Exemplaren zeigte sich nun, dass der hintere Teil des Abdomens in mehr 
oder weniger weit fortgeschrittener Regeneration begriffen ist; in einem Falle war das Regenerat schon ziemlich vollständig wieder ergänzt. Es handelt sich hierbei um die Regenerierung einer vom Abdomen abgestossenen Körperpartie, welch letztere sich nach ihrer Ablösung zur vegetativen Knospe entwickelt.

In einem Falle gelang es mir, eine abgestossene abdominale Knospe lose hinter dem Mutterwurm in der Röhre eingeschlossen aufzufinden. Der Mutterwurm incl. Kiemen ca. 10,5 mm lang, mit 11 Strahlen pro Kieme und mit 12 Thoraxsegmenten, enthält noch ca. 20 normale Abdominalsegmente und ist am Hinterende wieder in noch nicht weit vorgeschrittener Regeneration begriffen. - Die lose Knospe hat mit der Kieme eine Länge von ca. $4 \mathrm{~mm}$ und eine noch in Entwicklung begriffene Kiemenkrone, die etwa $3 \frac{1}{2}$ mal so kurz wie der Knospenkörper ist und mindestens doch 5 Strahlen pro Kieme erkennen lässt. Die Segmente der Knospe sind alle abdominal, ich habe noch kein vorderes neu gebildetes thoracales Segment erkennen können. Das Collare ist schon ganz gut ausgebildet, es hat jederseits einen tiefen Einschnitt. Bei einem anderen grossen Exemplar dieser Sabellide zeigte sich an dem sonst normal aussehenden Abdomenende ein Stück von der Endspitze entfernt eine Einschnürung, die vielleicht die nahe bevorstehende Abstossung einer Knospe anzeigte. Zwei Tiere mit regeneriertem Hinterende enthalten ungefähr 40 oder einige 40 normale Abdominalsegmente.

Hypsicomus torquatus Gr.

Caracas-Bai: 2. IV. 20, aus Korallen; 3. V. 20, unter Steinen am Ufer.

Die nur bei dem einen der 2 kleinen Exemplare erhaltene Kiemenkrone enthält 10 Strahlen pro Kieme. Das ventral durchaus ganzrandige Collare ist hier schwach konvex vorgezogen. Die Lage der Kiemenocellen ist erkennbar, ihre Zahl ist wegen ihrer starken Zusammendrängung nicht gut zu ermitteln. Diese atlantische Hypsicomus-Art steht der indo-pazifischen H. phaeotaenia Schm. so nahe, dass sie wohl mit ihr vereinigt werden kann.

Hypsicomatopsis circumspiciens Ehl.

Caracas-Bai : 2. IV. 20, aus Korallen; 7. IV. 20, aus Maeandrina.

Die wenigen Exemplare sind klein und haben alle 8 Thoraxsegmente. Ein vollständiges Tier ist ca. $21 \mathrm{~mm}$ lang ohne die Kiemen. An einem der grösseren Exemplare zählte ich ca. 14 Strahlen pro Kieme. Die genaue Anordnung und Zahl der Kiemenocellen habe ich auch unter dem Mikroskop nicht ermitteln können. Abweichend von Hypsicomus ist wie bei den früher von mir gesehenen Individuen dieser Art das Collare ventro-median mit einem deutlichen Einschnitt versehen.

Hypsicomatides loangoënsis Aug.

Spaansch Water, 5. V. 20, aus Korallen.

Caracas-Bai, 5. V. 20, aus Korallen.

Diese eigenartige Sabellide war in 2 hinten nicht vollständigen Exemplaren vorhanden. Bei demjenigen von Spaansch Water fehlt ein Teil des Abdomens hinten, es ist mit Kiemen ca. 60, ohne Kiemen ca. $42 \mathrm{~mm}$ lang. Die Färbung ist dunkel bräınlich-graugelblich; schwarzbraun sind die thoracalen Bauchschilder, eine dorsale Längsmediane, die Thoraxparapodien liegen in einem so gefärbten Längsstreifen. Die Kiemenstrahlen, ca. 22 pro Kieme, sind düster graubräunlich, ohne dunkle Binden. Die Zahl der Thoraxsegmente beträgt 45 .

Der 2te Wurm, noch grösser als der 1ste, ist ca. $5 \mathrm{~mm}$ breit. Leider fehlt an dem sonst sehr gut konservierten Wurm hinten zum mindesten das ganze Abdomen. Es sind ca. 30 Kiemenstrahlen pro Kieme vorhanden. Von Thoraxsegmenten sind 47 erhalten, es mag aber sein, dass ihre Zahl bei voller Erhaltung des Tieres noch grösser war.

Die Ocellenzone ist namentlich bei dem 2ten Wurm unter der Lupe sehr deutlich und sogar mit blossem Auge an ihrer schwarzbraunen Färbung erkennbar. An dem 2ten Wurm ist auch die dünn bündelförmige Gestalt des Buccalborstenbündels in Abweichung von den 2 vorhergehenden Gattungen mit Sicherheit festzustellen. Das Collare ist ventro-median in Uebereinstimmung. mit meinen früheren Beobachtungen mit einem deutlichen Einschnitt versehen. Die Stellung und Anzahl der Kiemenocellen. annähernd genau zu ermitteln, hinderte die dunkle Färbung der Ocellenzone, sie lässt sich bei dieser wie bei den verwandten Gattungen am besten an verblassten entfärbten Exemplaren untersuchen. 


\section{Dasychone nigromaculata Baird.}

Spaansch Water: 13. IV. 20, aus Porites furcata; 5. IV. 20, aus Spongien auf Mangrove-Wurzeln; 3,17 und 29. IV. $20 ; 5,19$ und 25. V. 20.

Caracas-Bai, aus Korallen.

Boca labadera, 12. V. 20.

Diese zu den grösseren westindischen Sabelliden gehörende Art ist bei Curaçao häufig und mit einer Anzahl kleiner bis grosser Individuen vertreten. Grosse Exemplare sind ca. $45-50 \mathrm{~mm}$ lang ohne die Kiemen. Die aussen mit Schlamm bekleideten Röhren tragen zuweilen auch andere Fremdkörper wie Spongien z. B.; Röhren vom 17. IV. 20. steckten zwischen Kalkalgen.

Was die Körperfärbung angeht, so kommen Individuen vor, an denen die dunkle Spritzerzeichnung nicht oder so gut wie nicht entwickelt ist. Im Allgemeinen zeigen die kleinen Exemplare dieses Materials keine oder wenig dunkle Spritzerzeichnung. Die Anzahl der Kiemenstrahlen habe ich an 2 in einem Glase zusammenliegenden Tieren festgestellt. Von diesen hatte das kleine ca. 19, das grosse ca. 49 Strahlen pro Kieme.

An einem kleinen Wurm fanden sich abweichend von der Norm nur 6 Thoraxsegmente, rechts war am 6ten Thoraxsegment nur das Hakenpolster entwickelt. Hinten am Abdomen war offenbar ein Stück in Regeneration. Es handelt sich in diesem Falle um wohl nur im Zusammenhange mit Körperverletzungen stehende Erscheinungen, da massenhafte Regenerationen im Sinne der D. cingulata Gir. var. curta Ehl: bisher niemals von mir an D. nigromaculata beobachtet wurden.

Ich hatte früher geglaubt, $D$. nigromaculata von der später aufgestellten gleichfalls westindischen D. bairdi McInt. trennen zu sollen auf Grund der verschiedenen Ausbildung der Kiemenstrahlanhänge. Ich halte es nunmehr für angebracht, nur eine Art mit dem Namen D. nigromaculata Baird anzunehmen, die auch die anderen noch in Frage kommenden westindischen Synonyme aufzunehmen hat. Ich finde längere und kürzere Anhangspaare am gleichen Kiemenstrahl sowohl bei grossen wie bei kleinen Individuen. Andererseits finden sich Tiere, bei denen die Anhangspaare am gleichen Kiemenstrahl nur ganz unbedeutende Längenunterschiede aufweisen.

\section{Fam. SERPULIDAE.}

Spirobranchus giganteus Pall. (Textfig. 6).

Caracas-Bai: 23. V. 20 und 5. V. 20, aus Korallen; 7. IV. 20, aus Maeandrina.

Boca labadera, 12. V. 20.

Spaansche Bai: 11. V. 20 und in der Brandung.

Diese grosse prachtvolle Serpulide habe ich in einer Anzahl grosser und kleiner Individuen vor mir gehabt. Ueber die grossen Exemplare sei nur bemerkt, dass ein Teil dieser Tiere 3 Paare von Deckelstangen auf der Deckelscheibe trägt. Das medio-ventrale Stangenpaar - das auch als ein einziger am Ende wieder gegabelter Stab aufgefasst werden kann - liegt so gut wie horizontal über der Deckelscheibe. Bei anderen Exemplaren wieder ist das medio-ventrale Stangenpaar garnicht entwickelt.

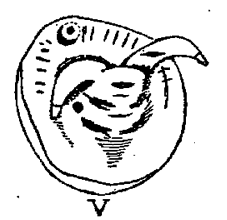

Fig. 6. Spirobranchus giganteus Pall. juv.? Deckel mit den 2 dorsalen hornförmigen Fortsätzen. In schräger Richtung und etwas nach der einen Seite geneigt gesehen. $v .=$ Ventralrand. $14 \times$.
Die Deckelscheibe ist oft dicht mit die Deckelstangen einhüllenden Algen bewachsen; einmal war auf einem Deckel eine kleine Tangpflanze angesiedelt. Einige mitgesammelte Röhren sind innen rötlich und aussen von Koralle umwachsen.

Ausser diesen grossen Individuen liegt aber noch eine ganze Anzahl kleiner Spirobranchus-Exemplare vor, die in der Form der Deckelstangen von den grossen Exemplaren abweichen, und die ich für junge resp. jüngere Tiere des $S p$. giganteus halte. Im Allgemeinen ist von diesen kleinen Individuen zu sagen, dass die Flügel des Deckelstiels an ihrem oberen Rande stets ganzrandig sind wie bei grossen giganteus. Wenn die Färbung gut erhalten ist, ist die Deckelscheibe wie bei grossen giganteus rot berandet.

Es seien zuerst einige kleinere Individuen von Boca labadera hier erörtert. Ihre z. T. erhaltenen Röhren bilden ein Konglomerat und sind wie bei giganteus beschaffen, dickwandig, mit starkem Fortsatz an der Mündung. An dem ungefähr stärksten Exemplar von ca. $31 \mathrm{~mm}$ Länge incl. Deckel haben die 
ventralen Haken von einem mittleren Thoraxsegment ca. 15-17 Zähne an der Schneide, ein paar weniger als bei grossen giganteus. Bie Deckelstäbe sind schwächer entwickelt als in der Regel bei grossen Exemplaren. Sie bestehen aus 2 Fortsätzen mit einfacher Spitze, die den 2 dorsalen Stangenpaaren grosser Exemplare entsprechen. Im besten Falle sind diese 2 Fortsätze wie 2 Ochsenhörner entwickelt und mit einigen Nebendornen am oberen Rande versehen. Bei den anderen kleinen Exemplaren dieses Fundortes sind die Deckelfortsätze merklich schwächer und kürzer bis zu kurzer Stummelform. Das Aussehen der Deckelscheibe mit den 2 Fortsätzen erinnert sehr an den indo-pazifischen Sp. bucephalus Mörch.

Bei einigen kleinen Individuen von Spaansche Bai und von Caracas-Bai 23. V. 20, deren Röhren ebenfalls ein. Konglomerat bilden, trägt der Deckel auf seiner Scheibe 2 kurze, glatte Hörner, die ungefähr in der Mitte der Scheibe oder etwas oberhalb derselben entspringen. Der Deckel hat so das Aussehen eines Ochsenschädels mit 2 einspitzigen Hörnern. Die mittlere Partie der Scheibe springt mehr oder weniger erhabén vor wie die Stirn am Ochsenschädel. In einem Glasrohr vom gleichen Fundort ohne Datum, mit der Notiz „In der Brandung” lagen gegen 20 weitere kleine Indviduen, von denen einige sehr klein, nur 6,5-7 mm lang sind inclus. Deckel. Wo hier der Deckel überhaupt erhalten ist, trägt er auf der Scheibe meist 2 glatte Ochsenhörner, die länger oder kürzer und mehr oder minder gebogen sind. - An einigen Individuen zeigt sich eine etwas variierende Oberflächenbeschaffenheit der Deckelscheibe. An Stelle der deutlichen 2 Hörner steht eine senkrechte, quere, am Endrande konkav ausgerandete Platte (Tier von 6,5 mm Länge). Das gleiche zeigt sich bei einem etwas grösseren Wurm, nur ist die Endausrandung der Platte noch flacher als bei dem vorhergehenden, sehr flach. Bei einem Tier ist der Deckelaufsatz ähnlich wie bei dem 2ten Wurm, aber am Endrande der senkrechten Platte ist eine Ausrandung überhaupt kaum vorhanden. - Bei einem Wurm mit 2 Deckelhörnern befindet sich medio-dorsal zwischen und oberhalb von den Basen der Hörner eine kleine, kegelförmige Hervorragung. Bei einem weiteren Wurm ist in gleicher Lage eine kurze aufrechte Spitze zu erkennen nebst einer sehr kleinen Spitze daneben; solche kleinen Spitzen neben der dorso-medianen Spitze wurden auch sonst beobachtet.

Diese kleinen Würmer sind im Maximum 13-14 mm lang incl. Deckel, eines der grössten hat gegen 40 schlecht zu zählende Strahlen pro Kieme, das kleinste von ca. 6,5 mm Länge etwa 15-17 Strahlen pro Kieme. Der Körper ist heller oder dunkler hellbraun. Vereinzelt sind Collare und Thoracalmembran blau gefärbt, die weisslich-ockergelben Kiemen höchst selten auf den Kiemenblättern bläulich überlaufen.

Zusammenfassend meine ich betreffs diese kleinen Spirobranchus-Tiere, dass sie wegen des stets ganzrandigen oberen Randes der Deckelstielflügel nicht mit Sp. dendropoma in Beziehung gebracht werden können, ausserdem aber auch nicht mit Sp. polycerus, wie ich glaube. Jedenfalls habe ich keine kleinen Individuen von Spirobranchus bisher gesehen, die in der Form ihrer Deckelstäbe mit grossen Sp. giganteus ganz übereingestimmt hätten. Da es nun doch von Sp. giganteus auch junge Tiere in der Grösse der vorliegenden kleinen Würmer geben muss und bekanntermassen in der Form der Deckelstäbe bei Spirobranchus grosse Variation herrscht, halte ich es für angebracht, die hier zur Erörterung stehenden kleinen Würmer einstweilen als junge Individuen von $S p$. giganteus zu bewerten. Damit muss dann zugleich angenommen werden, dass bei weiterem Grössenwachstum die Deckelstäbe allmählich `die den grossen giganteus-Individuen eigentümliche Form annehmen.

\section{Spirobranchus dendropoma Mörch.}

Spaansch Water: 6, 13,14 und 19. IV. 20 und 5. V. 20, aus Porites furcata; 8. IV. 20, aus Spongien auf Mangrove-Wurzeln; 25. V. 20.

Caracas-Bai, 23. IV. 20, von Korallen.

Curaçao, Schottegat, 22. II. 1905, (BOEKE leg.).

Dieser in einer Anzahl von Individuen gesammelte, bei Curaçao häufige Spirobranchus, ist wie sein Vorkommen an Mangrove-Wurzeln zeigt, nicht streng an die Korallen bezüglich seiner Ansiedlung gebunden. Erhaltene Röhren, z. B. vom 6. IV. 20., befanden sich an Porites und sind in diesem Falle zum grösseren Teil oder so gut wie ganz von der Koralle umwachsen. Ihre Endstrecke kann wenig oder auch mehr frei emporragen oder ein Teil der Röhre liegt auf einer Seite frei, während die 
andere Seite an und in die Koralle angeheftet ist, vereinzelt liegen die Röhren ihrer Länge nach auf: der einen Seite angeheftet auf der Koralle. An einer Röhre, die mit einem Teil ihrer Endstrecke ganz. frei aus der Korallenoberfläche emporragt, ist an dieser Endstrecke ausser dem medianen in den dreieckigen Mündungszahn auslaufenden Längskiel jederseits noch ein sehr schwacher weiterer Längskiel vorhanden. Die Röhren sind innen öfter sehr zart bläulich gefärbt. An von Mangrove-Wurzeln herstammenden Röhren haften Spongienteile. Die aus den Röhren entnommenen Würmer, im Maximum incl. Deckel ca. 52-59 $\mathrm{mm}$ lang, haben in diesem Zustande eine sehr gestreckte Körperform bei einer Maximalbreite von ca. 2,5 mm. Die Färbung ist satt rotgelb; die Kiemen sind dunkelblau oder schwärzlich mit hellen Querbinden, die sehr schmal sein oder auch die dunkle Färbung stark verdrängen können.

Der Deckel ist bei dieser Art immer mehr oder weniger von Schlamm und anderem Material eingehüllt bis zur völligen Unkenntlichkeit der Deckelstäbe. Ein Deckel trug einen langen, die Deckelstäbe ganz verhüllenden Algenschopf. - Variationen in der Form der Deckelstäbe, wenn letztere überhaupt entwickelt sind, mögen vorkommen, sie sind wegen der geringen Grösse des ganzen Deckels schwer zu bestimmen. Von sonstigen Anomalien in der Gestaltung der Deckelscheibe' seien folgende von mir beobachtete erwähnt. So hat ein durchaus nicht ganz kleiner Wurm von 25. V. 20. einen Deckel, der oben niedrig-kegelförmig emporgewölbt ist, ohne irgendwelche Deckelstäbe, von denen auch keine basalen Abbruchstellen erkennbar sind. In der Mitte des Kegels hebt sich eine nabelartige Partie noch wieder von der übrigen Oberfläche ab. An einem Wurm von Mangrove-Wurzeln - er lag neben einem Tier dieser Art mit ganz normalen Deckelstäben - von ca. 12 mm Länge incl. Deckel, ist der Deckel ohne jegliche Stäbe, von denen auch keine Abbruchstellen erkennbar sind. Die Deckelscheibe erhebt sich in einen glatten, schief aufgesetzten Kegel, der ca. ${ }^{2} / 5$ so hoch wie die Deckelscheibe breit ist und ca. $1 / 2$ so lang an seiner senkrechten Dorsalfläche wie an seiner schiefen Ventralfläche ist. Seine Ventralfläche ist mit schwachen, dicht übereinander stehenden Querringeln versehen; seine alleräusserste Endspitze ist sehr kurz und an ihrer Basis gegen den übrigen Kegel abgeschnürt. Ähnlich iśt der Deckel bei einem kaum mittelgrossen Wurm, an dem die Scheibe einen gut entwickelten Kegel trägt, der ebenfalls ventralwärts schräge abfällt und an der Ventralfläche einige schwach vortretende Querrippen zeigt. An der Spitze des Kegels entspringen wenige kurze dünne Fortsätze, die als Aequivalent der normalen Deckelstäbe zu betrachten sind. Endlich sei noch ein Deckel erwähnt, an dem die hier vorhandenen Deckelstäbe von einer unregelmässig geformten, weissen Kalkmasse z. T. eingehüllt werden.

\section{Spirobranchus polycerus Schm.}

Spirobranchus insignifer Augener 1922. Spirobranchus polycerus Augener 1925.

Spaansch Water: 25. V. 20.

Caracas-Bai: 7. IV. 20, aus Maeandrina und von der Boje; 5. und 25. V. 20.

West Punt, 14. V. 20.

Dieser kleine Spirobranchus lag mir in geringer Zahl vor. Erhaltene Röhren waren z. T. vergesellschaftet mit Pomatoceros caerulescens, von dessen Röhren sie durch ihre weisse Innenwand unterscheidbar sind. Röhren von 7. IV. 20. sind fast ganz aneinander verlötet; ausser dem kurzen dreieckigen Mündungszahn ist ein dorsaler Längsmediankiel an ihnen erkennbar.

Ich kann an diesen kleinen Tieren die allgemeinen Charaktere des Sp. insignifer bestätigen. Das Collare ist ventral stumpf lappenartig vorgezogen, die Deckelstielflügel sind an ihrem Oberrande ganzrandig. Die Thoracalmembran greift hinten um die Länge der 2 oder 3 letzten Thoraxsegmente über den Thorax hinaus.

Die Färbung ist gelbbräunlich oder satt gelb-rötlich. An einem Wurm von ca. $19 \mathrm{~mm}$ Länge mit, von ca. $15 \mathrm{~mm}$ Länge ohne den Deckel, zählte ich ungefähr 40 Strahlen pro Kieme.

Betreffs der Form der Deckelstäbe ist folgendes zu bemerken. Bei dem $19 \mathrm{~mm}$ langen Wurm passen die Deckelstäbe nach Zahl, Form und Lage gut zu insignifer, die 4 ventralwärts gerichteten Stäbe liegen horizontal, dem Deckel angewachsen, auf diesem. Das gleiche ist der Fall bei einem excl. Deckel ca. $28 \mathrm{~mm}$ langen Wurm. Bei einem weiteren Exemplar sind die 4 ventralen Stäbe am Ende 
etwas nach oben gebogen, bei einem 4ten Ẉurm zwar auch im Ganzen der Deckelscheibe angeheftet, aber ihr Endteil aufwärts aufgerichtet. Die vogelfussartige Bildung am Ende der 4 ventralen Deckelstäbe war bei diesen Würmern nicht recht entwickelt.

Nach der Klarstellung des Sp. polycerus von SCHMARDA bin ich zu der Ansicht gelangt, dass dieser mit $S p$. insignifer zusammenfällt. Die Tatsache, dass bei wenigen Tieren der Curaçao-Exemplare die 4 ventralen Deckelfortsätze mit ihrem Endteil mehr oder minder frei aufgerichtet sind, betrachte ich als vermittelnde Variationserscheinung zwischen typischen insignifer-Deckeln und dem Deckel des $S p$. polycerus, an dem die 4 ventralen Fortsätze schräg aufwärts und ventralwärts emporragen.

Es erhebt sich hier die Frage, ob man nicht die bei Sp. giganteus besprochenen jungen Individuen als Deckelvariationen lieber zu $S p$. polycerus stellen sollte. Ich verneine das bis auf weiteres, sah auch z. B. bisher noch nie eine rote Deckelberandung im Sinne von giganteus an den polycerusinsignifer-Individuen. Oder sollen gar die insignifer- resp. polycerus-Individuen mitsamt den mutmasslichen jungen giganteus-Individuen junge giganteus sein? Gehören aber beide kleinen Formen nicht zu giganteus, wie sehen dann wirkliche junge giganteus auf der Deckelscheibe aus?

Pomatostegus stellatus Abildg. (Textfig. 7).

Spaansch Water: 25. V. 20 , aus Porites furcata; 7, 13, 14. IV. 20, aus Porites furcata; 29. IV. 20, aus Siderastrea; von Mangrove-Wurzeln. Caracas-Bai, 2. IV. 20, aus Korallen.

Diese im Westindien-Meer nicht seltene Serpulide ist mit einer Anzahl von Individuen von verschiedener Grösse vertreten. Von erhaltenen Röhren befanden sich z. B. solche von kleinen Exemplaren auf einer lebenden Bivalve in einer Koralle.

Die Zahl der Deckelstockwerke beträgt - wie schon früher beobachtet, findet sich eine hohe Stockwerkzahl bei kleinen und grossen Exemplaren - bei 13 Exemplaren: 2 mal 2; 3 mal 3; 6 mal 4; 2 mal 5. In der Regel hat das Endstockwerk die normale Gestalt des kleinen bestachelten Endkranzes, ein paar Abweichungen hiervon sind $z u$ verzeichnen. So ist in einem Falle das Endstockwerk ersetzt durch einen kurzen Fortsatz. Bei einem 2ten Wurm erhebt sich auf dem normalen, mit einer weissen Kalkschicht überzogenen 1 sten Stockwerk das 2te und das Endstockwerk median nahe am Dorsalrande des 1 sten Stockwerks, und zwar ist das 2te scheibenförmig, aber sehr viel kleiner als das 1ste, während das Endstockwerk die Form eines aufrechten, kegelförmigen Zapfens hat. Bei einem 3ten Wurm ist das Endstockwerk nur ein kurzer, sehr schmaler, fast stachelartiger, kegelförmiger Fortsatz. An einem ganz jungen Wurm aus Siderastrea trägt die Deckelscheibe nur ein Stockwerk und zwar eine Säule mit dem terminalen Stachelkranz am Ende.

Besondere Erwähnung verdient ausserdem ein Exemplar mit einem ganz abweichend gestalteten Deckel, sodass man zunächst das Tier gar nicht für einen Pomatostegus halten würde. Der am. Mittelkörper in einem Stück seiner Röhre steckende Wurm (Spaansch Water, 7. IV. 20., aus Porites furcata) ist incl. Deckel ca. $53 \mathrm{~mm}$ lang; sein Deckel erinnert an die Deckelbildung eines anderen Wurmes vom 13. IV. 20. des gleichen Fundorts, bei welchem das 3te und zugleich oberste Stockwerk kegelförmig aufrecht ist, ist aber noch erheblich aberranter gestaltet. Die Stielsäume sind viel schmäler als normal, so dass der Stiel - vorn sind freie Stielflügel nicht entwickelt - incl. .der Säume nur etwa halb so breit wie der Deckel ist, während er bei normaler Ausbildung mindestens eben so breit wie der Deckel ist. Der an der rechten Kieme entspringende Deckel hat eine nicht-chitinisierte Scheibe, die in ihrem Aussehen entfernt an einen Deckel von Serpula vermicularis erinnert und keinerlei scheibenförmige Stockwerke im Sinne von Poma-

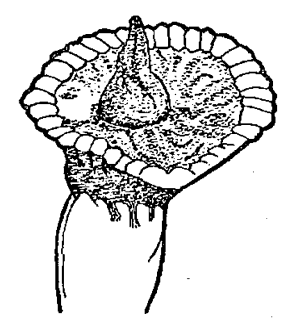

Fig. 7. Pomatostegus stellatus Abildg. Merkwürdiger aberranter Deckel. Schräg von oben und von der Seite gesehen. Exemplar von Spaansch Water. 7. IV. 20. $14 \times$.

tostegus trägt. Auf ihrer Fläche steht etwas oberhalb der Mitte einzig ein braun chitinöser, scharf kegelförmiger Fortsatz mit verjüngter etwas hakig nach hinten gebogener Endspitze. Diese merkwürdige Deckelform mag vielleicht infolge Regeneration ihre abweichende Gestalt erhalten haben. Im übrigen ist das Tier normal, z. B. endet an dem aus 7 Segmenten bestehenden Thorax die Thoracalmembran seitlich wie sonst etwas hinter dem 3ten Borstenbündel. 
Pomatoceros (Pomatoleios) caerulescens Aug.

Caracas-Bai, 7. IV. 20, aus Maeandrina.

Es liegt ein kleines Röhrenkonglomerat an Maeandrina vor zusammen mit Sp. polycerus. Diese Art ist kenntlich an den inwendig schwarzbraunen Röhren und an dem flachen, jeglicher Fortsätze entbehrenden Deckel, der in einem Falle auf der Endfläche ein wenig konvex gewölbt ist.

\section{Hydroides (Eupomatus) floridanus C. Bush.}

Spaansch Water: 3. IV. 20; 25. V. 20; 22. IV. 20, aus Spongien; von Mangrove-Wurzeln. Curaçao. Schottegat. 22. IX. 1905. (BoEkE leg.).

Von dieser in kleinerer Anzahl vorliegenden Hydroides-Art waren z. T. Röhren erhalten, an denen Spongienstücke hafteten, eine Röhre war nebst der Röhre einer anderen Hydroides-Art teilweise von einer Bryozoë umwachsen. Eines der grösseren Exemplare ist incl. Deckel ca. $28 \mathrm{~mm}$ lang.

Die Zahl der Deckelstäbe an diesen Würmern ergab folgende Werte: $7 ; 3$ mal 12;3 mal 13; 4 mal $14 ; 15 ; 16$. Die auffallend niedrige Zahl 7 fand ich bei einem kleineren Exemplar.

Hydroides (Eupomatus) parvus Treadw. (Textfig. 8).

Spaansch Water: 3. IV. 20; 5. V. 20; von Mangrove-Wuŕzeln.

Curaçao, Schottegat, 22. IV. 1905, (BOEKE leg.).

Die in geringer Zahl mir vorliegenden Würmer sind viel grösser als die jungen Individuen TREADWELL's. Ein vollständiger, aus seiner Röhre entnommener Wurm ist ca. $39 \mathrm{~mm}$ lang incl. Deckel. Der Deckel hat am Scheibenrande ca. 24 Zähne und trägt 6 Stäbe, von denen ein Stab an der Spitze. ausnahmsweise wieder gegabelt ist. Kiemenstrahlen sind 13 pro Kieme vorhanden. Bei den anderen Exemplaren kommen 5 mal 8, 4 mal 9 Deckelstäbe vor.

Die Deckelstäbe sind im Prinzip ganz so gestaltet wie sie von TrEadwell für seine jungen Individuen abgebildet werden. Nur finde ich den einwärts gebogenen Endabschnitt der Stäbe länger

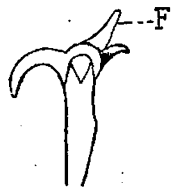

Fig. 8. Hydroides (Eupomatus) parvus Treadw. Ein Deckelstab. Von der Seite gesehen. Mit aufrechtem, stark entwickeltem Fersenfortsatz. - Wurm von Curaçao, Schottegat. $23 \times$. und besser entwickelt, aụch scharfspitziger. Die 2 seitlichen Fortsätze an der Stelle, wo der Endabschnitt einwärts in seine horizontale Lage umbiegt, sind ebenfalls etwas länger und spitzer, ferner ist der fersenartige Fortsatz aussen an der Umbiegungsstelle länger und besser ausgebildet. Auch bei dem einzigen Wurm von Schottegat, einem ca. $21 \mathrm{~mm}$ incl. Deckel langen Wurm, mit 13 Strahlen pro. Kieme, ist der äussere Fersenfortsatz der Stäbe länger und spitzer und in diesem Falle nicht horizontal nach aussen gerichtet wie gewöhnlich sondern nur ganz schwach nach auswärts geneigt, nahezu in der Verlängerung des basalen Abschnitts der Stäbe liegend.

TrEadWELl sah bei seinen Exemplaren (1900) am Abdomen nur ventrale Haarborsten, solche sehe ich ebenfalls an einer kurzen Endstrecke des Abdomens. An den vorhergehenden Abdominalsegmenten stehen ventral die von TREADWELL vermissten spatelförmigen, an der Endkante gezähnten Borsten wie bei anderen Hydroides. Ich zählte bei einem grossen Wurm. ca. 18 pro Polster an nicht weit vom Hinterende befindlichen Segmenten.

Ein grosser Wurm war ein mit grossen Eiern erfülltes Weibchen.

Erhaltene Röhren sind quergerunzelt, mit 2 schwachen dorsalen Längskielen, zuweilen mit Andeutung eines 3ten, medio-dorsalen Kieles zwischen diesen beiden versehen.

\section{Vermiliopsis annulata Schm.}

Caracas-Bai, 23. IV. 20 und 13. V. 20, aus Korallen.

Diese Art ist durch wenige Exemplare vertreten. Erhaltene Röhren sind starkwandig, zu einem Konglomerat vereinigt und oft streckenweise sehr stark gewunden; stellenweise sind an ihnen niedrige Querrippen erkennbar.

Diese Würmer, ein ganzes Tier ist z. B. incl. Deckel ca. $15 \mathrm{~mm}$ lang, passen gut zu dem von 
mir (1925) untersuchten Original, so in der Gestalt der verschiedenen Borstenformen und der Haken. Wie dort endet auch bei ihnen die Thoracalmembran etwas hinter dem 4ten Thoraxsegment; auch das weissliche eiförmige Blättchen hinten oben an den Dorsalborstenhöckern des Thorax ist vorhanden. Bei einigen Individuen sind die Kiemenstrahlen aussen immer mit Ueberspringung eines Kiemenstrahles ziemlich dicht kurz weisslich quer gestrichelt.

Der Deckel dieser Würmer - ich fand ihn mit einer Ausnahme stets an der linken Kieme stehend - weist Variationen in seiner Bildung auf wie schon früher festgestellt. So ist die Deckelscheibe eines Wurmes vom 23. IV. 20. - Scheibe und obere Hälfte des Deckels war von einer ablösbaren weisslichen kalkigen Schicht bedeckt - zu einem braunen chitinigen, am Anfang und am Ende durchaus stumpf abgerundeten Kegelstumpf erhoben. Der Deckelfortsatz, von gleicher Höhe wie die Ampulle, ist etwas schief dorsalwärts geneigt, also schwach mützenartig und lässt keine Stockwerkquerlinien erkennen. Bei einem 2ten Wurm vom gleichen Fundort ist der Deckel im Prinzip dem 1sten ähnlich, auch etwas schief dorsalwärts geneigt und ohne Querlinien, aber niedriger, etwa wie ein weiblicher sog. Topfhut gestaltet, am Ende flach abgestutzt abgerundet. Bei einem 3ten Wurm ist der Deckelapparat nur $2 / 3$ so lang wie die Kiemen und war von letzteren vollkommen eingehüllt. Dieser Deckel. - er ist vermutlich ein noch nicht vollendetes Regenerat und nicht dunkelbraun chitinös wie normale Deckel - hat einschliesslich der Ampulle die Form eines umgekehrten Kegels mit sehr flach konvexer und kaum schräger Endfläche. Endlich hat ein Wurm vom 13. V. 20. einen am Ende tadellos èrhaltenen Deckel, der erheblich länger als die Ampulle, an der Endhälfte durchscheinend bernsteingelb und an der unteren Hälfte mit 3 ganz herumgreifenden Querlinien versehen ist. Der Deckel ist zylindrisch, an der Ventralseite schwach konvex, dorsal etwas konkav ausgehöhit. Die Endfläche ist schief dorsalwärts nach hinten vorgezogen abgestutzt und mit einer flachen trichterförmigen Einsenkung versehen. Bezüglich der terminalen Einsenkung am Deckel glaube ich nunmehr, dass auch die tiefe terminale Einsenkung des Originals von SCHMARDA nicht auf Verletzung des Deckels zurückführbar ist, unbeschadet des Umstandes, dass die Endränder des Deckels nicht ganz gut erhalten waren.

Salmacina incrustans Clap. (Textfig. 9).

Spaansch Water: 5. und 7. IV. 20, an Mangrove-Wurzeln; 15. V. 20.

Salmacinen-artige fadendünne Röhren finden sich vom 15. V. 20 , auf einer toten MolluskenSchaie in Gesellschaft von Spirorbis. Von Mangrove-Wurzeln (5. IV. 20.) liegen in Alkohol konserviert Salmacinen-Röhren mit Insassen, vom 7. IV. 20. ebenfalls solche in Formolkonservierung vor; die letzteren sind besonders bezüglich der Kiemen erheblich schlechter erhalten als die Alkoholtiere. Die Röhren von Mangrove-Wurzeln bilden keine kompakten Röhrenkonglomerate im Sinne der S. huxleyi Ehl. (1887), sondern durchsetzen Hornschwamm-Massen. Es ist schwierig, den Verlauf der Röhren in ihrer ganzen Länge zu verfolgen. Die meisten Röhren scheinen einzeln, wenn auch nahe bei einander, durch die Schwamm-Masse zu verlaufen, mitunter sind sehr wenige aneinander gelötet und das vielleicht auch nur streckenweise. Öfter sieht es so aus, als wenn die Röhren streckenweise auf der Schwamm-Masse daraufliegen.

Von diesen winzigen Würmern selbst ist zu bemerken, dass an den Kiemenstrahlen unterhalb der Endspitze eine kissenartige Erweiterung vorhanden und dass die ventralen Abdominalborsten richtige Salmacinenborsten sind, d. h. in Profillage an der einen Kante mit Sägezähnen versehen. Diese Zähne lassen sich sicher nur bei guter Profillage der Borsten und in nicht stark aufhellenden Medien erkennen. Diese Würmer würden somit Charaktere von $S$. incrustans Clap. und $S$. aedificatrix Clap. vereinigen, wie sie Langerhans von Madeira (Wurmfauna von Madeira. III. 1880) beschrieben hat. S. incrustans hat nach LANGERHANS subterminale Kiemenstrahlerweiterungen, aber glatt gesäumte ventrale Abdominalborsten,

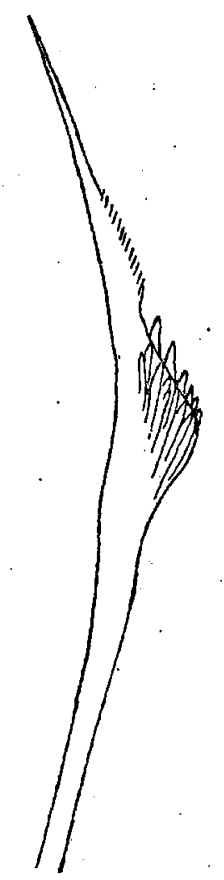

Fig. 9. Salmacina incrustans Clap. Flügelborste vom Buccalborstenbündel. Profil ziemlich genau. $600 \times$. während $S$. aedificatrix richtige gezähnte ventrale Abdominalborsten haben, dagegen der subterminalen 
Kiemenstrahlerweiterungen entbehren soll. Ich vermute nun, dass die 2 Madeira-Arten zusammenfallen und dass LangerHans die Zähne an den Salmacinenborsten seiner S. incrustans nicht erkannt hat.

FAUVEL führt (1914. p. 328) S. incrustans an und gibt auch echte, gesägte Salmacinenborsten für diese Art an (soies capillaires geniculées, dentelées) abweichend von LANGERHANS also so wie ich diese Borsten gesehen habe. Bei S. dysteri Huxl. erwähnt Fauvel (1914. p. 329), dass ihm unter dem Namen „S. aedificatrix Clap.” von Neapel zugesandte Salmacinen sich als $S$. dysteri erwiesen hätten. Er habe die echte $S$. aedificatrix Clap. (ClaPARÈde 1870), die nach ClaPARĖde keine subterminalen Kiemenstrahlerweiterungen haben soll, niemals angetroffen. Hiernach scheint es mir möglich, dass S. aedificatrix Clap. nichts weiter als $\mathcal{S}$. dysteri ist. Sie könnte dann allerdings wieder nicht mit der $S$. aedificatrix von LANGERHANS identisch sein, da LANGERHANS von letzterer an den buccalen Flügelborsten nur wenige grobe Zähne am Flügelsaum abgebildet hat.

Ich gebe von den buccalen Flügelborsten der vorliegenden Würmer eine Figur. Die Zähne des Flügelsaumes verlaufen in 2 Längsreihen, je einer an den Saumkanten, was bei totaler oder teilweiser Kantenlage der Borsten erkennbar ist.

Die S. huxleyi Ehl. Westindiens (sie ist keine Filograna, zu der sie von diesem Autor gestellt wurde) muss ich nunmehr für identisch mit der vorliegenden nicht in kompakten Röhrenkolonien auftretenden Form halten.

\section{Spirorbis spec.}

Spaansch Water: aus Porites furcata; 29. IV. 20, aus Siderastrea; 15. und 25. V. 20.

Es liegen Röhren von mindestens 2 Arten von verschiedenen Fundorten vor, eine rechts- und eine linksgewundene. Röhren yom 29. IV. 20. befanden sich auf einer lebenden Muschel in Gesellschaft anderer Serpuliden-Röhren, so junger Pomatostegus. 